


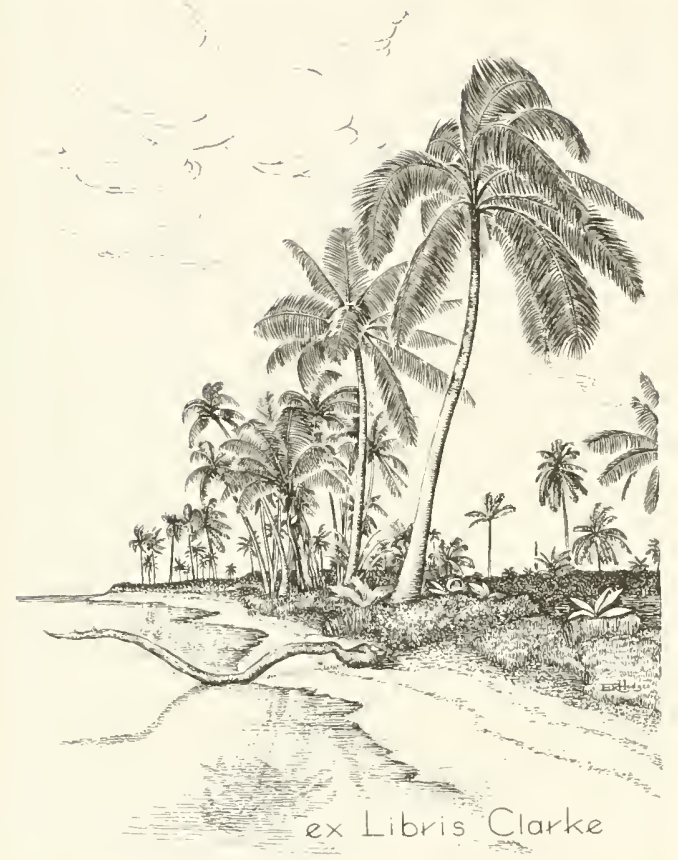


T. Priz f. Wr. Eater Elarke with complimienta of

Hency Bird

and hiv estomological piend who appreciales yout good wack,

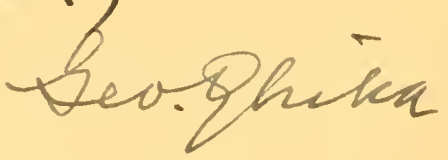



THE GENitAliA OF THE BRITISH NOCTUIDE 

"Ho who nerer makes a mistake, neicr makes anything." 



\section{The Genitalia of The Group Noctuidæ of the Lepidoptera of the British Islands.}

AN ACCOUNT OF THE MORPHOLOGY OF THE MALE CLASPING ORGANS.

\section{BY . \\ F. N. PIERCE, F.E.S.}

Hon. Librarian of the Lancashire and Cheshire Entomological Society ; Vice-President of the Liverpool Microscopical Society. 



\section{GENERAL INDEX.}

\begin{tabular}{|c|c|c|c|}
\hline \multicolumn{2}{|c|}{ Plate Page } & \multicolumn{2}{|c|}{ Plate Page } \\
\hline Edœeagus ........... & $2 \quad 13$ & Material used ....... & 17 \\
\hline Ampulla ........... & 1 & Microscopical Objects & 17 \\
\hline Anal Angle ......... & 1 & Mounting ............. & 8 \\
\hline Anal Spine ........ & 1 & New Species ......... & 16 \\
\hline Anus ................. & 1 & Nomenclature of & \\
\hline Assembling ......... & 18 & Parts 1 & 10 \\
\hline Asymmetry ......... & 17 & Do. of Species & 19 \\
\hline Band of Teeth ...... & 2 & Ovipositor ........... 2 & 14 \\
\hline Battledore Harpe... & 3 & Peaked .............. 3 & 11 \\
\hline Bifurcate Uneus ... & 10 & Pencils of Hair......29 & 18 \\
\hline Bulbed Cornutus ... & 2 & Penis ................ 2 & 13 \\
\hline Chapman's Trorlis & 3 & Peniculus .......... 1 & 11 \\
\hline Clasper ............... & 1 & Pollex $\quad \because . \cdots \cdots$ & 12 \\
\hline Classification ...... & 15 & Preparation of & \\
\hline Clavus $\ldots . . . \ldots \ldots . . .$. & 12 & Specimens...... & 7 \\
\hline Comb of Teeth ...... & 14 & Sacculus ......... 2 & 12 \\
\hline Cornutus ............ & 14 & Scapbium .......... 3 & 13 \\
\hline Corona ............. & 3 & Scent Distributors & 18 \\
\hline Crested .............. & 15 & Scent of Hepialus & \\
\hline Cucullus ........... & 311 & humuli ${ }^{2} . . . . .$. & 18 \\
\hline Cygnated ............ & 3 & Scobinated ........ 2 & 15 \\
\hline Dentated ............ & 15 & Scudder's Worlis ... & 2 \\
\hline Diamond pointed & & $\begin{array}{l}\text { Serrated ........... } \\
\text { Sickle form }\end{array}$ & 15 \\
\hline Digitus . & 3 & Simple Uncus ...... 3 & 11 \\
\hline Donors $\ldots . . . \ldots \ldots \ldots$ & 4 & Sunith's Worlis..... & 3 \\
\hline Dry manipulation & ? & Spatulate ........... 3 & 11 \\
\hline Fditum .............. & 1 & $\begin{array}{l}\text { Spreule ........... } \\
\text { Spinose ........ }\end{array}$ & $\begin{array}{l}14 \\
15\end{array}$ \\
\hline Female ............. & 2 & Squamose ........... & 15 \\
\hline Foot $\ldots . . . \ldots \ldots \ldots \ldots$ & 12 & Staining ............ & 9 \\
\hline Genital Plate ...... & 2 & $\begin{array}{l}\text { Subscaphrum } \\
\text { Subscribers }\end{array}$ & $\begin{array}{l}13 \\
85\end{array}$ \\
\hline sorks ...... & & Tequmen & (5) \\
\hline & 3 & Toe ..... & 12 \\
\hline 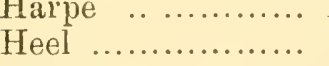 & 11 & 'Tongue sliapert...... & 11 \\
\hline Juxta ................ & 1: & Trigonate $\ldots . . . \ldots \ldots$ & 11 \\
\hline Lodix............. & 1. & Uneus $\ldots . \ldots \ldots \ldots . . .63$ & 10 \\
\hline 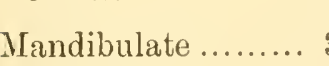 & 3 & Value of Genitalia & 15 \\
\hline Manipulation .... & 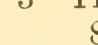 & 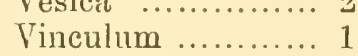 & 13 \\
\hline Margin .............. & 1 & White's, Dr. & \\
\hline Marginal Spines ... & 3 & Buchanan, Works & 2 \\
\hline
\end{tabular}


siii.

INDEX OF GENERA.

\begin{tabular}{|c|c|c|c|}
\hline \multicolumn{3}{|c|}{ Page } & rage \\
\hline Icontia ................. & 80 & Grommesia & 43 \\
\hline cosmetia............. & 45 & Habrostola & 78 \\
\hline cronyctit .............. & 24 & Hadena ................ & 69 \\
\hline Agriopis $\quad . . . . . . . . . .$. & 67 & Hecatera .............. & 65 \\
\hline Agrotis ................ & 48 & Heliaca ................. & 80 \\
\hline Igrophila .............. & 8i) & Heliophobus ............ & 37 \\
\hline Amphipyra $\quad . . . . . . .$. & 78 & Heliothis .............. & 76 \\
\hline 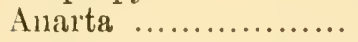 & 79 & 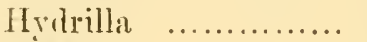 & 45 \\
\hline Anchocelis $\quad . . . . . . . .$. & 59 & Ifydrelia........... & 81 \\
\hline Apamea................ & 28 & Hydrocia . & 31 \\
\hline Aplecta ................ & 68 & Laphyguma & 37 \\
\hline Aporophyla ........... & 37 & Lencanid .. & $26 ;$ \\
\hline Arsilonche $\quad . . . . . . .$. & 24 & Luperina .. & 38 \\
\hline Asphalia ... .......... & 22 & Mimestra. & $3 ! 9$ \\
\hline Asteroscopus ........ & 75 & Mania .... & 78 \\
\hline 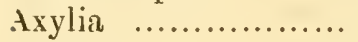 & 36 & Meliana... & 22 \\
\hline Bamkia ................. & 81 & Mellinia..... & 62 \\
\hline Brephos $\quad . . . . . . . . .$. & 83 & Miana $\ldots .$. & $3: 3$ \\
\hline Bryophila ............. & 23 & Miselia ...... & 175 \\
\hline Calamia................ & $4 t i$ & Moma $\quad .$. & 23 \\
\hline Calmia ................. & 34 & Neuria ..... & 37 \\
\hline Calocampa ......... & 71 & Nemronia .. & 37 \\
\hline Calymnia .............. & 46 & Noctua ..... & 48 \\
\hline Caradrina .............. & 43 & Nonagria .............. & 30 \\
\hline Catephia ............ & 82 & Oporiua................. & 60 \\
\hline Catocala $\quad . . . . . . . . . .$. & 82 & Orthosia $\quad \ldots . \ldots \ldots \ldots$ & \\
\hline Celøена ................. & 43 & Pachetra .. & 3 \\
\hline Cerastis................. & 59 & Pachnobia .............. & 52 \\
\hline Cerigo............. & 37 & Panolis ................. & $56 ;$ \\
\hline C'hariclea ............... & 76 & Phlogophora ............ & 68 \\
\hline Charæas $\quad . . . . . . . . . . .$. & 43 & Phothedles............... & 32 \\
\hline Cirrhodia .............. & 61 & Phytometra ........ .. & 81 \\
\hline 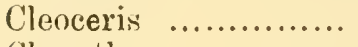 & 67 & Plusia $\quad \ldots \ldots \ldots \ldots \ldots$ & 76 \\
\hline Cloantha $\ldots \ldots \ldots \ldots . . .$. & 36 & Polia .................. & \\
\hline Cnenobia $\quad . . . . . . . . . . .$. & 31 & Rusina ................. & 4 \\
\hline Cosmia ................. & 45 & Scopelosoma........... & (i) \\
\hline Crymodes ............... & 42 & Senta .................. & 49 \\
\hline Cucullia $\quad . . . . . . . . . . .$. & 74 & Stilbia .. & 45 \\
\hline Cymatophoi:a ........ & 21 & Synia.................... & 30 \\
\hline Dasycampa ........... & 60 & Tieniocampa ............ & $56 i$ \\
\hline Dasypolia .............. & 66 & 'lapinostola ........... & 3 \\
\hline Demas $\ldots . . . . . . . . . . .$. & 22 & 'Tethen ................... & 45 \\
\hline Diantlınecia $\ldots . . . . . . .$. & 62 & 'Тoxосатрия ............ & 83 \\
\hline Dicycla .............. & 46 & 'Thyatira .......... & 21 \\
\hline Dipthera $\quad . . . . . . . . .$. & 23 & T'rachea................. & $56(i$ \\
\hline Dipterygia.............. & 36 & 'Irigonophora ........ & 68 \\
\hline 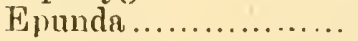 & 66 & 'T'iphæna .............. & $46 i$ \\
\hline Erastria $\quad . . . . . . . . . . .$. & 80 & 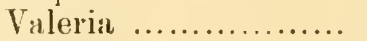 & 76 \\
\hline Eremolia ............... & 62 & Xanthia................. & 61 \\
\hline Enclidia $\quad \ldots . . . \ldots \ldots . .$. & 81 & Xylina ................ & 72 \\
\hline Euperia................. & 45 & Xylocampa ............ & 71 \\
\hline Euplexia ............... & 67 & Xylomiges................ & 71 \\
\hline Gonoptera ............... & 79 & Xylophasia $\ldots . . . . . . .$. & 40 \\
\hline 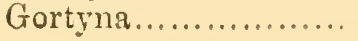 & $3 t$ & & \\
\hline
\end{tabular}




\title{
INDEX OF SPECIES.
}

\author{
(Synonyms in Italics.)
}

\begin{tabular}{|c|c|c|c|}
\hline \multicolumn{2}{|c|}{ P'ate Page } & \multicolumn{2}{|c|}{ Plate Page } \\
\hline Abjecta. & 40 & Brassicæ .... & 40 \\
\hline Absynthii & 75 & Brevilinea & 36 \\
\hline Aceris ..... & 25 & Brunnea.. & 55 \\
\hline Adusta....... & 71 & Cresia ..... & 65 \\
\hline Advena.... & 69 & Caliginosa & 45 \\
\hline Anea ......... & 81 & Cannæ ........ & 31 \\
\hline Affinis ..............14 & 46 & Candelarum. & 51 \\
\hline Agathina ............17 & 52 & Capsincola .. & 64 \\
\hline Albicolon.............11 & 39 & Capsophila .. & 63 \\
\hline Albimacula ..........22 & 64 & Captiuncula & 32 \\
\hline Albipuncta ........... 6 & 27 & Carpophaga . & 63 \\
\hline Albovenosa ............. & 24 & Cassinea ........ & 75 \\
\hline Alchymista ............32 & 82 & Castanea ........ & 48 \\
\hline Alni ................. 5 & 25 & Cerago............ & 61 \\
\hline Alpina .......... & 52 & Cespitis ....... & 38 \\
\hline Alsines $\quad . . .$. & 43 & Chamomilla & 74 \\
\hline Ambigua ...... & 44 & Chenopodii..... & 64 \\
\hline Anceps $\ldots . .$. & 39 & 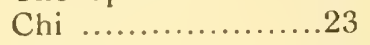 & 66 \\
\hline Anomala ....... & 45 & Chrysitis ........ & 76 \\
\hline Aprilina ...... & 67 & Chryson ........ & 77 \\
\hline Aquilina ...... & 54 & Chrysozona ...... & 65 \\
\hline Arbuti ......... & 80 & Cinerea ........ & 48 \\
\hline Arcuosa $\ldots . .$. & 32 & Circellaris ...... & 62 \\
\hline Areola ........... & 71 & Citrago ....... & 61 \\
\hline Argentula ........ & 81 & C-Nigrum . & 51 \\
\hline Arundinis ..........8 8 & 31 & Comes .......... & 47 \\
\hline Armigera.............28 & 76 & Comma ........ & 28 \\
\hline Arundineta .......... 8 & 31 & Compta ....... & 65 \\
\hline Ashworthii ...... & 50 & Concolor........... & 32 \\
\hline Asteris........... & 74 & Conflua .......... & 55 \\
\hline Atlantica .......... & 35 & Conformls ..... & 73 \\
\hline Atriplicis ......... & 70 & Conigera ........ & 28 \\
\hline Augur ............. & 48 & Connexa ....... & 38 \\
\hline Aurago........ & 61 & Conspersa ..... & 64 \\
\hline Auricoma $\quad . . . .$. & 25 & Conspicillaris ... & 71 \\
\hline Australis ............ 10 & 37 & Contigua .......... & 70 \\
\hline & & Cordigera ....... & 79 \\
\hline Baja....... & 52 & Corticea .......... & 49 \\
\hline Barrettii ............22 & 64 & Coryli ............. & 22 \\
\hline Basilinea............11 & 39 & Cracce........ & 83 \\
\hline Batis ............. & 21 & Crinanensis.......... 9 & 35 \\
\hline Bella ............ & 55 & Croceago.............21 & 60 \\
\hline Bicoloria .............13 & 32 & Cruda ...............19 & 57 \\
\hline Bimaculosa.........28 & 75 & Cubicularis ........ & 44 \\
\hline Blanda...............14 & 44 & Cucubali ............ & 63 \\
\hline Bondii .............. 9 & 32 & Cursoria ............18 & 54 \\
\hline Bractea ...........29 & 77 & Cytherea .............10 & 37 \\
\hline
\end{tabular}


INDEX OF SPECIES.-Synonyms in Italics.

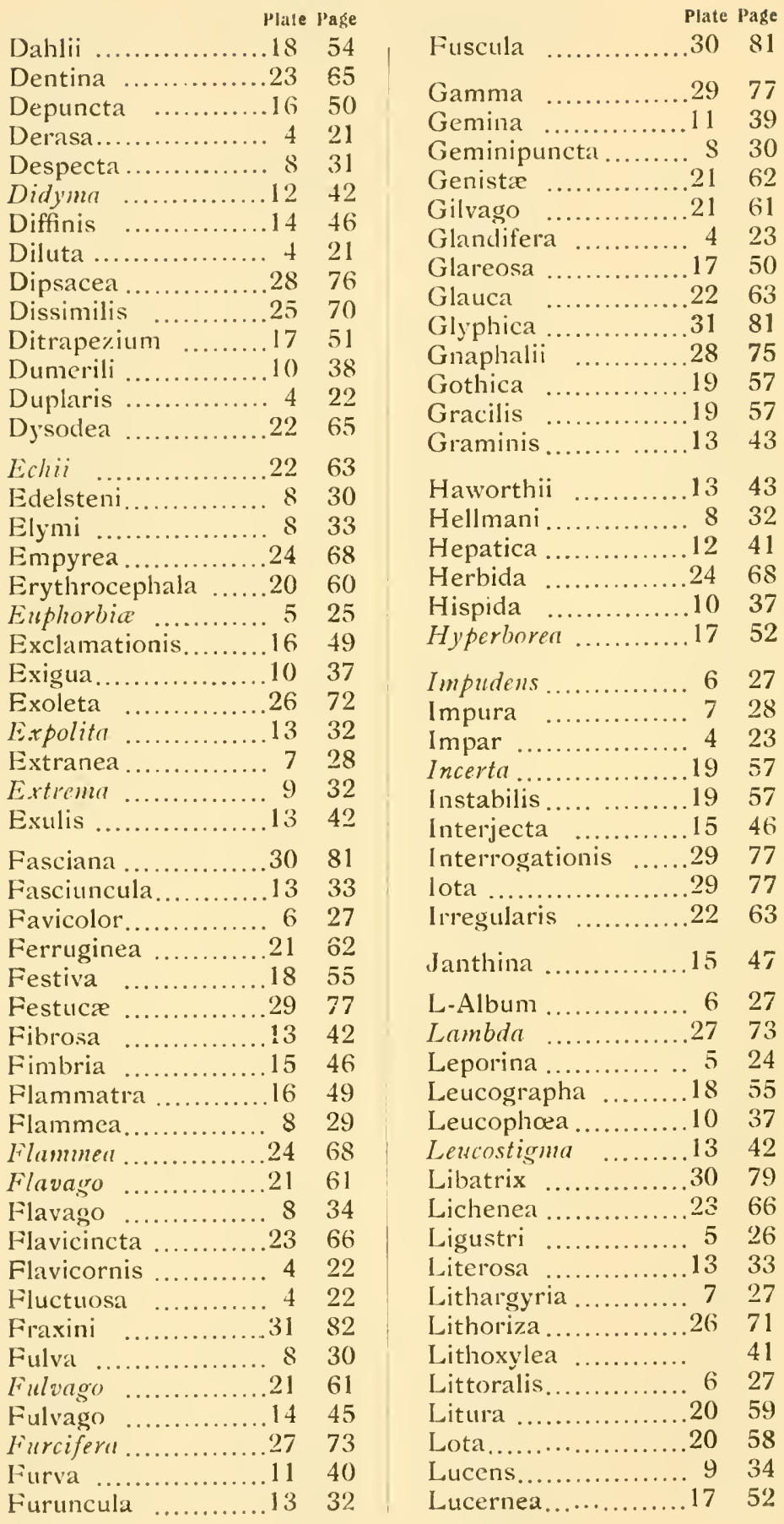


INDEX OF SPECIES - Synonyms in Italics.

\begin{tabular}{|c|c|c|c|}
\hline \multicolumn{2}{|c|}{ Plate Page } & \multicolumn{2}{|c|}{ Plate Page } \\
\hline -ucipara. & 67 & Oleagina & \\
\hline Luctuosa.. & So & Oleracea & \\
\hline unigera... & 48 & Oo $\ldots . . . \ldots \ldots$ & \\
\hline cunosa .. & 59 & Ophiogramma... & \\
\hline Luteago. & 64 & Opima ............. & \\
\hline cutosa..... & 34 & Or $\ldots$. & \\
\hline Lutulenta & 66 & Orbona & \\
\hline .ychnitis.... & $7 \frac{4}{x}$ & Orbona..... & \\
\hline Macilenta. & 58 & $\begin{array}{r}29 \\
4\end{array}$ & \\
\hline Marginata ... & 76 & Ornithopus & \\
\hline Maritima ..... & 49 & Oxyacantha & \\
\hline Maturu..... & 37 & & \\
\hline Maura ......... & 78 & Paleacea & \\
\hline Megacephala & 26 & $\begin{array}{l}\text { Paleniea ... } \\
\text { Pallens }\end{array}$ & \\
\hline Melanopa ... & 79 & $\begin{array}{l}\text { Pallens...... } \\
\text { Paludis. }\end{array}$ & \\
\hline Menyanthidis & 25 & Paludis $\ldots$ & \\
\hline Meticulosa ... & 68 & Palustris .... & \\
\hline Mi $\quad \ldots . \ldots . .$. & 81 & Parthenias .. & \\
\hline Micacea & 35 & $\begin{array}{l}\text { Pastinum..... } \\
\text { Peltiger }\end{array}$ & \\
\hline Miniosa & 57 & Peltigera .... & \\
\hline Moneta ..... & 78 & Peregrina & \\
\hline Monoglypha... & 41 & Perla ..... & \\
\hline Morpheus ... & 44 & Persicaria ... & \\
\hline Munda ....... & 50 & Perspicillaris & \\
\hline Muralis ..... & 23 & tis ..... & \\
\hline Musculosa ... & 30 & ata.. & \\
\hline Myricae $\quad . . . . .$. & 25 & mitidis & \\
\hline Myrtilli . & 80 & $\begin{array}{l}\text { Pinastri } \ldots . . . . \\
\text { Piniperda }\end{array}$ & \\
\hline Nana $\ldots . .$. & 64 & Pisi & \\
\hline Nebulosa ......... & 68 & Pistacina... & \\
\hline Neglecta ........... & 48 & Plec & \\
\hline Neurica......... & 30 & Polyodon.... & \\
\hline Nictitans ....... & 34 & Polyodon .... & \\
\hline Nigra $\ldots . . . . . . . . . .23$ & 67 & $\operatorname{aris} . . . . . . .$. & \\
\hline Nigricans............. 18 & 53 & Populeti ..... & \\
\hline Nigrocincta ..........23 & 66 & Porphyrea ........ & \\
\hline Notha $\ldots . . . . . . . . . .32$ & 83 & Porpliyrea ....... & \\
\hline Nubeculosa ..........2s & 75 & Præcox $\quad \ldots \ldots \ldots$ & \\
\hline Nupta ..............31 & 82 & Prasina $\quad . . . . .$. & \\
\hline .18 & 53 & ba $\ldots \ldots \ldots$. & \\
\hline bscwra ...........15 & 48 & Protea .............. & \\
\hline Obsoleta ............. 7 & 29 & Psi $\ldots . . . . . . . . . .$. & \\
\hline Occulta........... & 68 & Pudorina ..... & \\
\hline cea ........... & 34 & Pulchrina..... & \\
\hline leuca ..... & 62 & Pulierulenta & \\
\hline ctogesime ...... & 22 & Puta......... & \\
\hline$\ldots 4$ & 22 & Putrescens. & \\
\hline Oculea ........... & 42 & Putris ....... & \\
\hline
\end{tabular}


INDEX OF SPECIES. - Synonyms in Italics.

\begin{tabular}{|c|c|c|c|}
\hline \multicolumn{2}{|c|}{ Plate Page } & \multicolumn{2}{|c|}{ Plate Page } \\
\hline Pyralina ... & 46 & Suffusa $\ldots . .$. & 48 \\
\hline Pyramidea & 78 & Sulphuralis.. & 80 \\
\hline Pyrophila & 56 & Superstes .. & 44 \\
\hline Quadrifunctata & 44 & Suspecta.. & 58 \\
\hline Ravida ........... & 48 & Taraxaci.... & 44 \\
\hline Reticulata & 40 & Templi....... & 66 \\
\hline Rectilinea & 70 & Tenebrosa. & 44 \\
\hline Retusa..... & 45 & Tenebrata & 80 \\
\hline .27 & 72 & Testacea........ & 38 \\
\hline homboidea ... & 51 & Thalassina ..... & 69 \\
\hline idens............ & 23 & Tincta ......... & 69 \\
\hline ipæ ............ & 49 & Trabealis ...... & 80 \\
\hline 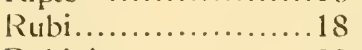 & 55 & Tragopogonis .. & 78 \\
\hline ubiginea ....... & 60 & Trapezina ..... & 46 \\
\hline ubricosa & 56 & Triangulum ..... & 51 \\
\hline$u f(l \quad \ldots .$. & 31 & Tridens ........ & 25 \\
\hline ufina ..... & 59 & Trifolii ....... & 64 \\
\hline Rumicis .. & 24 & Trigrammica. & 43 \\
\hline Rurea ...............12 & 40 & Trilinea ..... & 43 \\
\hline apponariz......... & 40 & Tripartita .. & 78 \\
\hline tia ..............21 & 60 & Triplasia .... & 78 \\
\hline atura.... & 71 & Tritici .... & 54 \\
\hline Satıcia ...............18 & 54 & Turca .... & 26 \\
\hline Scabriuscula ..... & 36 & Typhz .... & 31 \\
\hline Scolopacina $\quad \ldots \ldots \ldots 13$ & 42 & Typica .. & 78 \\
\hline Scrophulariæ ..... & 74 & Ulvæ ... & 49 \\
\hline am ............16 & 49 & Umbra.......... & 76 \\
\hline runnea $\ldots . \ldots . .27$ & 73 & Umbrosa ......... & 51 \\
\hline Serena...............21 & 62 & Umbratica ........ & 74 \\
\hline ...............21 & 61 & Unanimis $\ldots . . .$. & 39 \\
\hline Simulans ............19 & 56 & Unca $\ldots . . . . . .$. & 81 \\
\hline Sobrina ............ & 5.5 & Uncula........... & $\$ 1$ \\
\hline 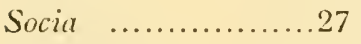 & 73 & Upsilon $\ldots . . . . .$. & 58 \\
\hline Solidaginis ............ & 72 & Urticæe........... & 78 \\
\hline Sordida $\ldots . . . . . . .$. & 39 & .20 & 59 \\
\hline Spadicea ............20 & 60 & ra.......... & 49 \\
\hline Spargani ............ 8 & 31 & eum ............. & 77 \\
\hline Sphinx..............28 & 75 & 5 & 24 \\
\hline Sponsa $\ldots . . \ldots \ldots . . .32$ & 83 & .30 & 80 \\
\hline Stablis ...............19 & 57 & Verbasci ... & 74 \\
\hline Stigmatica ..........17 & 51 & Vestigialis & 49 \\
\hline Straminea ......... 7 & 28 & .26 & 71 \\
\hline Strigilis ...........13 & 33 & Viminalis... & 67 \\
\hline Strigosa ............ 5 & 25 & Viridaria.... & 81 \\
\hline Strigula $\ldots \ldots \ldots \ldots \ldots 17$ & 52 & Vitellina .... & 27 \\
\hline Suasa ..............25 & 70 & $\ldots 17$ & 51 \\
\hline Sublustris $\ldots \ldots \ldots \ldots 12$ & 41 & $\ldots 23$ & 66 \\
\hline Subrosea.............18 & $\begin{array}{l}52 \\
47\end{array}$ & Xerampelina & 61 \\
\hline $\begin{array}{l}\text { Subsequa } \ldots \ldots \ldots \ldots 15 \\
\text { Subtusa ............14 }\end{array}$ & $\begin{array}{l}47 \\
45\end{array}$ & Zinckenii .............27 & 73 \\
\hline
\end{tabular}




\section{PREFACE.}

In these present days, when so much is known about the habits and life history of our Noctuid moths, there is little scope for a student to throw any new light on these subjects; hence we often find the more studious entomologists directing their attention, rather to the dry investigation of nomenclature, than to the deeper examination of the structure of the insects which they study. There are however still many students who ask for work rather than books and mere cabinet specimens. So work must be forthcoming or interest will flag. When I conceived the idea of working upon the male genital organs of the Noctuid group, I fondly hoped the investigations would settle finally most of the points in dispute amongst systematists. In this, as in other of our incipient thoughts we must be prepared for disappointments. There have been plenty of these, but so interesting was the work that when they occurred they only urged me on to a deeper insight into the marvellous anatomy of these organs. And even now, were it not for the earnest solicitations of my friends, and the duty I owe to entomologists of all ranks (who have so generously helped me with specimens, even to the extent of taking them out of the much prized series of their cabinets) to publish what I have already done, I fear the temptation to continue my already extensive preparations and examination of other groups. wouk be too strong to be withstood. 
It is therefore not without misgivings that I am induced to record the results of 20 years spent in happy investigations, made in odd hours stolen from so busy a life that often weelis would elapse, before I could spare the time to continue my favourite pursuits, this coupled with the fact that I have suffered nearly every year with a distressing eye trouble, must be sufficient excuse for not falling in with my friends wishes earlies.

A mere accident drew my attention to these organs, and about the same time a question arose as to the identity of certain specimens of Miana taken in Ireland, which appeared to puzzle the savants of that time.

I made preparations of the several species of the genus, and had the satisfaction of being able to prove there are distinct and unalterable forms of genitalia to each species; so that any doubtful specimen could be at once determined by an examination of these parts. I then discovered that other investigators had already worked certain groups from a similar standpoint. I found that P. H. Gosse had published an illustrated monograph of the Papilionida in the transactions of the Limnaan Society for 1883 . This work which is beautifully illustrated, contains an account of the genital organs as seen in diried specimens, by the removal of one valve, (harpe), and certain parts were named. Unfortunately in several instances the drawings are quite incorrect, and the majority entirely misleading, owing to the most important structures being hidden by clessication. He also gives a short Bibliography of his subject. Dr. Buchanan White had previously, in 1876 , published in the transactions of the same society, a paper on the genitalia of the European Rhopalocera. His figures which are very poor, show only the outline of the parts as seen by removing the scales. This is most unsatisfactory and gives no idea of the important internal structure. Scudder's work published about 
1888 , and in previous writings, treats of the parts in a similar way.

In 1889, Professor John B. Smith of New Jersey, U.S.A., in conjunction with Professor Riley and H. G. Dyrar, commenced a series of monographs on the Noctuida of North America, in which he laid great stress on the value of the genitalia. These monographs are illustrated by rough outline drawings of one harpe and clasper only, of the various species. These figures were a step in the right direction, but were not carried out sufficiently, and appear to me, very much like illustrating a butterfly book with drawings of fore wings alone. It is evident that for scientific purposes the whole apparatus must be dealt with.

In the Transactions of the London Entomological Society for 1889 , pp. 209, Dr. T. A. Chapman follow's Professor Smith in an exhaustive article on the Erebias, and has also from time to time published notes on various species. None of these works seem to me to utilise to the fullest extent the information which may be gathered from the examination of the genitalia. The complete organs must be studied, for the reason that in different groups, certain particular parts form the chief distinguishing feature; often the harpes are so similar that reference must be made to the uncus; at other times it is the juxta that differs; generally the penis is a safe organ for differentiation.

Recognising the importance of this, I resolved to figure the whole apparatus, but never having been taught drawing and having no natural gift I at first secured the services of Mr. Henry Butler, a rising young artist, and endearoured to help him to draw what I saw. His figures are signed with his initials. I drew the remaining figures myself, and have also gone over his, making them uniform with $\mathrm{my}$ own.

The drawings are all done to one scale. At one time I hoped photography would have aided their 
delineation, but after photographing some two hundred preparations, I found that they were not suitable for my purpose. Firstly, owing to the great transparency, including both upper and under surfaces, which instead of elucidating the structure, simply bewildered and confused the picture. Secondly, on account of the great difficulty in getting the preparations exactly balanced. In drawing it was possible to exclude extraneous parts and rectify misplacements and so produce a figure, that would be much simpler and more correct for comparison.

I now regret that I did not include the penis in the figures, as it is often of the utmost importance in critical cases; but at first I did not estimate this organ at its true value, and the confusion produced by its central position, coupled with the extreme difficulty in getting anything like uniformity, owing to the softness of the structure and the difficulty of extroverting the eversible parts, has made me feel that a short description is even better than a draving, which as often as not, might be misleading.

I have adopted the scheme of placing the name of the species beside each drawing. This deviation from the ordinary numbering of the figures (which necessitates having to turn to another page for an explanation) will I am sure be appreciated as an important saving of time.

For supply of specimens, both local and rare. I wish to express my warmest thanks to our British Lepidopterists all over the country, without whose help I could never have got the work to its present complete state, and I wish here to place on record my grateful thanks to my old and valued friend Samuel James Capper, the veteran and life long president of the Lancashire and Cheshire Entomological Society, and not less to E. R. Bankes, G. T. Porritt, W. G. Sheldon, Louis B. Prout, Dr. T. A. Chapman, J. W. Tutt, 
E. C. Stott, R. South, A. Bacot, William Mansbridge, Charles H. Walker, Dr. Willian Bell, The Rev. C. R. N. Burrows, H. M. Edelsten, A. Robinson, Herbert Massey, J. A. Simes, W. Mounfield, Dr. Cotton.

Whilst to others who have rendered me noble assistance, my thanks come too late. For years that queen of entomologists Mrs. Emma Sarah Hutchinson, put aside for me spoiled specimens of rarities she was breeding, thus helping to spare my feelings in having to sacrifice cabinet specimens. The late John E. Robson that kindest of entomologists, who placed his entire cabinet at my disposal. The late Charles G. Barrett, J. A. Clark, Dr. Philip Mason, the Rev. Joseph Green, and my companions in field work George A. Harker and Rathbone Hughes. Alas! They are no more.

I also particularly wish to acknowledge my debt of gratitude to my friend the Rev. C. R. N. Burrows, whose love of accuracy has so greatly helped me in the production of the letter press. His unwearying care in correcting the proof sheets, and his many suggestions for elucidating difficult passages, have proved him to be a valuable friend, especially to one who for so many years worked entirely alone.

F. N. PIERCE.

The Elns,

Dingle,

Liverpool.

4th January, 1909. 



\section{INTRODUCTION.}

Before entering upon the descriptive part of the work, it will be necessary to make some preliminary observations, in order that those who have not worked at this branch of entomology may be able to follow the points touched upon.

The organs constitute the last abdominal segments of the insect, and are generally withdrawn into the preceding segment, and hidden by an abundance of scales and hairs, either on the last segment of the body or on the organs themselves. Reference to various writers shows that the segmentation of the body is still unsettled. This is mainly owing to the author's speaking of a certain segment, without describing its position ; I have therefore thought it wise to definitely state the plan I have followed. The body consists of a head, three thoracic segments, eight abdominal segments, which may have 6,7 or 8 true spiracles, and the genitalia. I treat these as a whole, notwithstanding the opinion of some authorities that a division can be discovered. Without throwing doubt upon their investigations, I consider it unnecessary to discuss the matter, being unable to locate a definite segmentation, and finding the matter unimportant from the point of view from which I am describing the organs in this work. 


\section{MANIPULATION.}

In order to obtain a comprehensive view, the organs must be extruded, and made transparent, this is very simple. Having removed the body near the thorax, it is soaked in a 10 per cent. solution of Caustic potash, for about 24 hours to 2 or 3 days, according to the size and nature of the body. Or it may be boiled in a test tube, for a short time in the same solution, which is a quicker method. When it is quite soft, it is taken out and placed in a shallow dish of water. The body is then gently tapped with a small bent spatula or a brush, when the parts will fly out. If a little pressure be now put on the junction of the harpes, they will separate, exposing the interior with all the parts beautifully displayed. The Alkali must then be carefully washed out of the preparation, which should next be slid on to a glass slip, arranged with needles, and covered with a small piece of glass, (I generally use a $3 \times 1$ inch slip cut into 3 , i.e., one inch square), which gives about the right amount of pressure. A small quantity of Absolute Alcohol should now be allowed to flow in to remove the water; after dehydrating for about half an hour, Oil of cloves must be run in from one side, and allowed to soak in until the parts are clear and free from air bubbles. The object is then ready for mounting. This can be easily done by placing a couple of drops of Canada balsam in benzole, slightly spread on a clean slip to fit the cover glass. The preparation should now be gently lowered into the Balsam, right way up; the cover glass placed over, and the slide put aside to dry.

I find it better not to hurry the drying, and patience pays well at this stage.

Should the mount be very thick, a cavity slip should be used. I do not recommend the use of clips, though in very tough species, they are useful if carefully applied to the edges of the cover glass. 
I lay great stress on having the mounts right way up, and uniform. In the examination of a number of slides this will be found a great time saver, and productive of an easy conscience, no matter how many slides are to be examined.

The labels also should be so uniformly placed, that the name can be read without difficulty, whilst the slide is on the stage of the microscope. The importance of this will be felt when comparing a number of slides.

\section{STAINING.}

Besides improving the look of the mount, staining is useful in bringing up details in transparent parts, that might otherwise be difficult to see. If Carbol fuscin, or Carbol Methyl Blue be added to the Alcohol used for dehydration, the tissues and chitine wiil be stained red or green.

When this is done the preparation must not be left too long in oil of cloves, and it will be necessary to immerse it for a few minutes in spirits of turpentine, before placing it in the Balsam.

\section{DRY MANIPULATION.}

When an examination is necessary without destroying the specimen, it may often be accomplished by inserting into the genital cavity a drop of wood naptha, by means of a camels hair brush; in a few moments the harpes will be sufficiently relaxed, to allow the insertion of the points of fine tweezers, the spring of which will force the harpes apart, and allow a close examination with a Coddington lens.

The harpes may afterwards be gently pinched together without damage to the specimen.

This method will be found especially useful in the Hydrecias, Nonasria neurica and arundineta, and any species where a rough and ready examination is 
needed. The females should be held by the pin head between the thumb and first finger, with the body resting on the second finger. It should then be brushed with a short stiff brush on the ventral surface, which will expose the lodix and genital plate, which can then be easily examined with a lens.

\section{NOMENCLATURE AND DESCRIPTIONS.}

It has been found necessary to construct, as far as possible, a typical set of organs giving to each a distinctive name. This so far has never been done. Various writers having used various terms for the parts. These I have endeavoured to make use of, adding thereto names for those parts that I believe to be undescribed. It must be understood that in the descriptions following, the specimens are examined from beneath, with the uncus at the top.

\section{MALE.}

The ninth abdominal segment consists of The Tegumen, the base of which rests on the plane of the ventral surface of the abdomen, the upper part curvings anally, until it lies longitudinally in the plane of the dorsal surface. It is a flattened sac of thin chitine, enclosed in a stronger ring, the dorsal point of which is called The Uncus, and the basal portion The Vinculum. This ring is sometimes articulated, in the middle laterally, enabling the uncus half to be thrown backward towards the head.

The Uncus, present in all the Noctuida, is of hardened chitine and occupies in this group the central upper part of the tegumen. It varies considerably in shape, and may be a single hook, bifurcate or trifurcate or even bifid or trifid. When divided to the base, the side portions will sometimes travel to wide distances apart, upon the edge of the tegumen. However widely 
the side pieces are separated, they are still to be treated as forming the uncus. The central hook of the uncus may be
Simple,
Sickleform,
Cygnated,
Tongue shaped,
Diamond form,
Spatulate,
Mandibulate.

It is doubtful what is the exact use of the uncus; generally it is presumed to grasp the female dorsally. It has also been suggested that it is thrown back and acts as a guide, sometimes fitting between the lobes of the ovipositor of the female.

On either side of the tegumen laterally, in the vicinity of the articulation is a lobed process, densely clothed with hairs which I call The Peniculus; and which appears to act as a brush to the penis. The basal portion of the ring of the tegumen, which I have called The Vinculum, varies considerably in form, being generally pointed ventrally; the point being sometimes enormously extended (e.g. Apatura iris). Below the articulation of the tegumen, are hinged, on either side the two large wing like processes which form The Harpes. For convenience I have divided these into three portions, upper, lower and central, although the divisions are sometimes difficult to define. The upper part, which I have called The Cucullus is sometimes divided, i.e., plainly differentiated from the central portion by a fold or groove. The Cucullus may be

$$
\begin{aligned}
& \text { Peaked, } \\
& \text { Bifurcate, } \\
& \text { Trigonate, } \\
& \text { Battledore shaped. }
\end{aligned}
$$


The upper edge is called The Margin, to which is often attached a uniform row of incurved spines, which I call The Corona, there are also attached to the edge of the harpe long spines which I term Marginal Spines. The outer margin of the cucullus, where the division usually occurs is called The Anal Angle and is sometimes armed with a large Anal Spine. Where the division is not evident, this position is sometimes occupied by a projecting column or thumb, which I call The Pollex. The upper inner angle is sometimes produced to a point, and occasionally below this, proceeding from the skin, on the inner side of the cucullus, is another small papilla called The Digitus.

The lower portion of the harpe I term The Sacculus. This invests the base of the harpe, and is free along the costal edge. It is attached to the outer margin of the harpe, but is sometimes extended into a free arm, almost to the extremity of the harpe. From within the base of the costa of the sacculus, arises a small organ which I have termed The Clavus, which may be rounded, produced, peaked or brush form.

The central area of the harpe is occupied by a complicated series of organs, which practically vary in every species and afford a great help in differentiation. For convenience salie they may be divided into The Clasper and Ampulla. The Clasper which arises toward the outer side and is generally a free arm, produced from a peculiarly curved base, by which it may frequently be recognised. Sometimes it is foot shaped, as in the Nocture, in which case the terms, toe, heel, \&c., indicate the parts spoken of; or it may be a simple swelling, entirely attached to the skin, when it is spoken of as, not free. On the inner side of the central area is The Ampulla, a process arising direct from the skin. It is a very variable organ and difficult to locate. It is often a small papilla, sometimes only a wart, at other 
times a long shaft extending beyond the cucullus, or it may be only a flap on the skin. Below the ampulla, on the costal side, is often a small finely spined prominence called The Editum.

At the base of the uncus, on the inner surface of the tegumen, is an opening through which passes, a thin transparent tube which is The Anus. Attached to the anus on the upper surface, is a process only present in some of the Noctuidce which is The Scaphium (of Gosse). This is well worth further study. There is often another process somewhat similar, attached beneath the Anus, which I propose to call The Subscaphium. These organs are sometimes united, forming a tube, through which the anus passes.

My friend, The Rev. C. R. N. Burrows and I, have examined these organs most carefully and have come to the conclusion, that they are only an armature of the Anus.

Beneath the anal aperture, and attached to the same articulation as the harpes, is a band like sheath, through which the penis is protruded, this I have previously called The Juxta. Although sometimes only a transparent tube, it is often decorated with a shieldlike plate in front, which may extend right round the band until it becomes a really complicated organ (vide Tceniocampa gothica).

The Penis itself is a tube of varying length and width, bulbed at the base. The outside covering is called The Adveagus, and consists of a stout tube, with an opening in the side near the base (which receives the seminal duct), and contains the eversible, balloon-like, membrane The Vesica. This is attached to the irregular edge of the orifice of the xdoagus. This vesica is of the most delicate texture and can only be examined when extruded, it is usually furnished with 
one or more strong spines, which for descriptive purposes I have termed Cornuti. This armature of the vesica may be represented by a bulbed cornutus, a short bulbed cornutus, a spicule, a band of teeth, or a comb of teeth.

The orifice of the Adoagus may be hooked, scobinated, dentated or crested.

\section{FEMALE.}

It may be thought with such elaborate organs for clasping, that corresponding features would be found to exist on the exterior of the female abdomen. This is not entirely so, indeed so far as known to me at present, with a few notable exceptions, the external organs are:

The Lodix (coverlet). The central plate upon the anal edge of the lower surface of the 7 th abdominal segment, and which covers the genital plate.

The Genital Plate, a strongly chitinous plate varying in different species, leading to the genital tube.

The Ovipositor, a segmented tube of varying length bearing a lateral pair of lobes, which is usually withdrawn within the body cavity.

In cases where there is a specialised complicated structure in this sex, there is little doubt the mechanism is specially adapted for oviposition, and not for copulation. (Vide Nonagria canna and Calymnia pyralina).

Recent investigations tend to show that some variation exists in the internal female organs, especially among the Geometrce; Copulation takes place by the insertion of the penis into the genital tube.

I have found it necessary to make use of certain adjectives in the descriptions, which will convey a definite meaning to various ornamentations of the chitine. 
Spinose; clothed with spines.

Hairy ; clothed with hairs.

Scobinated; with rasp like teeth.

Squamous; scaled.

Dentated; teeth larger than scobinations.

Crested; edged with large teeth.

Serrated; edged with small teeth.

\section{CLASSIFICATION.}

It may be taken as an axiom that no single stage or organ can be used exclusively for the purpose of classification of the Lepidoptera. Any attempt at this must fail entirely. But it cannot be denied that the genitalia are most important features in many cases.

Certain genera can often be distinguished by the general uniformity of the organs, some genera assuming so distinct a pattern, and the individuals included, running so close, that only minute differences separate them into species. Others are superficially so very different, that they can only with difficulty be connected into genera.

Occasionally in a long run of species there will be a sudden divergence, and were it not for the accepted relationship, combined with the study of the larvæ, ova, \&c. ; it would be impossible to imagine them to belong to the same genus.

It will therefore be seen, that great care must be taken that a divergent species is not separated from a natural genus. In this work classification is largely based on the genital organs. It is not however put forward as the only true system, but that the student may use it in his studies from this particular standpoint.

\section{VALUE.}

It will be necessary to give some idea of the value of the genital characters. In his great work "The 
Noctuidce of Temperate North America," Professor John B. Smith says :--

"The study of the primary sexual characters is one of the most valuable guides in the recognition of species. The structures are within my experience absolutely invariable within specific limits; and species otherwise closely allied are sometimes well separated by these characters. They have proved invaluable in settling questions of identity of American and European forms so closely allied as to be considered races, and in several instances they have proved the identity or distinctness of species when superficial characters left it in doubt. It has removed individual judgment as a factor in many cases, and allows a final appeal in cases of difference."

These remarks are obvious from our investigations in recent years of the genus Miana; the genus Oporabia; the specific distinction of Coremia ferrugata and C. unidentaria; of Retinea buoliana and R. pinicolana, and of new species added to our British list, or even to Science, Zygrena achillad; Hydrocia crinanensis ; H. lucens and H.paludis; Cidaria concmnata; Nonagria edlesteni; N.neurict and $N$. arundincta. The recognition of all of which is mainly due to examination of the genitalia.

When I first took up the work, one of the great difficulties was to convince entomologists that species did not differ inter se, or alter with drying. This is generally accepted now, and it would be useless entering into the arguments brought forward to lessen the value of my observations, all of which were found to be groundless. At the same time it must not be taken for granted that there is no variation in the organs. To a certain extent there must always be some. Dr. T. A. Chapman in a plate in the "Entomologist," vol. XL. (1907) May, shows several slight variations in Acronycto tridens, some of which may be errors in interpretation. Generally, however, the organs are remarkably constant. 


\section{ASYMMETRY.}

But in certain species the organs of the genitalia are never symmetrical, and where this asymmetry occurs it is as far as I know also constant. I have found this want of symmetry in the harpes and their armature, in the juxta, and in the vinculum. Dr. T. A. Chapman records it also in the penis, (Trans London Entomological Society, Part IV., 1902), but for my own part I fail to see how a single organ, especially when it is cylindrical and curved, can be spoken of as asymmetrical.

It is a noticeable fact that this want of symmetry appears to affect particular genera, and even groups.

\section{MATERIAL USED.}

Where I had no reason to doubt a species, I have made the drawing from a single specimen, but in the majority of cases two or more specimens have been examined for verification; and in the case of the Hydrocia nictitans group close on 100 examples were prepared, before satisfactory evidence could be produced of the existence of several species, amongst insects which had previously been popularly considered one; confirming Mr. Tutt's suggestions of 20 years ago.

Care must be taken that the correct bodies are on the specimens before they are prepared. It is a common failing with collectors, rather than have a specimen in their cabinet without a body, to glue on the body of any species that first comes to hand. I need hardly say that, to the genitalia worker, this is productive of much unhappiness. It is also well-to examine the frenulum for the sex, before detaching the insect's body.

\section{AS MICROSCOPICAL OBJECTS.}

The examination of these parts is most interesting and often at times exciting. The marvellous variety 
and the extraordinary beauty of the minutest parts, far surpassing many of the more popular microscopical studies, especially when a little stain is used.

\section{PENCILS OF HAIR.}

Before proceeding to the descriptions of the various species I should like to call attention to the hair pencils possessed by many of the male Noctuida, which appear to be almost unknown.

These beautiful tufts are often in close proximity to the genital organs, but generally upon one of the earliest abdominal segments. The usual construction put upon them is that they are scent distributors.

In the face of the wonderful power possessed by so many Lepidoptera of assembling, one would expect to find these scent organs in the fenrale, and used to attract a partner, as is customary in nature, instead of which we find the sombre, and often portly dame credited with chasing after the elegant, dandy, love sick swain, attracted by the scent he distributes!

That the male does in some species possess scent organs 1 cannot doubt, as it was unquestionably proved by my old friend John E. Robson, who imprisoned males of the genus Hepialus in a chip box, and found on opening, that it was impregnated with a distinct odour, strongly resembling pine apple. My own experience with $H$. humuli was, that the odour in this case resembled violet powder, and a friend who was with me, at the time I made the observation, suggested heliotrope.

But then the colouring of the sexes, and the observations made in paring, prove that in this species at any rate, the female is attracted to the male, not only by the scent, but also by its brilliant white wings, whilst it pendulates in the summer twilight, forming a conspicuous object to perhaps, the none too sensitive vision of its future spouse. 
In the case of $H$. hectus, another species in which the male attracts the female, the scent distributors are understood to be on the hind leg, the tibia of which has no terminal joints, but is round like a bladder. This species does not possess hair pencils.

These pencils are situated at either side of the ventral surface of one of the earliest segments of the insects body. There is a large base, from which the pencils spring; the hairs are generally about half as long as the body, the basal portion being aglutinated together, they then spread out into an expanded tuft. As a rule they are invisible to the eye, being cunningly concealed in two long lobed pockets. In fresh specimens these hairs can easily be withdrawn by the aid of a pin. Whether the moth has powver to replace them I am unable to say. But as we rarely capture a specimen with them extended we can only conclude-

1. That they can be replaced, or

2. That they are seldom used, or

3. That they fulfil their functions in their natural position within the pockets.

They are of no generic value. In the undoubted genus Hydrocia, nictitans does not possess them and the others do, and also Nonagria arundineta does not possess them and neurica; edelsteni does.

Where, in the course of my dissections I have come across them I have recorded the fact of their presence or absence. Where this is not stated the species still require examination.

\section{NOMENCLATURE.}

I have adopted the specific names generally used by British Lepidopterists, and have also added the name used by Richard South in his "Entomologist List" ; merely for identification purposes, leaving the question of priority and synonomy for abler hands than mine. 



\section{Classification of the Noctuidæ based on the Structure of the male Genitalia.}

The Cymatophoridas are a very distinct group of the Heterocera. They are at once distinguished from the Noctuidce by the fact that the uncus is trifurcate. The present grouping is fairly correct.

\section{Thyatira derasa.}

Harpes simple without armature; the sacculus forming a projecting hook on the outer margin; uncus trifurcate ; vesica with a mass of teeth.

Batis. From John Gardner. Pencils present. Harpes shorter than preceding species; sacculus projecting from the outer margin; uncus trifurcate.

The Cymatophoras are by no means as easy to determine. First I should place as being a near approach to Thiatira; diluta, having simple harpes, with the sacculus produced; fluctuosa has also the sacculus strongly marlied; ocularis and or, having a distinct form of uncus, seem almost to require a separate genus; duplaris again has such a distinct form of uncus, and harpe, that it must also be separated from the Cymatophoras, and could be easily included in the same genus as coryli, to which on account of the similarity of the uncus it is evidently closely allied.

Cymatophora diluta. From R. Hughes.

Harpes simple; sacculus ending in hook set with scobinated teeth: uncus trifurcate; ædoeagus dentated, and divided at the tip; vesica simple; juxta composed of two antler like processes scobinated. 
Fluctuosa. From John E. Robson. Pencils absent. Harpes peaked; sacculus terminating in small teeth with a scobinated process nearer the base; uncus trifurcate.

\section{Or. From S. J. Capper.}

Harpes rounded, simple; sacculus slightly produced with papilla nearer the base; uncus trifurcate, the downward and upward curve of the lateral prongs seeming to suggest a pincer like arrangement; vesica with small cornutus; ædœeagus with wide mouth.

Ocularis; octogresima. From Eustace Bankes. Pencils absent.

Harpes rounded, simple; sacculus with papilla; uncus trifurcate strongly mandibulate; vesica with small scobinations; ædœagus with wide mouth. The juxta of this, as in the preceding species, or, appears to be connected with the harpes.

Cross pairing here should not be difficult, and was accomplished by W. H. B. Fletcher, vide "Entomologist." vol. Xxv1 (1893), p.p. 329.

\section{Duplaris.}

Harpe rounded with thick curved costal edge; cucullus is divided, below the division is a row of strong teeth; the sacculus terminates in a bunch of long strong teeth ; uncus is trifurcate, having a dentated subscaphium; vesica simple.

\section{Demas copyli.}

Harpe rounded; clasper indicated by papilla; uncus trifurcate, the lateral pieces wide apart; vesica with two masses of teeth ; juxta curled, squamous behind, the upper part set with a dentated process of long teeth at either side.

Asphalia flavicornis. From Dr. J. Cotton.

Harpes peaked; sacculus is produced into a sucker-like process; the uncus almost defies description, arising from a blunt central base, are two stout columns, each of which terminate in three short arms, the inner pair being finely 
scobinated, the outer pair terminating in a sharply emarginate hook, the hinder pair are broad and rounded. The Columns are united to the tegumen by a buttress, which opens out into an ovate lobe; the vesica has a strong spicule.

Ridens. From C. H. Walker.

The Harpe is peaked; the clasper is more developed and becomes a straight column; in the centre of the sacculus is a large flap, similar to that found on several of the Cymatophora; the uncus is bifurcate, and appears to work laterally; there is also an indication of a scaphium; the Adœagus terminates in two strong hooks of uneven length, curved inwards; the vesica has a small scobinated process.

The Noctuidæ now start with a long run, in which the uncus consists of a single hook, with the exception of two species, Xanthia silago and Miselia oxyacanthce, in which it is bifurcate.

The Bryophilidæe are strongly generic.

Bryophila glandifera ; muralis. From C. H. Walker.

The harpes are rounded, widening at the apex; the clasper consists of an elbowed hook; the uncus is tongue shaped; the vesica has a strong cornutus.

Impar.

Pencils absent.

The harpes are rounded, wider at the apex; clasper an elbowed hook; uncus tongue shaped; vesica has a large and small cornutus.

Perla. From George Harker. Pencils absent. Harpe rounded not wider at the apex; clasper a column ; uncus tongue shaped; vesica with scobinated process.

\section{Moma orion.}

Harpe rounded emarginate at the anal angle, producing a pollex; clasper broad at the base tapers to a point; uncus simple with curved point; vesica with small bunch of cornuti, and rosette of short teeth. 
The Acronyctas have been so fully written upon by Professor J. B. Smith, and Dr. T. A. Chapman, that it would be presumptious on my part to appear to suggest any criticisms on the work of these specialists in the group. I shall content myself with merely treating them from a genitalia standpoint.

As a whole the group are closely generic, with the exception of megacephala and ligustri. Ligustri evidently belongs to a separate genus, megacephala is entirely different, and I should be inclined to make a separate genus for it, were it not for the fact that Dr. Chapman considers in other respects it belongs here. We are therefore bound to conclude that it is a strong example of one of those curious sports that will be met with throughout the order Lepidoptera.

Taking rumicis as the type venosa, leporina and aceris all run closely into it; note should here be made of the curious little peduncle described by Prof. Smith, on the apex of the harpe, in the American species albovenosa, which does not occur in our British species venosa.

The next group including myrica, strigosa, auricoma, menyanthidis, alni and $p s i$, have the clasper bifurcate in various forms; that of tridens as its name suggests being in the form of a trident.

\section{Acronyeta pumicis.}

Harpe rounded; clasper a long arm ; uncus tongue shaped ; vesica with large scobinated processes and band of teeth.

Venosa. From Dr. Chapman. Pencils absent. Harpes rounded; clasper a long arm; uncus simple; vesica has a scobinated process. In albovenosa the vesica has, besides a scobinated process, six long bulbed cornuti.

Lepopina. From Dr. Chapman.

Harpes rounded; clasper a long arm; uncus deep and curved, ending in a hook; vesica with bunch of cornuti. 
Aceris. From S. J. Capper.

Harpes broad; clasper with long hook; uncus is very large and cygnated, with long neck; vesica with long band of strong cornuti.

Mypica. From J. W. Tutt.

Harpe rounded; clasper reaches nearly to the apex of the harpe and is bifurcate; uncus short and blunt; vesica has a short band of strong cornuti.

Strigosa. From Dr. Chapman.

Harpe rounded; clasper bifurcate, the outer hook prolonged and ending in a sharp point; uncus is slender and simple; vesica has a thick bunch of long cornuti.

Aupicoma. From John E. Robson.

Harpe rounded; clasper bifurcate, the inner hook long; uncus cygnated; vesica with several sliort cornuti.

Menyanthidis. From S. J. Capper.

Harpe rounded; clasper bifurcate, the arms being of equal length, the inner one terminating in a pointed hook; uncus is tongue shaped; vesica has a bunch of strong bulbed cornuti.

Alni. From Dr. Chapman.

Harpe rounded; clasper bifurcate with an indication of further division of the outer arm; the inner arm is very long and curved; below the base is a well marked editum; uncus is simple; vesica has a number of small bulbed cornuti.

Tridens. From Dr. Chapman.

Harpe rounded; clasper trifurcate; uncus long and simple; vesica has a large bunch of short stout cornuti hardly bulbed; the juxta is broad and strongly scobinated.

Psi.

Pencils absent.

Harpe rounded; clasper bifurcate the outer arm being rudimentary and rounded; uncus simple; vesica with a large bunch of strong stout teeth; juxta large, the scobination being only on the upper portion. 


\section{Megacephala.}

Harpe deeply emarginate on the outer edge of the cucullus, forming a strong curved hook; clasper a single curved arm; uncus simple; the vesica has a large bunch of long and short cornuti.

\section{Ligustri.}

Harpe rounded, quite simple, with a fold arising from the sacculus; there are no claspers; uncus cygnated, with a long scaphium; vesica has a mass of small cornuti.

The Genus Leucania is a most unnatural sequence to the Acronyctas. After throwing out brevilinea, which evidently belongs more to the Hydrocias, the Leucanias separate naturally into two distinct divisions; those with the rounded battledore harpes, and strong corona; and those in which the harpes are not battledore, and only have marginal spines. Of the first division we may take turca as a type, we have in order pallens, faricolor, lithargyria, littoralis, ritellina, pudorina, albipuncta, and L-album. Conigera, impura, and straminea are separated from the foregoing by the pointed apex of the harpe, whilst extranea takes the most exaggerated form, the pointed apex forming a strong spine, whilst the lower portion of the harpe bulges out enormously.

The second group is composed of putrescens, comma, and obsoleta, keeping flammea, which appears to closely follow this second group, in its separate genus Meliana.

Turea. From S. J. Capper.

Harpe battledore, several rows of spines on the cucullus; clasper. long; ampulla sickle shaped; uncus tongue shaped; the vesica has long band of short teeth.

\section{Pallens.}

Harpe battledore, with spinose cucullus; clasper with elbowed arm; ampulla curved; uncus cygnated; vesica with long band of short teeth ending in a mass of larger ones. 
Favicolor. From Gervase Mathew, (his original type specimen).

Harpe battledore; cucullus strongly spinose; clasper with elbowed arm; ampulla curved; uncus cygnated; vesica with long band of short teeth ending in mass of larger ones.

I can see no difference in the form of the genitalia of this and pallens, except that faricolor is larger.

Lithargyria. Pencils present and central tufts of black hair.

Harpe battledore; cucullus with heavy spines; the clasper protrudes and is curved; ampulla curved; clavus rounded; uncus tapered; vesica with single cornutus.

\section{Littoralis.}

Pencils present and central tufts of black hair.

Harpe battledore; cucullus spinose ; clasper protrudes, the arm being bulged; ampulla curved; uncus tapered; vesica without cornutus.

Vitellina. From E. R. Bankes. Pencils sparse. Harpes battledore; cucullus spinose; clasper with blunt head; ampulla curved and pointed; clavus a small round knob; uncus tapered; vesica with long band of short teeth and single cornutus.

\section{Pudorina ; impudens.}

Harpe battledore; cucullus with fine spines; clasper a short arm; ampulla curved; uncus cygnated; vesica with long band of teeth and single cornutus.

Albipuncta. From E. R. Bankes. Pencils present and in addition has a large bunch of black hair. Harpes battledore; cucullus spinose; clasper short with rounded head; ampulla curved; clavus produced to a bent column, the upper and inner surfaces of which are finely scobinated; uncus tapered.

L-Album. From L. B. Prout Pencils present, besides bunch of black hair.

Harpe battledore; cucullus almost covered with rows of strong spines; the clasper short; ampulla curved; uncus tapered. 


\section{Conigera.}

Harpes battledore; cucullus with obtuse apex, almost pointed, spinose; clasper long; ampulla curved; clavus small and outcurved to a point; uncus cygnated and elbowed; vesica with long band of shortish teeth.

Impura. From S. J. Capper.

Harpe battledore, apex of cucullus produced to a small sharp point, spinose; clasper curved; ampulla curved; clavus sharply incurved to a point; uncus tapered; vesica with long band of very short teeth and bunch of larger teeth.

Straminea.

Pencils sparse.

Harpe battledore; cucullus sharply pointed at the apex, spinose; near the centre of the cucullus is a curious fold; clasper curved, widest at the top and truncated; ampulla curved; clavus peaked and strong; uncus tapered; vesica has long band of short teeth.

\section{Extranea.}

Pencils present.

Harpe battledore; apex of cucullus ending in a long point, thickly spinose; the lower part of the harpe below the waist is produced into a long lobe; clasper very small, as is also the ampulla; uncus tongue-shaped; vesica with broad band of large teeth, dwindling down to quite small ones.

\section{Putrescens.}

Harpe divided at the base of the cucullus; corona absent, nor is there any spinose clothing, but the edge of the cucullus has long straight marginal spines; clasper long, bulbed at the tip; ampulla curved; clavus bulbed; uncus cygnated: vesica has a long band of shortish teeth and one long cornutus.

\section{Comma.}

Harpe has the cucullus long and narrower than the preceding species; clasper is very long; ampulla stout, narrowing quickly to a point; clavus slightly bulbed; uncus cygnated; vesica with a long wide band of longish teeth, and one long cornutus. 
Obsoleta. From Eustace Bankes. Pencils present. Harpe with cucullus longer than preceding species; clasper shortish and pointed; ampulla curved; clavus hardly produced and scobinated; vesica with band of longish teeth and one very long strong cornutus.

For the purpose of comparison, the following two lists of the Lencanidce are given from Staudinger and Barrett, with the distinguishing mark " $\mathrm{x}$ " for the first division with the rounded cucullus, those marked "o" have the pointed cucullus, and those marked "i" for the three species that are quite separate, but which are at present intruded between closely connected species. Staudinger still continues to include breviline and phragmitidis which obviously do not belong here.

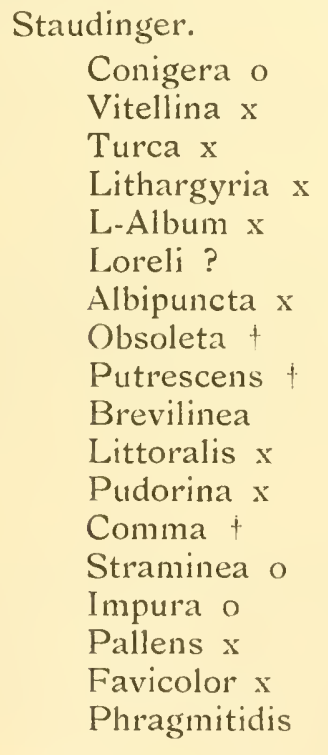

Barrett.

Pudorina $\mathrm{x}$

Impura $o$

Pallens $\mathrm{x}$

Favicolor $\mathrm{x}$

Straminea o

Obsoleta $t$

Putrescens +

Comma +

L-Album $x$

Littoralis $\mathrm{x}$

Loreyi ?

Extranea o

Vitellina $\mathrm{x}$

Conigera $o$

Albipuncta $\mathrm{x}$

Lithargyria $\mathrm{x}$

Turca $\mathrm{x}$

Meliana flammea. Appears to be an off-shoot of the second group of Lencanias.

Harpe with cucullus divided, without corona, but with marginal spines; clasper a trident, in which the inner prong is a club, the middle one a spear, and the outer one a scythe; clavus angulated; uncus tapered: vesica with band of short teeth and two long cornuti. 
Synia musculosa, should certainly not preceed the Lencanias with which it has nothing in common. Barrett places it among the Tapinostolas; this might easily be if the Tapinostolas were made to include several of the Nonagrias and also (Miana) arcuosa and cxpolita which undoubtedly belong to this group; and possibly the remainder of the Mianas. From a genitalia point of view, I suggest the following alteration, as being nearer to true relationship, at the same time admitting that the grouping is distinctly difficult, mostly leading directly or indirectly to the Hydroecias,

\section{Nonagria musculosa.}

Harpe peaked, with corona; from the base of the cucullus arises a spatulate flap, which is connected with a rudimentary clasper; clavus rounded and scobinated; uncus bluntly pointed; redœagus strongly toothed at the orifice; vesica with short bulbed cornutus.

\section{Fulva.}

Harpe rounded, with marginal spines, no corona; clasper extends from the cucullus, and is strong and pointed; uncus tongue shaped; vesica with bunch of small teeth; the juxta is produced into two flaps turned over, and scobinated.

\section{Geminipuneta.}

Harpe simple, hairy, with indication of cucullus being divided, without corona or marginal spines: clasper and ampulla atrophied; clavus lobed; uncus cygnated; peniculus curiously peaked; vesica with spicule.

Neurica; edelsteni. Tutt.

Pencils present. Harpe trigonate, with a corona of 20 spines; clasper attached to the skin, except at the head, where it turns to a short peaked arm; ampulla a papilla; clavus rounded; uncus tongue shaped; ædœagus with a short tooth; vesica with scobinated process where it joins the zedœagus at the orifice. 
Apundineta; neurica.

Pencils absent.

Harpe hardly trigonate, with corona of 10 spines; clasper a longer arm than preceding; clavus rounded; uncus tongue shaped; xdoeagus strongly crested at the orifice; vesica with small cornutus.

Despecta; pufa. From J. Gardner. Pencils absent. Harpe with cucullus narrow and rounded, with marginal spines, spinose, without corona; clasper strong, arises from below the sacculus, curved, terminating in a flattened sucker, with a sharp point; uncus tongue shaped; ædoagus dentated at the orifice; vesica without teeth.

Cannæ. From W. G. Sheldon.

Harpe divided, with corona; cucullus hairy; ampulla clubbed; uncus very curious, tapering from the base, it again broadens out into a flat diamond shaped surface, the points being rounded, the lateral edges are then incurved, forming a deep hollow; redoeagus dentated; vesica without teeth.

Sparganii. From Eustace Bankes. Pencils absent. Harpe almost trigonate, with corona; cucullus divided and hairy; ampulla a simple arm; clavus produced, peaked and clothed with papillæ, each emitting a fine hair; uncus shaped like an arm bone (humerus); ædœeagus dentated at the orifice; vesica without teeth; juxta has two hairy editi.

Typhæ; arundinis. From S. J. Capper.

Harpe divided, with corona; cucullus spinose; clasper bifurcate at the tip; uncus strong, round and pointed; adœeagus strongly toothed at the orifice.

\section{Tapinostola phragmitidis.}

Harpe trigonate, with corona, divided; clasper not free; ampulla a small clubbed arm; at the base of the cucullus on the costal side is a rounded flap clothed with hair; clavus rounded; uncus flat and parallel, hardly pointed; ædœagus with a dentated plate at the orifice; vesica with a short bunch of teeth; juxta produced at either side into a pair of antlers. 
Hellmanni. From Eustace Bankes. Pencils absent. Harpe with corona, divided; cucullus hairy; ampulla a stumpy arm; clavus peaked; uncus widens considerably to the tip, which is very broad, ending in two lobes; the peniculus is curious, the tegumen extending upwards into two cones, the inner surfaces of which are clothed with long hair; redoeagus has two sharp teeth at the orifice; vesica with short band of teeth.

Concolor; extrema. from Eustace Bankes.

Pencils absent.

Harpe with corona; cucullus divided, spinose; clavus produced, stout and clothed with hair; uncus not tapered; aedœagus studded with short teeth at the orifice; vesica with short band of teeth.

\section{Bondii.}

Harpe with corona; cucullus divided and spinose; clavus long, tapered and clothed with hair; uncus parallel; adœeagus scobinated at the orifice; vesica with band of spines and short bulbed cornutus.

\section{Arcuosa.}

Harpe without corona; cucullus divided, with the anal angle pointed, clothed with fine spines; clasper not produced; ampulla a papilla; clavus long peaked and clothed with hair; uncus tapered; peniculus angulated; vesica with bunch of teeth.

Captiuncula; expolita. From J. E. Robson.

Harpe rounded, without corona; cucullus not divided, spinose; clasper not produced; ampulla bulbed; clavus peaked and clothed with hair; uncus tapered; peniculus angulated; vesica with bunch of teeth. This little specis is wonderfully close to arcuosa.

Furuncula; bicoloria.

Pencils present.

Harpe peaked, with corona; cucullus divided, anal angle pointed, but not produced; clasper not produced; 
ampulla very small; clavus simple, indented at top; uncus very broad and tapered, rounded at the tip; vesica with two bunches of matted teeth and a row of stronger teeth.

\section{Literosa.}

Harpe with part corona; cucullus thickly spined at the anal angle; clasper not produced; ampulla bulbed; uncus tapered; vesica with bunch of matted teeth.

Elymi. From J. E. Robson.

Harpe divided, with corona, cucullus densely clothed with hair; clasper and ampulla each a short rounded arm; uncus tapered, not pointed: vesica with patch of long teeth and strong cornutus.

Miana strigilis. I examined a great number of this, and the other species of the Mianas, of every variety; for the material of which, I am indebted to W. H. Harwood, C. S. Gregson, J. E. Robson, S. J. Capper, C. E. Stott, \&c.

Harpe angulated, with corona; cucullus divided, the anal angle produced and lobed, the lobe being thickly clothed with spines; below the cucullus on the outer edge is a straight arm; clasper not produced; ampulla rounded; clavus peaked, bulbed at the base, and clothed with short hair; uncus narrow waist, diamond pointed; vesica with curved bulbed cornutus; juxta without side spines.

\section{Fasciuncula.}

Harpe augulated, with corona; cucullus divided, the anal angle produced and lobed, the lobe being thinly clothed with spines; below the cucullus on the outer edge is a straight arm; clasper not produced; ampulla stout and rounded; clavus peaked and clothed with short hair; uncus broad without waist and pointed: vesica with bulbed cornutus; juxta has two arms surmounted with a bunch of spines at either side. 
Hydroecia lutosa. Barrett and South remove this from the Nonagrias; its formation brings it between musculosa and nictitans. I include it in the Hydroecias. Harpe obliquely rounded; cucullus divided, densely clothed with long spines, and corona; immediately below the cucullus arises a strong hook nearly divided from the clasper, which is not produced; the ampulla is club shaped and spined; the tegumen is extended into two lobes, which form the base of the uncus, which is tapered; the redneagus is very long, terminating in a star shaped plate; vesica has a small limpet-like cornutus.

\section{(Gortyna) flavago; ochracea.}

Harpe rounded, with cucullus divided, spinose, with corona; the clasper extends from the cucullus, and is strong and pointed; ampulla clubbed; clavus scobinated; uncus tapered; xdoagus dentated; vesica with bulbed cornutus and bunch of teeth.

Nictitans. From H. Massey. Without pencils. Harpe trigonate, rounded, with corona extending half way along the margin; a large patch of spines at the anal angle; clasper bifurcate with short arms; ampulla a papilla; clavus produced to a tapered hairy arm; uncus slender, slightly tapered; vesica with bunch of six or eight longish teeth.

Paludis. From the Rev. C. R. N. Burrows. Pencils present.

Harpe trigonate, angulated; corona extending threequarter way along the margin; the cucullus has a large patch of spines at the anal angle, which is obtusely pointed; clasper bifurcate, inner arm short, sometimes very short, outer arm long, and generally straight; ampulla a papilla; clavus produced to a long hairy arm, pointed at the tip; uncus widest in the centre; vesica with bunch of short strongish teeth.

Lueens. From Joseph Collins. Pencils present. Harpe trigonate, angulated; corona extending beyond three-quarters of the way along the margin: cucullus 
with a small patch of spines at the anal angle which is acutely pointed; clasper bifurcate, inner arm long, often curved, outer arm long, often curved; ampulla a papilla shorter than preceeding; uncus widest in the centre; vesica with a bunch of fine long teeth.

Crinanensis. From A. Bacot and J. A. Simes.

Pencils present.

Harpe trigonate, rounded; with corona only on the upper fourth of the margin; cucullus almost filled with spines; below the cucullus on the inner side, longitudinally, is a semi-circular flap with a serrated edge; clasper not produced, is attached to the skin of the harpe; clavus produced and tapered, hairy part way up, the tip being naked; attached to the base, and produced is a pointed plate with dentated edge; uncus widest at the centre, but wider above than below; vesica with bunch of shortish strong teeth.

Atlantica. (American species). From Dr. James Fletcher, included here, in case it may be found among the series of so-called nictitans, from the imaginal markings of which it is almost impossible to be distinguished.

Pencils present.

Harpe hardly trigonate, with corona extending threequarters of the way down the margin; cucullus spined along the base; clasper hardly bifurcate, the inner arm almost absent, having the appearance of being broken off; clavus produced and tapered, hairy on the inner surface, to the base of this is attached a sharply pointed flap, the edge of which is deeply indented; uncus parallel, widest in the centre; vesica with band of shortish teeth.

\section{Micacea.}

Harpe with small trigonate cucullus, divided, with corona; anal angle rounded; clasper extends to the base of the cucullus in a long pointed arm; ampulla curved; uncus simple tapered to a point; vesica with short strong bulbed cornutus. 
Petasitis. From S. J. Capper.

Harpe with small trigonate cucullus, divided, with corona; anal angle pointed; clasper extends to the cucullus, tapered; ampulla a short arm; uncus broad, tongue shaped, not pointed; adœagus dentated at the orifice; vesica with strong short bulbed cornutus.

\section{Brevilinea.}

Pencils present.

Harpe with corona only on the upper 4th; cucullus divided, rounded at the anal angle; the clasper a tapered arm; uncus slender, not pointed; vesica with two short cornuti.

\section{Axylia putpis.}

Harpe with round cucullus, corona with 3 rows of very long spines; clasper curved ; ampulla short and rounded; clavus raised and spinose; uncus simple.

We now come to a number of genera of single species wherein the genitalia do not suggest modifications of the existing arrangement; I have therefore adhered to this, omitting sapponarice, which appears to have been included only on account of its reticulated wing markings; really it belongs to the trigonate group of Xylophasias Mamestras, \&c.

Dipterygia pinastri. Pencils present. Harpe rounded; cucullus spinose with long spines, at the anal angle, is a bifurcate jointed tooth ; clasper a straight arm; sacculus thickly clothed with long hair; uncus broad and bluntly tipped; vesica clothed with a number of strong cornuti.

Cloantha perspicillaris; polyodon. From L. B. Prout.

Pencils absent.

Harpe with corona; cucullus divided, and hairy ; clasper very wide, with blunt tip; ampulla bifurcate, with extending finger; uncus broad and tapered; vesica with two long, strong cornuti. 
Aporophyla australis. From A. Bacot. Pencils absent.

Harpe with corona; cucullus angular, spinose; clasper spatulate, and pointed; ampulla small, simple; clavus scobinated; uncus cygnated; ædœagus thickly scobinated; vesica with band of teeth.

Laphygma exigua. From Eustace Banks and A. Bacot, the latter supplying a number of specimens from Australia; Pencils are absent, but it has in place large beautiful tufts of broadly tipped scales at the extremity of the body.

Harpe rounded without corona; cucullus spined on the margin; clasper a long curved hook; uncus slender; vesica with strong cornutus with long base.

Neuria reticulata; sapponariæ. See p.p. 40 Neuronia popularis. From S. J. Capper. Pencils absent.

Harpe angulated, without corona; cucullus hairy, from the base outwards is produced a form of pollex; clasper flattened and lobed; uncus spatulate, very broad, and rounded at the tip; ædœagus with short teeth at the orifice; vesica with band of short teeth.

Heliophobus hispida. From S. J. Capper. Harpe narrow, rounded, without corona; clasper an arm, with curled tip; uncus cygnated; vesica with six or seven cornuti, united at the base, and small bulbed cornutus.

Pachetra leucophœa. From G. T. Porritt. Harpe with corona; cucullus spinose, with jointed tooth at the anal angle, below which the harpe is bulged out; ampulla long and curved; uncus short, spatulate; ædœagus furnished with a row of square teeth or cogs; vesica with long band of teeth.

\section{Cerigo eytherea; matura.}

Harpe angulated with corona; cucullus hairy, with marginal spines; clasper with open snake-like mouth; uncus broad, cygnated; vesica with a number of cornuti. 
There is nothing in common in the three species of Luperina.

\section{Luperina testacea.}

Harpe angulated without corona; anal angle of cucullus produced, and peaked, spinose; clasper not raised; ampulla bulbed; clavus angulated and scobinated; uncus cygnated; ædœagus scobinated; vesica. with number of small cornuti.

Dumerili.

Pencils absent.

Harpe with corona; cucullus spinose, pointed at the anal angle; clasper a short peaked arm; ampulla a papilla; uncus flattened at the tip, with a back ridge; ædœagus scobinated at the orifice.

\section{Cespitis.}

Harpe without corona; cucullus spinose; clasper flattened, and curved at the apex, forming an absurd likeness of a sculptured bust; uncus broad, and tapered; vesica with strong cornutus.

Connexa may easily be included here, with basilinea, unanimis, and gemina it forms a connecting link from the Hydroecias to the Mamestras, which are not separable from the Apameas, and should all be included with the Xylophasias. Following gemina, we get anceps, albicolon, furva, brassica, and persicarice with its abnormal scaphium. Neuria sapponarice should be here included, to be followed by abjecta, rurea, hepatica, and finishing with the masterpieces polyodon and sublustris, whose minute points of difference have made it doubtful if lithoxylea is not merely a coloration form of polyodon. This same trigonate form is carried out in exulis, following which we get the distinct modification oculea, which is not unlike Xylophasia scolopacina, and should hardly be included in the group.

\section{Apamea connexa.}

Harpe angular, with corona; cucullus spinose; anal angle with projecting point; clasper absent; ampulla a simple arm; uncus slender; vesica with single strong cornutus. 
Basilinea.

Pencils absent.

Harpe trigonate, with corona; cucullus spinose at the anal angle and hairy; clasper stout, bent outwards; ampulla very long and slender; clavus short, irregular, pointed; uncus with the tip tongue shaped; redœagus strongly toothed.

\section{Unanimis.}

Pencils present.

Harpe trigonate, with corona; cucullus spinose and hairy; clasper stout, bent outwards and upwards; ampulla short, rounded at the tip; clavus not produced, scobinated; uncus tip tongue shaped; redœagus toothed; vesica with bulbed cornutus.

\section{Gemina.}

Harpe trigonate, with corona; cucullus spinose and hairy; clasper long, thin and curved; ampulla long and elbowed; clavus produced and rounded; uncus parallel and pointed; redœagus terminating with a cock's-comb; vesica with shortish bulbed cornutus.

\section{Mamestra anceps; sordida.}

Harpe trigonate, with corona; cucullus spinose and hairy; clasper bifurcate, or deeply emarginate, with other projecting points; ampulla long and slender; clavus bluntly pointed, strongly scobinated; uncus parallel, slightly widening at the tip; xdœeagus terminating with three or four strong teeth; vesica with shortish cornutus, heavily bulbed.

\section{Albicolon.}

Harpe trigonate, with corona; cucullus with outer margin rounded, spinose; clasper bifurcate, joined to the bend of the harpe below the cucullus, and produces a strong outer arm; the inner arm bluntly pointed and roughly scobinated; clavus produced and rounded; uncus long and tapered; vesica has a band of matted teeth, and joins the rdœagus with a row of short teeth. 


\section{Furva.}

Harpe trigonate, indented at the crown, with corona; cucullus hairy; clasper strong pointed; ampulla slender; clavus produced, plain and rounded; uncus diamond shaped tip.

Brassicæ.

Pencils present.

Harpe trigonate, rounded, with corona; cucullus hooded and spinose; clasper a flap attached to the skin; uncus tongue shaped.

Persicariæ.

Pencils present.

Harpe trigonate, pointed at the apex; cucullus spinose; clasper a flap attached to the harpe; arising from the inside of the inner edge of harpe is a strong column with a rounded head; the clavus is produced, rounded and scobinated; the sacculus extends high up the harpe, and ends in a rounded squamous head; uncus long and tongue shaped, beneath which is a large diamond shaped scaphium; vesica with bulbed cornutus.

\section{Sapponariæ; reticulata.}

Harpe trigonate, with corona; cucullus spinose, with sharp curved hook at the bend of the harpe, below the cucullus; clasper a flap attached to the skin of the harpe; clavus not produced, scobinated; sacculus produced into a pointed head, squamous, and scobinated; uncus tongue shaped; vesica with long band of teeth.

Abjecta. From Gervase Mathew.

Harpe trigonate, deeply indented on the margin, with corona; cucullus thickly spined along the base, and hairy; clasper long and curved; ampulla long and slender; clavus produced and rounded, quite plain ; uncus slender; vesica with bulbed cornutus.

\section{Xylophasia rurea.}

Harpe trigonate, with corona; cucullus with a double row of spines at the base, remainder hairy; clasper shortish; ampulla long and slender; clavus rounded and plain; uncus diamond shaped; vesica with two shortish bulbed cornuti. 
Hepatica.

Pencils present.

Harpe trigonate, with corona; cucullus heavily spined along the base ; clasper a strong arm; ampulla short and bulbed; uncus spatulate, very broad at the base; æedœeagus heavily toothed at the orifice.

Sublustris. From Mrs. Hutchinson.

Harpe trigonate, with corona; cucullus spinose on base, deepest in the centre, and hairy; clasper long and curved; ampulla long, very slender, ending in a single fine bristle; clavus rounded and simple; uncus long and narrow, tongue shaped; vesica with two very short bulbed cornuti.

Lithoxylea. From Mrs. Hutchinson.

Harpe trigonate, with corona; cucullus with a row of spines on the base, deepest at the anal angle; clasper broad and suddenly narrowed toward the tip; ampulla long and slender, terminating with several bristles; clavus broad and round, plain; uncus long and narrow tongue shaped; vesica with two minute cornuti.

\section{Polyodon; monoglypha. Pencils present.}

Harpe trigonate, with corona; cucullus with a row of spines along the base, deepest at the anal angle; clasper broad, narrowing towards the tip; ampulla long and slender, terminating with four bristles; clavus rounded and plain; uncus long and narrow, tongue shaped; vesica with two bulbed cornuti.

These three species are wonderfully alike. The most important character lying in the vesica, the smallest pair of cornuti belonging to lithoxylea; those of sublustris being only just larger, whereas in polyodon they are a fair size. This I consider is sufficient to do away with the old theory, that the first and last are colour varieties of the same species. The ampulla also affords some small difference, sublustris with one bristle, polyodon with four, and lithoxylea with more probably five or six. Polyodon also has larger built genitalia. 
Crymodes exulis. From Dr. Mason, and Eustace Bankes.

Pencils absent.

Harpe trigonate, with corona; cucullus spinose, enclosing before the bend a rounded knob densely clothed with hair; clasper short and pointed; ampulla slender, slightly thicker towards the base; clavus round and scobinated; uncus parallel and pointed; vesica with two short bulbed cornuti.

\section{Scolopacina.}

Pencils absent.

Harpe trigonate, and rounded; corona present on the upper half only; clasper springing from the base of cucullus is broad and curved, the end being lobed; ampulla short and slender; clavus protruding and rounded plain; apex of sacculus produced to a scobinated flap; uncus very narrow and tapered; æedoagus with dentation at the orifice.

\section{Oculea; didyma.}

Harpe battledore, or very roundly trigonate, with corona; cucullus spinose; clasper atrophied; ampulla a short arm ; clavus rounded and scobinated; uncus dianond pointed; vesica with cornutus; adøeagus with cock's comb serrations on the orifice.

\section{Ophiogramma.}

Pencils present.

Harpe with half corona; cucullus rounded, with a sharp tooth at the anal angle; on the inner margin of the cucullus is a round concave plate, producing a pencil of strong hairs; clasper a short pointed arm; uncus pointed; vesica with a bunch of teeth.

\section{Fibrosa; leucostigma.}

Harpe peaked, with long marginal spines; cucullus divided, the anal angle forming an arm; clasper not produced; ampulla bulbed; the uncus which is slender and curved, is set on two lobes produced from the tegumen, to the junction of which is united a circular squamous plate; the base of the peniculus has a tuft of curved hairs; vesica has a strong curved cornutus with 
a long base, and a minute bulbed cornutus. This species is a singular form, and it is doubtful if it should be included in any existing genus.

\section{Charæas graminis.}

Harpe with half corona; cucullus hardly divided, the anal angle forming a curved tip, with a single tooth; clasper, broad at the base is tapered; clavus rounded and scobinated; uncus broad and tapered; vesica with small bunch of fine teeth.

\section{Celœna haworthii.}

Harpe rounded, without corona; clasper terminates with a sharp spine at the anal angle of the cucullus; ampulla bulbed; clavus not produced; uncus tapered at the tip; vesica with cornutus with two small projections at the base.

\section{Grammesia trilinea; trigrammica.}

Harpe without corona; cucullus ends with a curved point at the apex; from the base of the cucullus, there is a deep cavity from which springs the clasper, a plain arm; the ampulla is a short stump clothed with long spines; the clavus is rounded, with small scobinations; the sacculus is extended, and peaked; uncus tongue shaped and spatulate; vesica has six short bands of thickly matted spines; the juxta terminates in a scobinated blunt tip.

In the group Caradrina, morpheus and cubicularis are very distinct from the other four species, which are strongly generic.

\section{Caradrina alsines.}

Harpe peaked, with corona; cucullus hairy and divided; clasper a fold attached to the skin of the harpe; ampulla slender, slightly thicker towards the apex, which is rounded; uncus sickle form; vesica with a tremendously long band of teeth, and mass of short bulbed cornuti. 


\section{Blanda; taraxaci.}

Similar to preceding, but ampulla not rounded at the apex, and slightly tapered. The upper part of the sacculus ends in a triangle, the base of which is squamous.

Superstes. From L. B. Prout.

Similar to preceeding species, but has the upper part of the sacculus ending in a triangle, the whole of which is squamous.

Ambigua. From L. B. Prout.

Harpe peaked, with corona ; cucullus divided, hairy ; ampulla broadest at the base, curved; sacculus ending in a scobinated bulb; uncus sickle form; vesica with shortish band of matted teeth, and a number of long cornuti, generally about 14 or 15 .

Morpheus. From Geo. Harker.

Harpe deeply emarginate on the inner edge at the apex, without corona; cucullus divided, and overlaps the outer margin; clasper peaked; uncus flat and parallel; vesica with band of fine teeth.

\section{Cubicularis; quadripunctata.}

From Geo. Harker.

Pencils absent.

Harpe without corona; cucullus not divided, square at the apex, the upper angle being produced to a long blunt point; clasper curved, ending in a bulb; the sacculus has three raised folds on the inner surface; uncus slender; vesica with band of short fine teeth and rosette of small teeth; vinculum long and slender.

\section{Rusina tenebrosa.}

Harpe rounded, without corona, the costal edge of the harpe projects beyond the apex, and is bifurcate; cucullus undivided; clasper elbowed, and extending from the cucullus which it overlaps, is produced to a long curved arm; clavus angulated and scobinated; uncus slender and tapered; vesica filled with strings of matted teeth. 


\section{Acosmetia caliginosa.}

Harpe roundly peaked, without corona, the costal edge curved; at the base of the cucullus is a raised flap; clasper curved and bulbed at the end; sacculus consists of two round balloons; uncus spatulate, broad; vesica simple.

Hydrilla palustris. From Eustace Bankes. Pencils absent.

Harpe rounded, without corona; clasper tapered; editum raised, with long spines; vesica with long slender cornutus; juxta with a lateral pair of spined processes.

It may here be convenient to take the following species, the peculiar formation of the harpes, and general appearance of which seem to form a separate group, the Cosmiidce, which appears to lead naturally to the Triphcenidce, which again, forms a connecting link to the Agrotidce.

Stilbia anomala. From F, de Kane.

Harpe peaked, without corona ; clasper peaked; sacculus very narrow; clavus long and club shaped; uncus not pointed; vesica with bands of long teeth.

Tethea subtusa.

Pencils present.

Harpe peaked, with corona; clasper curved; ampulla very weak; uncus flattened; peniculus protruded above; vesica with a bunch of teeth.

\section{Retusa.}

Harpe trigonate, peaked, with corona ; cucullus divided ; clasper elbowed and strong; ampulla absent; uncus slender; vesica with short bulbed cornuti.

Euperia fulvago; paleacea. Pencils present. Harpe peaked, with double corona; cucullus long; clasper curved; the structure of the tegumen is exceptional, the peniculus is produced into a high shoulder; the uncus slender and tapered, is set on a rounded process, at either side of which, are two bent lobes; the vesica has two cornuti. 


\section{Dicyela oo.}

Harpe peaked, with corona; cucullus divided; clasper with curved point; uncus short and parallel; vesica with scobinated process.

Calymnia pyralina. From L. B. Prout, and Dr. W. E. Riding. Pencils absent.

Harpe peaked, without corona; clasper club shaped, scobinated and terminating in a curved point; uncus is a short strong hook wide at the base; redoagus dentated at the orifice; vesica with a small curved cornutus.

\section{Diffinis.}

Pencils absent.

Harpe peaked, without corona; cucullus narrow and rounded; clasper concave, terminating in a point at the apex; clavus not produced, scobinated; uncus sickle form; æedœagus serrated at the orifice.

\section{Affinis.}

Pencils absent. Harpe peaked, without corona; cucullus narrow and rounded; clasper a stout column with a concave head; uncus tapered, with an enlarged tip not pointed; ædœagus serrated at the orifice; vesica with a single large cornutus.

\section{Trapezina.}

Harpe roundly peaked, without corona; clasper a stout arm dentated at the base; clavus extends far up the sacculus, and is strongly scobinated; uncus sickle form; vesica simple.

Triphæna fimbria. From A. Harrison, Harpe peaked, pointed at the anal angle, slightly bulging on the costa, without corona; clasper large, curved and pointed; tegumen greatly extended, terminating in a short uncus, set between two squamous lobes; peniculus absent; ædœagus serrated at the orifice.

Interjecta. From J. E. Robson. Pencils absent. Harpe peaked, pointed at the apex, bulged at the costa; clasper curved, tip curled; uncus cygnated; vesica with a quadruple bulbed cornutus, and a second single one. 


\section{Janthina.}

Harpe with cucullus sickle form pointed, below the cucullus, projecting over the costa, is a sharp curved arm; the ampulla arises close to the costa, and is wavy, thickest in the middle; uncus cygnated; redœagus scobinated at the orifice; vesica with a short bulbed cornutus.

\section{Pronuba.}

Harpe with cucullus, curved and pointed, at the base on the costa is a small projection or fold, beyond this the costa is strongly bulged; the clasper forms a hood, into which the upper part of the sacculus extends; the ampulla is very long, with spines branching throughout the length; uncus long and slender; the vesica has a circular serrated process, sparsely clothed with short teeth. The base of the vinculum is joined vertically with a strong, round plate of chitine.

Subsequa; orbona. From R. Tait, junr. and J. E. R. Allen. Pencils absent. Harpe tapered to a point, elbowed; clasper a curved club, uncus tongue shaped, from the upper side of which arises a small peak; zedœagus sparsely dentated at the orifice.

\section{Orbona; comes.}

Harpe tapered to a point; clasper a curved arm, concave at the extremity; uncus curled at the tip; vesica with a mass of small, matted, irregular shaped teeth.

The sequence from the Triphanida to the Noctuce and Agrotidce is very evident. If we make augur the connecting link with ravida, picking up neglecta, we easily take up lunigera, suffusa, cinerea, valligera, ripa, puta, exclamationis, segetum, corticea, fammatra, ulvce (which belongs here), and plecta, we may then pick up the connecting link precox, leading to depuncta and glareosa, after which the anal angle produces a thumb $=$ pollex. We next get ashworthii, umbrosa, triangulum, xanthographa, c-nigrum, ditrapezium, rhomboidea, with an extreme form in baja and alpina, and possibly also lucernea. There is then a branch off to the 
Taniocampas, continuing the run, agathina leads the way to aquilina, tritici, obelisca, nigricans, cursoria, and again to saucia, dahlii, rubi, and brumnea, when we get to the height of elaboration, descending to festiva, conflua, leucographa, sobrina, pyrophila, and porphyrea.

\section{Agrotis augur.}

Harpe tapered to a point, without corona; clasper hooked above, on the outer margin there is a blunt point, showing the junction of the sacculus with the edge of the harpe; uncus is tongue shaped; vesica has a short bulbed cornutus, and a scobinated process; the juxta is bi-lobed.

Ravida; obscura. From John Gardner.

Harpe tapered to a curved point; clasper elbowed; uncus short and pointed; redceagus has a jointed cap which is crested; vesica with round process, scobinated, and toothed; juxta a thin plate.

Neglecta; castanea. From S. J. Capper.

Harpe peaked, without corona; cucullus with a tooth at the anal angle; clasper rounded at the elbow; uncus blunt at the tip; redoeagus serrated and scobinated at the orifice; vesica with a small cornutus; juxta with a thick ring at the base.

In the following species only the salient features will be noted. The harpe is peaked, with corona; the clasper is bulbed at the base conically, and curved upvards to a point.

\section{Suffusa.}

Harpe long; clavus very small and spined; uncus parallel and pointed; vesica with long band of small teeth; juxta a thin plate.

Lunigera. From J. W. Tutt.

Harpe long; clavus produced and spined; uncus cygnated; vesica with small teeth; juxta a thin plate.

Cinerea. From J. W. Tutt.

Harpe short; clavus small and spined; uncus parallel, curved at the tip, which is not pointed; vesica with small curved scobinated process; juxta wide, pointed at the base. 


\section{Valligera; vestigialis.}

Harpe short; clavus small and spined; uncus cygnated; vesica with curved scobinated process; the juxta has a deep point at the base, forming less than a right angle.

\section{Segetum.}

Below the cucullus is an indication of a small flap; clasper hardly a cone, tip blunt; clavus small; uncus long and bent; vesica with curved crested process; juxta pointed at the base.

\section{Ripæ.}

Clasper only just present; ampulla flattened on the inner side; uncus short; vesica with round scobinated process; juxta pointed.

\section{Puta.}

Clavus short; clasper flattened on the outer side; uncus cygnated; vesica with rounded scobinated process; juxta pointed.

\section{Exclamationis.}

Clavus not long; clasper pointed; uncus cygnated; vesica with irregular scobinated process.

\section{Corticea.}

Below the cucullus there is an indication of a small flap; clasper pointed; clavus not produced; uncus long and bent; vesica with curved crested process; juxta sharply pointed at the base.

\section{Flammatra.}

Without pencils. Harpe indented before the cucullus; below the curcullus, the small flap indicated in segetum and corticea becomes more developed, and is shown in a peaked hook; clasper very narrow above the lobe ; clavus not produced; uncus cygnated; vesica with short cornutus; juxta pointed.

Senta ulvæ; maritima. From John Gardner. Pencils absent.

Similar general form; clasper pointed; clavus rounded, not produced; uncus slender; vesica with small teeth.

\section{Plecta.}

Clasper very slender; clavus produced and spined, bulbed at the base; uncus pointed; vesica with large cornutus; juxta pointed. 
There is a division here, the form of the harpe alters and looses its corona, and the clasper develops an elbowed base.

\section{Præcox.}

Harpe peaked, without corona; clasper pointed; clavus not produced; uncus widens twice, the tip being densely clothed with stiff hairs; vesica with round process of small cornuti; juxta emarginate at the base.

The clasper now taking another form, is attached to the harpe on the outer margin, where it is sometimes rounded, and sometimes produced direct from the skin, it proceeds towards the inner margin, when it takes a sharp turn towards the apex, forming an elbow; in the descriptions, attachment $=$ where it joins the harpe, foot $=$ the bent part of the clasper corresponding in shape with a human foot: The terms heel foot and toe being used to describe the parts.

Depuncta. From J. Gardner.

Harpe rounded, without corona; clasper attachment rounded; heel pointed, foot long, flattened, and curved inwards; uncus curved; ædœagus scobinated at the orifice; vesica with small bunch of teeth; juxta slightly pointed.

The following species have the juxta strong and well marked.

Glareosa. From Rath Hughes.

Harpe peaked, without corona; clasper attachment not rounded; heel pointed, foot long and flattened on the inner side; uncus cygnated; vesica with stumpy cornutus; juxta cleft in the centre forming two scobinated lobes.

The following species with pollex :

Ashworthii. From C. S. Gregson, W. Gardner, and W. Mansbridge.

Without pencils.

Harpe rounded, without corona; pollex rounded; clasper attachment not rounded, heel angulated, foot short and not flattened, with several protruding papillæ, (each emitting a single hair) on the instep; uncus cygnated; sedoeagus terminating with a curved tooth at the orifice; juxta lobed and plain. 
Candelarum. From J. Arkle. I cannot distinguish any difference between this and ashworthii.

\section{Umbrosa.}

Harpe peaked, without corona; pollex rounded; clasper not rounded at the attachnent, heel pointed, foot flattened inside, tip curled, instep with several papillae, each emitting a single hair; uncus short tapered and pointed; juxta produced to a high peak deeply cleft; redneagus crested at the orifice.

Triangulum. From S. J. Capper.

Harpe rounded, without corona; pollex rounded; clasper not rounded at the attachment; heel gently curved, foot short and stout, almost round; uncus pointed; vesica with curved spicule; juxta peaked, not cleft, and plain.

Xanthographa. From Mrs. Hutchinson.

Harpe peaked, without corona; pollex rounded; clasper not rounded at the attachment, heel pointed, foot curved and pointed; uncus pointed; xdoeagus with dentate plate and scobinated process; juxta a column on which the dentated plate of the aedøeagus fits.

C-nigrum. From S. J. Capper.

Harpe peaked; pollex rounded; clasper not rounded at the attachment, heel angulated, foot short; uncus slender; ædœagus serrated at the orifice; vesica with small spicule; juxta a scobinated lobe sharply indented in the centre.

Ditrapezium. From A. Harrison. Pencils absent. Harpe peaked, without corona; pollex rounded; clasper simply attached, foot almost lobed; uncus suddenly narrows from the centre to the tip; xedœagus with a small tooth at the orifice; juxta a high peak, plain.

\section{Rhomboidea; stigmatica.}

Harpe peaked; pollex rounded ; clasper simply attached, heel rounded, toe pointed; uncus simple; rdœagus scobinated at the orifice; vesica with a single spicule; juxta with short narrow peak. 
Baja. From Thos. Tunstall.

Harpe peaked, pollex high in the cucullus, rounded; below this, arising from the inside of the harpe, is a second arm; clasper with the foot lobed; uncus slender; vesica with hooked process; juxta peaked.

Agathina. From Eustace Bankes. Pencils absent. Harpe slightly emarginate on the margin, without corona; pollex produced from the base of the cucullus, which is divided; clasper rounded at the heel, toe pointed; uncus round at the tip, broad above; æedœagus serrated at the orifice; vesica with scobinated process and small cornutus; juxta thin.

Pachnobia alpina; hyperborea. From Eustace Bankes.

Pencils absent.

Harpe, without corona, emarginate on the margin; the pollex forming the outer tip; clasper angulated at the heel, rounded at the toe; uncus cygnated, flattened at the tip; æedœagus with a long row of serrations at the orifice; juxta thin.

\section{Lucernea.}

Harpe with a long narrow cucullus, without corona, the costal margin terminates, at the base of the cucullus, in a double lobed flattened plate; the clasper is a straight arm; the uncus is simple; the redoagus broad, scobinated, and dentated at the orifice.

\section{Subrosea.}

Harpe without corona, spinose, emarginate on the margin; the large pollex forming the outer tip; clasper rounded at the heel, toe extended and pointed, flattened inwards; uncus fiat at the tip; ædoagus with long row of serrations at the orifice; vesica with spicule; juxta strong, roundly peaked.

Porphyrea; strigula. From S. J. Capper.

This species lacks nearly every characteristic of the group. 
Harpe without corona, bifurcate, pointed at each extremity of the margin; the only indication of the clasper is a fold; the sacculus extends far into the cucullus, and is rounded and scobinated; the uncus is barely broader in the centre, with a curved tip; xdneagus scobinated at the orifice; juxta thin. It is quite possible the Treniocampids branch off here.

The following group of five species is strongly generic, and is an example of a failure of the genitalia for specific classification, the points of difference being very minute. In Professor Smith's work on the Agrotidce, he calls this group Carneades, and records some 120 species, mostly with the harpes so similar that he in some cases makes one figure do for 13 species. It is not, therefore, surprising in dealing with a group of this kind that little, if any, difference can be detected in tritici and aquilina, and if they are to be proved to be distinct species resource must be had to other characters. Reasoning by analogy that seeing two such distinct species as obelisca and tritici are almost undistinguishable from the genitalia, it is feasable to believe that the same resemblance may occur in tritici and aquilina. The following is an attempt to collate the points of difference.

Obelisca. From E. R. Bankes. Pencils absent. Harpe acutely pointed at the apex, anal angle obtuse, with corona; clasper long, curved, curled at the tip and clothed with short fine spines, almost to the base; clavus absent: sacculus produced to a long arm, projecting beyond the anal angle of the harpe; uncus tapered; ædœagus with indefinite structure; vesica with two short fine cornuti; juxta upright, deeply cleft to a point in the centre, the two peaked heads being squamose.

\section{Nigricans.}

Harpe similar to preceding; clasper slightly broader, set with a number of coarse spines; clavus produced, 
club shaped, and clothed with spines; arm of sacculus extends only just beyond the anal angle; uncus tapered; vesica with a small cornutus, thicker than preceding; juxta deeply cleft, the base of the opening being round.

\section{Cursoria.}

Harpe similar, asvmmetrical; clasper slender, wider at the tip, which is blunt, and set with a very few coarse spines; clavus longer than nigricans not clubbed; the arm of the sacculus on the right harpe produced beyond the anal angle, that on the left harpe not reaching the anal angle; uncus tapered; I can find no cornutus on the vesica; juxta not deeply cleft, the base of opening being rounded.

\section{Tritiei.}

Harpe similar; clasper broader than cursoria, the upper half clothed with short fine spines; uncus very long; vesica with two minute cornuti; juxta not deeply cleft.

Aquilina. From J. E. Robson and Rev. C. N. R. Burrows. Similar to tritici.

There is here a further departure.

\section{Saucia.}

Harpe trigonate, with corona of strong spines; clasper with the heel pointed, foot long; ampulla arises below the sacculus and is a peaked concave houk; clavus slightly produced, rounded and scobinated; uncus cygnated; adcagus with a plate at the orifice having a long serrated tooth, and other smaller serrations; juxta strong, is a dome shaped pinacle.

Dahlii. Flom J. Whittle.

Harpe very broad with part corona, heavily spined expecially at the anal angle; clasper hardly elbowed, heel rounded; ampulla long and slender; uncus long and parallel; vesica contains a strong cornutus, a crested semi-circular crown, and other dentated processes; juxta fairly strong and peaked. 
Rubi. From Mrs. Smith.

Harpe wide, with corona, cucullus divided, and small, spinose; clasper elbowed at the base, which is wide; ampulla large, and antler shaped; uncus terminating in a round head; vesica with crested process, and short bunches of teeth; juxta shouldered, flattened above, and scobinated on either side.

Brunnea. From G. A. Harker. Pencils absent. Harpe trigonate, broad, with corona; cucullus small, a strong jointed tooth at the anal angle; clasper elbowed at the base, slender above; ampulla long and curved at the tip; clavus rounded and spined; uncus tongue shaped; vesica with strong cornutus with a heavy base; juxta produced into two arms.

\section{Festiva.}

Harpe peaked, with corona; clasper curved; ampulla a slender arm, bulbed at the hase; beneath the ampulla is a third arm, arising from the skin and emitting a few bristles from the head; uncus parallel, with rounded tip ; ædoengus dentated at the orifice; vesica with a band of teeth; juxta sharply peaked.

\section{Conflua.}

I can detect no difference between this and festira.

\section{Leucographa.}

Harpe peaked, without corona; clasper bulged in the centre and pointed; ampulla arises below the cucullus and is peaked; uncus simple: ædœagus dentated at the orifice ; vesica with 10 or 12 very long spines, reaching nearly the whole length of the ædœagus.

Sobrina. From Jno. E. Robson.

Harpe peaked, without corona, clasper rounded at the tip ; ampulla a fold ; clavus round and scobinated; uncus lobed at either side, supported along the back with a ridge of chitine; ædœagus serrated at the orifice; vesica with a curved spicule; juxta cleft and heavily scobinated. 
Pyrophila; simulans. From Eustace Bankes. Pencils absent. Harpe peaked, without corona ; clasper roundly elbowed at the base, the tip truncated; in place of the ampulla there are several spined papillæ; clavus absent, unless it is represented by a strong curved trifurcate arm which is attached to the sacculus; uncus tapered; resica has scattered over it a number of strong cornuti.

Trachea piniperda. From S. J. Capper.

Harpe peaked, without corona; clasper short and hardly produced; ampulla a long curved arm; uncus has a round tip with a dorsal support; ædœagus scobinated at the orifice; vesica with bulbed cornutus; juxta with a projecting and receding lip.

Rubricosa.

Pencils absent.

Harpe peaked and narrow. without corona; clasper curved and truncated; uncus flattened; vesica with strong bulbed cornutus; juxta has two lateral bunches of spines spread out like the wings of a bird.

The Tæniocampas form one of the most elaborate and interesting groups, inasmuch as they present a variety of forms that is quite unequalled in any other genus of the Noctuide, and yet to a large extent it is evident they are closely allied. The juxta is well developed in all the species, but takes a most exaggerated form in gothica.

\section{Tæniocampa populeti.}

Harpe without corona; cucullus antler form; the clasper is cornucopia shaped, from the mouth of which proceeds the ampulla, a long curved arm; uncus expanded at the tip, which is squared; resica with muscular interior; juxta cleft.

\section{Munda.}

Harpe without corona, cucullus antler form; clasper irregularly rounded; ampulla curled at the tip and flattened; the sacculus is produced on the inner edge, into a long curved arm; uncus tongue shaped; vesica with bunches of cornuti; juxta long and cleft. 


\section{Instabilis ; incerta.}

Harpe without corona, anal angle of cucullus pointed; clasper an irregularly curved arm; ampulla long with a pointed tip; sacculus with rounded clavus; uncus spatulate, broadest before the tip, which is pointed; rdceagus with a long cornutus on the outside of the orifice.

\section{Stabilis.}

Harpe without corona, emarginate at the anal angle, which is peaked; clasper rounded; ampulla lobed to a point and hearily scobinated; uncus roundly tongue shaped, emarginate laterally; vesica with a curled band of small fine teeth; juxta cleft, forming two strong peaks.

\section{Cruda; pulverulenta.}

Harpe without corona; clasper rounded; ampulla long, broader towards the base, tip spined; uncus tapered and sharply pointed; resica with muscular interior; juxta peaked in the centre.

\section{Miniosa.}

Harpe without corona. anal angle produced and pointed; clasper with wide mouth; ampulla shortish, pointed; uncus slender and parallel; vesica with bunch of teeth and short bulbed cornutus; juxta indented.

\section{Opima.}

Harpe with corona; cucullus divided, poirted at the anal angle; below the cucullus is a protruding pollex, terminating in small spines; clasper rounded with a small papilla; ampulla long and blunt at the tip; uncus rounded at the tip; resica with strong cornutus; juxta deepiy cleft.

\section{Gracilis.}

Harpe with corona, cucullus with pollex at the anal angle; clasper rounded, with a short papilla or nipple; ampulla long and curved; uncus cygnated; ædœagus toothed and crested at the orifice; vesica with bulbed cornutus and bunch of teeth; juxta cleft, forming two squamose peaks.

\section{Gothica.}

Harpe without corona, emarginate on the margin, forming a blunt point; from the upper part of the cucullus arises a 
short digitus; clasper with large round mouth; ampulla long, curved and tapered; uncus broad at the tip; rdœagus dentated at the orifice; vesica with scobinated process and short cornutus; the juxta is very elaborate, from a squamose collar there arise laterally, two long elbowed arms, deeply scobinated.

The Orthosias are a curiously separated group. The elaborate and highly developed uncus of macilenta, being worthy of attention, the long curved clasper of lota, making a good connecting link to the Anchocelias.

\section{Orthosia suspecta.}

Harpe peaked, with corona, cucullus divided and spinose; clasper curved; ampulla below the cucullus, small ; clavus rounded, studded with small spines; uncus slender; vesica with short cornutus; juxta weak.

\section{Upsilon.}

Pencils present.

Harpe peaked, almost trigonate, with corona; cucullus spinose and divided; clasper strong, opening into a round flattened plate with serrated edges; ampulla elbowed, and strong; uncus tougue shaped, emarginate laterally; vesica with strong cornutus; juxta doubly peaked, strong.

\section{Macilenta. From S. J. Capper.}

Harpe without corona, cucullus not divided, outer tip longest; clasper with curled tip; ampulla extends to centre of cucullus, the head being a rounded plate; clavus produced and lobed. It is almost imposible to describe the complicated uncus, nor does the figure give any idea of the extraordinary structure; vesica with a long and short cornutus, and a bunch of teeth; juxta weak.

\section{Lota.}

With pencils.

Harpe pointed, without corona; cucullus not divided; clasper long and very curved, typical of this group; ampulla extends to the centre of the cucullus, where it produces a sharp hook; clavus rounded; uncus sickle form; vesica with bunches of strong teeth, juxta weak. 
Anchocelis lunosa. From C. H. Walker.

Harpe peaked and pointed, without corona; cucullus not divided; clasper spined at the tip; ampulla produced from the base of the cucullus in a flap; clavus rounded; uncus broad, rounded at the tip; vesica with longish cornutus and bunch of teeth; juxta doubly pealied.

\section{Rufina.}

Harpe peaked, with corona; cucullus not divided ; clasper long and slender; ampulla flattened, with curled tip; uncus strong, produced from a curious termination of the tegumen; with a scaphium; vesica with long colnutus; juxta not cleft.

\section{Litura.}

Harpe with part corona; clasper short and curved; ampulla extends to the anal angle is a series of folds of the skin ; clavus produced and peaked, spinose; from the head of the tegumen arises a square flap, from the centre of which springs a short slender uncus; vesica with band of teeth and long cormutus.

\section{Pistacina.}

Pencils present.

Harpe without corona; cucullus lobed, the anal angle uniting with the ampulla forms a strong pointed arm; clasper long and bent into a pot-hook; uncus curved and pointed; ædœagus serrated at the orifice; juxta indented at the top.

The Cerastias are generically a continuation of the preceding, and should include rubiginea. Taccinii and spadicea, often a stumbling block for the beginner, are equally difficult to separate by the genitalia.

\section{Cerastis vaccinii.}

Harpe long, slender and pointed, without corona ; clasper long, slender and twisted; uncus flattened at the tip; vesica has a long cornutus at the base, a bunch of cornuti in the centre, and a bulbed cornutus above; juxta peaked, indented at the tip. 


\section{Spadicea.}

Harpe long, slender and pointed, without corona; clasper long, slender and twisted; uncus flattened at the tip; vesica has a long cornutus at the base, a bunch of long comuti in the centre, and a bulbed cornutus above; juxta peaked, indented at the top.

Erythrocephala. From Eustace Bankes. Pencils present. Harpe long, slender and pointed; clasper long and slender; ampulla forms folds or ridges into the cucullus; uncus simple; peniculus on a peduncle; vesica with large cornutus, and bunches of long strong teeth; juxta square at the top.

\section{Dasycampa rubiginea.}

Harpe pointed, without corona; cucullus divided ; clasper a straight arm; uncus paraliel square tipped; peniculus produced; vesica with huge cormutus, a band of teeth, and a tiny cornutus; juxta strong.

\section{Scopelosoma satellitia.}

Harpe with corona; cucullus divided; clasper imugularly twisted; ampulla antler shaped; editum strong, clothed with long hairs; sacculus produced into a long arm on the outer Edge; clavus rounded; uncus tapered; vesica with short bulbed cornuti, and bands of teeth.

\section{Oporina croceago.}

Harpe pointed inwardly, with corona, anal angle pointed; cucullus not divided; clasper long and curved; uncus simple, flattened at the tip; ædoagus with very large scobinations at the orifice; juxta peaked, emarginate in the centre.

The Xanthias present the difficulty of a genus containing forms which from colour, and shape, are obviously connected, and yet differ in their genital construction. The two species aurago and citragn, are closely allied; silago might easily be included here, were it not for the rare form of the uncus, which in this species is bifurcate. Since leaving the early groups of the Nortuidre the uncus has been a single hook, but in silago for some 
unaccountable reason it suddenly becomes bifurcate, (the only other species among the Noctuide, partaking of this character is oxyacanth(e), a close family likeness unites giliago, cerago, and xerampelina, whilst ferruginea differs in every particular and is evidently correctly placed in a separate genus Mellinia.

Xanthia aurago.

Pencils present. Harpe peaked, with corona; cucullus divided; clasper curved; ampulla rarrow and pointed; clavus rounded; uncus tapered, broad at the tip; vesica with bulbed cornutus, and spicule.

\section{Citrago.}

Harpe peaked, with corona; cucullus divided; clasper ovate; ampulla a long arm; uncus tongue shaped; vesica with bulbed cornutus, and band of teeth.

Silago ; flavago. From S. J. Capper.

Pencils present.

Harpe peaked with a weak corona; clasper toothed at the tip; uncus bifurcate, forming two pointed arms; peniculus on a peduncle; vesica with thick cornutus.

\section{Gilvago.}

Harpe with corona; cucullus divided; clasper long and pointed; ampulla much larger, lying in the same direction; uncus rounded at the tip; vesica with bands of teeth and two small bulbed cormuti.

Ceragro; fulvago. From S. J. Capper.

Harpe with corona; cueullus divided; clasper shorter and thicker than preceding; ampulla also short and thick; uncus parallel; vesica with bands of teeth and two cornuti.

Cirphœedia xerampelina. Without pencils. This species is so closely connected with the two preceding that it should be included with them, but as they are so different from the Yauthias, I suggest they should come into the genus Cirrha'dia.

Harpe similar to preceding; clasper elbowed, scobinated, and bifurcate at the tip ; ampulla pointed; uncus parallel; vesica with two small bulbed cornuti. 
Mellinia ferpuginea; circellaris.

Harpe peaked, without corona; clasper elbowed at the base, the upper part is again elbowed, terminating in a round head, flattened at the side and scobinated; ampulla hardly more than a papilla; uncus sickle form; vesica with cornutus and bunch of teeth.

\section{Eremobia ochroleuca.}

Harpe trigonate, with corona; cucullus divided; clasper. is a wide flat plate; uncus diamond pointed; vesica with band of teeth and scobinated process.

Dianthocias. - This interesting group should be remodelled. There are a number of species that show a strong generic tendeucy. Prof. Smith places them among the Mamestras. The species occuring in this country do not show this relationship, but rather agree with some of the Hadenide. The small white spot at the anal angle of the hind wing being a distinct character endorsed by the genitalia. Taking the form of cucubali as a type, we have serena, genistce, glanca, cucubati, carpophaga, capsoplita, capsincola and barrettii, with the cucullus bent over, forming a battledore harpe. The costal edge is curled inwards; where it joins the harpe it generally produces a curled rounded flap, this is really the ampulla; in glauca it becomes an arm, in genistre it is strong; but in the second group of the Dianthocias it is very large and connects this section comprising ronspersa, albimacnla, compta and cresia with the first group, between which it would otherwise be difficult to see the relationsbip. Dysorlea is evidently in this group.

\section{Serena.}

Harpe battledore, with corona; clasper broad and flattened; clavus peaked; nncus tongue shaped; vesica with small bulbed cornutus; covering the vinculum is a rounded plate slightly cleft in the centre and fringed with scales.

\section{Genistæ.}

Harpe short, battledore, spinose, with no distinct corona; clasper turns and is produced downwards toward the sacculus; uncus broad and pointed; vesica with short bulbed cornutus. 


\section{Oleracea.}

Harpe short, battledore, spinose with no distinct corona; clasper a curved arm; ampulla bifurcate, of the two arms one is stronger than the other, the weaker one is set with short fine bristles; below the fork and on the surface of the ampulla is an editum clothed with long hairs; clavus peaked and spinose; uncus long and slender, curved upwards at the tip, having the base on a central lobe of the tegumen; vesica with two short cornuti and bunch of fairly long teeth.

\section{Glauca.}

Harpe short, battledore, spinose, with no distinct corona; clasper turns but is attached to the skin of the harpe; ampulla is an arm projecting from the base of the cucullus; uncus slender, and tapered ; resica with band of teeth.

Cucubali. From D. Onslow.

Harpe full battledore, spinose, without corona; clasper a fold; ampulla a papilla from the base of the cucullus; clavus strongly scobinated, not produced; uncus simple; ædœagus with serrations at the orifice, extending along the vesica.

\section{Cappophaga.}

Harpe small, battledore, spinose, without corona; clasper a small projection; clavus peaked; uncus simple; vesica with small heavily bulbed cornutus and band of teetll.

\section{Capsophila.}

I can detect no difference between this and the preceding, unless it be that the band of teeth in the vesica are a little larger and stronger.

\section{Irregularis.}

Pencils absent.

Harpe small, battledore, without corona, spinose, especially at the anal angle, which is toothed; clasper a small projection ; ampulla a raised process with spines ; sacculus produced into a short arm; uncus cygnated; resica with bulbed cornutus and band of teeth. 


\section{Capsincola.}

Harpe battledore, spinose, without corona; clasper attached to skin of the barpe; sacculus terminating in a quadrilateral plate; uncus simple; vesica with two small bulbed cornuti, and band of teeth ; juxta strongly scobinated and deeply cleft.

Barpettii. From F. de Kane. Pencils absent. Harpe roughly battledore, spinose; clasper reduced to a fold; ampulla a broad flap; sacculus divided at the apex, where it forms a lobe; uncus broad and tapered; vesica with a spicule and bunch of teeth; juxta scobinated.

Chenopodii ; trifolii. From C. H. Walker. Pencils absent.

In this species the eyes are not hairy, the Dianthocias have hairy eyes. (Barrett).

Harpe full battledore, spinose; clasper attached to the skin of the harpe; sacculus asymmetrical, on the right harpe extending in a long dentated arm nearly to the base of the cucullus; on the left harpe this arm is slender, without a crest; clavus on the right side produced and rounded, with a point on the inner side; on the left side there are two scarcely raised lobes; uncus broad, tongue shaped; ædœagus with peaked projection dentated at the orifice; vesica with small bulbed cornutus; juxta peaked.

\section{Conspersa; nana.}

Harpe rounded, with corona, the cucullus being thrown to the outer edge; clasper indefinite, attached to the skin; ampulla broad and extending above the cucullus; below the cucullus is a strong pencil of hair attached to the harpe; the sacculus peaked; clavus sharply peaked and clothed with hair; uncus simple; vesica with bulbed cornutus and band of teeth ; juxta elbowed forming two long spiculated arms.

Albimacula. From Eustace Bankes.

Pencils absent.

Harpe rounded, with corona, the cucullus being thrown to the outer edge; clasper broad, not free; ampulla 
broad, extending above the cucullus; uncus simple; vesica with bunch of teeth; juxta divided, with two strong arms, spiculated on the inner surface.

\section{Compta.}

Similar form of harpe; uncus cygnated; vesica with bunch of teeth, and a curved bulbed cornutus; juxta more slender than the two preceding species, spiculated at the tip.

Crsia. From C. S. Gregson. Pencils absent. Harpe with corona, cucullus extending on the costal edge, elbowed, and spinose; clasper not free; ampulla strong; sacculus with quadrilateral termination; uncus simple; vesica with two short bulbed cornuti.

Dysodea; chrysozona. From S. J. Capper. Harpe battledore, without corona, spinose; cucullus thrown to the outer edge, the oval joint possibly being a curious form of ampulla; clasper a peaked plate; sacculus terminating in a long arm, the tip of which is lobed and bent at right angles; clavus produced and peaked; uncus tongue shaped; ædœagus ends in a strong tip at the orifice; vesica with a cormutus.

Dentina. From S. J. Capper.

Harpe battledore, spinose; clasper ending in a rounded concave head; ampulla strong, and produced below the cucullus; uncus short, tongue shaped; ædœagus with a strong barb at the orifice; vesica with a short band of teeth, juxta cleft.

\section{Peregrina.}

Pencils absent.

Harpe battledore, with corona, spinose; clasper a small pointed arm; ampulla bifurcate at the tip, the inner prong having a small hole; the sacculus terminates in a lobed plate; uncus long and simple; vesica with cornutus and bunch of teeth.

The Polias differ among themselves, but have a strong generic likeness, the three species are easily distinguished specifically. 


\section{Polia nigrocincta; xanthomista.}

Pencils absent.

Harpe with the cucullus bent at right angles to the harpe, spinose; the anal angle terminating in a tooth; clasper not free; ampulla a small arm; sacculus extends nearly to the cucullus, terminating in an arm rounded at the tip, which is attached to the outer margin of the harpe; uncus broad; vesica with band of teeth; juxta peaked.

\section{Chi.}

Harpe pointed, cucullus a pointed projection arising from below the margin, spinose; clasper not free; ampulla rounded and curved at the tip, often with papillæ protruding from the sides; uncus cygnated; vesica with a band of teeth, and dentated plate above the orifice of the ædœagus.

\section{Flavicineta.}

Harpe irregularly emarginate on the margin; spinose withcut corona; clasper a small pillar; ampulla extends like a pollex from the base of the cucullus; clavus rounded, scobinated, and hairy; uncus short and thick; vesica with two bunches of very long teeth; juxta with a beautiful scobinated head.

\section{Dasypolia templi.}

Harpe without rorona, hairy; cucullus with peaked pollex; clasper long and curved; editum ligh and spined; clavus slightly produced and rounded; uncus broad; ædœagus crested at the orifice; juxta peaked.

\section{Epunda lichenea.}

Harpe with cucullus divided, spinose, slightly pointed at the tip and strongly pointed at the anal angle; clasper not free; uncus with a hollow cap; vesica scobinated where it joins the ædœagus; juxta rounded and scobinated.

Lutulenta. From S. J. Capper.

Harpe squared above, emarginate on the margin, with corona, and spinose; clasper elbowed; ampulla strong, curved; uncus eygnated; vesica with a bunch of long teeth, besides two smaller bunches. 
Nigra. From G. O. Day.

Harpe trigonate, with corona, cucullus not divided, strongly spined at the anal angle; clasper with small club shaped projection; ampulla strong and curved; clavus produced and rounded; uncus simple; vesica with a large bunch of teeth, and a bulled cornutus.

\section{Cleoceris viminalis.}

Harpe without corona, spinose; clasper elbowed, terminating with a round flat plate; ampulla an arm extending towards the cucullus; uncus squat tongue slraped; resica with bunch of teeth, a bulbed cornutus, and a comb of teeth; juxta strong.

\section{Valeria oleagina. (See the Pluside). \\ Miselia oxyacanthæ.}

This extraordinary asymmetrical form with its bifureate uncus, is a complete study, and most difficult to understand.

Left harpe, long and narrow, rounded on the margin, without corona ; the clasper angulated at the base, where it meets the sacculus, is short and elbowed; right harpe long and narrow, just above the sacculus it throws out a long curved arm; clasper long and curved; uncus deeply cleft forming two lobes; resica with a bunch of teeth, and a number of strong cornuti; juxta a thickened plate; vineulum rery long.

Bimaculosa. (See the Cucullias).

\section{Agriopis aprilina.}

Harpe without corona, costal margin folds over, nearly to the anal angle, forming a sort of cup; clasper strong and tapered; uncus simple; the membrane of the vesica clothed with short spines; juxta cleft and squamose, particularly at the back of the rdœagus.

\section{Euplexia lucipara.}

Harpe trigonate, with corona; cueullus divided, and hairy; below the cucullus is an angular plate, sharply pointed outwards, the harpe again projects to a peaked shoulder; the clasper is long and almost straight, with a second short arm at the base; clarus peaked and scobinated; uneus tongue shaped; vesica contains a long transparent tube. 
Phlogophora meticulosa. Pencils present. Harpe peaked, with corona; clasper long and curved; ampulla a slender arm; uncus curved ; vesica with bulbed cornutus.

\section{Trigonophora empyrea; flammea.}

Harpe rounded, and pointed at the tip, with a small pillar projecting below, heavily spined on the inner margin : clasper not free; sacculus roundly peaked at the clavus; uncus very short, at the head of a dome-shaped flap arising from the tegumen; vesica with band of teeth; juxta long, producing a strong support for the rdœagus.

The Aplectas cuntain several forms of genitalia. Some species have a strong hook at the anal angle of the cucullus; this is so strongly marked that I consider it a guide to genera, and should therefore exclude from the genus, herbida and occulta, which obviously do not belong here. It is possible these two species, with Miselia limaculosa and Valeria oleagina, form a connecting link to the Cucullias, Plusias, \&c. As the former are not sufficiently definite to warrant their inclusion in these genera, for convenience they are described under the genus Aplecta.

\section{Aplecta herbida; prasina.}

Harpe rounded, without corona; clasper Noctua form, elbowed, curled at the tip; uncus very long and simple; rdcagus scobinated at the orifice; juxta a plate.

\section{Occulta.}

Harpe rounded, without corona, slightly pointed on the margin; clasper truncated; clavus produced, club shaped; uncus simple; vesica scobinated at the orifice, with bulbed cornutus.

Nebulosa.

Pencils present.

Harpe roughly battledore, with corona; cucullus spinose, the anal angle produced, carrying the anal spine; clasper not free; ampulla a scobinated arm; sacculus very broad, extending beyond the outer margin; uncus tongue shaped, having a round hood behind; vesica with a band of teeth. 


\section{Tincta.}

Harpe roughly battledore, with corona; cucullus spinose, with an anal spine; clasper long and doubly elbowed; sacculus broad, and extending beyond the outer margin; clavus produced and large; uncus cygnated: vesica with band of teeth: juxta a long plate.

\section{Advena.}

Pencils absent.

Harpe roughly battledore, with corona; cucullus spinose, with an anal spine: clasper not free; ampulla elbowed; sacculus very broad, extending beyond the onter margin and terminating in a bulb, with a pencil of long spines in the centre; on the upper part of the sacculus is a curious small round hole; uncus simple; vesica with band of teeth,

The Hadænas. In this protean group, we get many and raried forms, peregrina, dentira and glanca, being probably closely connected with the Dianthocios, of the others with the exception of sursu and thalassina being related the remainder are so different that genitalia fail here to indicate genera, and as in the genus Treniocampa, wing markings and other characteristics must be the guide. I have therefore with the exceptions above-named, talien the IIadcenas as they are usually arranged in the lists. The extraordinary difference in cetusta and exoleta should be noted as compared with their wing markings and general build, which some writers might put down to a case of mimicry.

Hadena thalassina. From C. H. Walker. Pencils absent.

Harpe deeply emarginate on the margin; the costal edge being produced to a sharp curved arm, ending in a tootl ; the clasper is difficult to define, it is divided, the basal part curving to a peak, the upper part extending to a rounder plate; the ampulla arises from the base of the cucullus and is a peaked plate; clarus peaked; uncus simple; vesica with a short band of teeth, and irregularly shayed small bulbed cornutus. 


\section{Suasa ; dissimilis.}

Harpe deeply emarginate on the margin, the costal erge being produced to a sharp curved arm, ending in a tooth, anal angle of cucullus rounded; clasper similar form to preceding, the basal part extending to a long peaked arm, the upper part terminating in an irregularly shaped head; ampulla elbowed; clarus peaked; uncus simple; resica with short band of teeth.

\section{Pisi.}

Harpe with spinose cucullus, which is peaked inwards; the costa is broken by two arms proceeding from its edge, the lower arm being long, the upper peaked; clasper not free; uncus cygnated; rdœagus with a strong hook at the orifice; vesica with an irregular shaped cornutus.

\section{Atriplicis.}

Harpe irregularly quadrilateral; cucullus divided, densely clothed with long straight hairs; clasper curved and pointed; uncus flattened and pointed; redagus scobinated at the orifice; resica with strong irregularly shaped cornuti.

\section{Contigua.}

Harpe with similar long hair as in atriplicis, cuenllus divided and peaked on the anal angle, from the point of which extends two small teeth; clasper curved; ampulla flattened and curved; uncus tapered; vesica with bunch of long teeth and a short bulbed cornutus.

\section{Protea.}

Harpe with an emarginate prolongation of the margin; cucullus divided, with corona, and hairy; clasper curved, with a bulbed base; ampulla a long pointed arm; uncus sickle form; vesica with three long cornuti and band of teeth.

\section{Rectilinea.}

Harpe with corona; cucullus rounded at the anal angle, spinose; the costal tube leares the margin and extends to the opening of the cucullus ; the clasper is elbowed, ending 
in a foot; sacculus broad and extended towards the cucullus in a free lobe; uncus short, spatulate and rounded at tip; vesica without teeth.

\section{Satura; porphypea. Pencils present.}

Harpe rounded, the costal tube, soldered along the base of the cucullus, extends beyond, forming a poller; cucullus heavily spined; clasper not free; ampulla reduced to a wart, emitting a few short spines; uncus short and tongue shaped; rdœagus has the orifice dentated; vesica with a small baud of teeth; juxta cleft in the centre.

\section{Adusta.}

Harpe with corona, spinose; inner margin of cucullus extended to a blunt point; clasper reaches to the base of the cucullus, and forms a foot; ampulla a very long slender club, spined; uncus flattened and bluntly pointed; resica with a comb of irregular teeth, and a band of teeth; the juxta terminates in two long scobinated arms.

\section{Xylocampa lithorhiza; areola. From}
G. C. Bignell.
Pencils absent.

Harpe with corona; cucullus produced in a sharp peaked pollex: clasper, an arm with a flattened lobed head; sacculus peaked above on the inner margin; urcus 'ygnated with a sharp curved point: ædœagus scobinated at the orifice; vesica crowded with several bunches of long teeth.

Xylomiges conspicillaris. Pencils absent. Harpe without corona; cucullus trigonate, and divided, with a few spines; clasper elbowed, termirnating in a slort rounded arm; ampulla a strong curred arm; clavus produced irregularly, spinose; uncus cyguated; resica with a bunch of teeth, and three bulbed cornuti.

\section{Calocampa vetusta.}

Harpe rounded at the anal angle, without corona : clasper long and curred; uncus tongue sliaped; resica with bulberl cornutus, and bunches of teeth. 


\section{Exoleta.}

Harpe a curious form, hifureate, without corona, inner point small and peaked, onter of much thicker chitine is larger and also peaked, but bent at right angles : clasper a curved arm; meus parallel to the tip which is broad and flattened; vesica has a bulbed cornutus also a slender cornutus; juxta peaked in the centre.

\section{Solidaginis.}

Harpe broad and rounded, without corona, or spines: cucullus which hardly leaves the costa, small, peaked at the anal angle; armature of hirpe absent: uncus tapered : vesica without teeth.

The Xylinas bear as a rule a strong family likeness, zinclienii probably forming a connecting link to the Cucullirs. The following genera require a good deal of re-arranging, and I believe the genitalia will prove an important help in the sequenco. There is a certain amount of connection between the groups, which in the present classification, has unfortunately been interrupter. by interspersing several little odd genera among natural relatives. The Cucullias, with their narrow coronated harpes and simple clasper, lead to the Ileliothida, from which should be excluded Anarta and Heliaca. The liarpe of the Heliothias, being rery closely allied to the C'ucullicis. except that the clasper is lost. Asteroscopus, including Valeria oleagina and Miselia bimarmlosa again form another connecting link, and continue the sequence to the Plusidr, which may be followed by Mabrostola and made to include. or at any rate be followed by the 1 imphipyrida.

\section{Xylina rhizolitha; ornithopus.}

Harpe with small cucullus divided, with a few spines of corona; clasper long and curved: ampulla extends below the cucullus in a long curved arm; clarus produced and roughly rounded; uncus tapered; vesica witl small bunch of teeth. 
Petrificata; socia. From .T. Tr. Tutt and R. South Without pencils. Haspe with small cucullus divided, has a few spines of corona; clasper a long curved arm; ampulla extends lelow the cucullus in a straight arm, below this is a second peaked projection; sacculus very broad; clarus rounded; uncus cygnated: vesica with a loand of strong teeth.

Semibrunnea. From J. E. Robson and R. South.

Without pencils.

Harpe peaked, witlout coronar clasper a stout curved arm; ampulia extends below the cucullus in a long curved al'm, rounded at the tip; below this is a second plate of some size; sacculus very broad; clavus rounded; uncus cygnated; resica with two bands of teetl.

Conformis; furcifera. Erom J. A. Clark.

Pencils absent.

Harpe with part corona; clasper stoutly peaked; ampulla produced and pealied; clavus scobinated; uncus terminating with a curious broad tip; vesica clothed with fine scobinations.

Zinckenii ; lambda.

Pencils absent.

Farpe slender, without corona; clasper curved; ampulla extendis to the tip of the harpe, and is studded with 13 umerous papillce beuring spines: clavus slightly produced; uncus tongue shaped; vesica with two short bands of teetl.

The Cucullias may easily be differentiated by the clavus, which varies in each species, except the mythical serophularice. I have failed to satisfy myself that this species really exists. The Continental dealers send out specinnens of rerbassi and lychnitis when scrophularire is ordered; sometimes in a series so sent there will be included specimens of each of these. The so-called English serophulurice from lient is identical with verbusci. Years ago Mr. liobson sent me "true scrophularice," this I have figured for wbat it is worth, but until reliable material is fortheoming, scrophularice eam have no place in our lists. 
Cucullia verbasci. From R. South.

Harpe tapering to the tip, with a very short corona; clasper flattened on the lower surface; clavus produced and rounded; uncus straight with a curved pointed tip; vesica with a long, strong, bulbed cornutus, and a finer one about half the length.

Scrophulapize. From John E. Robson.

Harpe long slender and parallel, with a corona of fine spines; clasper lies just below the upper half of the harpe, and is flattened on the lower surface; clavus rounded and spinose; uncus straight with a curved pointed tip; resica with a large and small bulbed cornutus.

Lychnitis. From Eustace Bankes and R. South.

Pencils absent.

Harpe broader than the preceding species, with a full corona; clasper lies below the upper half of the harpe, and is flattened on the lower surface; clavus rounded and spinose; uncus straight with a curved pointed tip; vesica with a large and small bulbed cornutus.

Asteris. From S. J. Capper.

Harpe slightly tapered, wider above, with full corona ; clasper lies on the upper third of the harpe, and is bulbed to a point; clavus produced to a small irregular knob, spinose; uncus cygnated; vesica has two strong cornuti not heavily bulbed.

\section{Umbratica.}

Harpe wide, almost parallel, with full corona; clasper, lies below the centre and is an irregular arm, bent at right angles; before the tip just above the clasper is a raised fold which probably represents the ampulla; the clavus is produced to a stout column, curved and blunt at the tip; meus long and tapered to a point; the vesica has a strong cornutus, double the length of a second one, as well as a third small one; vineulum long.

Chamomillæ. From S. J. Capper.

Harpe widens considerably above, with full corona: clasper short, and Hattened above; clavus a long club 
shaped arm; uncus short and stout, curved at the base; vesica with two bulbed cornuti of nearly equal length; vinculum short.

\section{Absynthii. From C. H. Walker.}

Harpe almost parallel, with full corona; clasper lies below the centre, is wide, pointed and flattened above, and studded with short bristles; clarus not produced; uncus has a colra-shaped head, ending in a point; vesica has two cornuti, one a little longer and stouter than the other.

Gnaphalii. From A. Pobinson, per H. M. Edelsten. Harpe broad at the base, with full corona; clasper lies just above the centre, is flattened below, and studded with short bristles above; clavus not produced, with serrated edge; uncus eygnated; vesica with a single strong cornutus.

Asteroscopus nubeeulosa. From Mrs. Hutchinson.

Harpe drawn to a point at the apex; the corona very long, extending considerably along the outer margin; the clasper is absent, the only indication being three or four spined warts; clavus rounded; uncus broad, pointed, and curved with the tegumen; vesica with strong bunches of long teeth.

\section{Cassinea; sphinx.}

Harpe rounded, without corona; clasper a short curved arm, well spined; the silcculus joins the outer margin in a sharp point; uncus broad and parallel; vesica with a bunch of regular longish teetl.

\section{IIiselia bimaculosa.}

Harpe slightly wider below, with full corona; considerably below the centre is the clasper, a strong clubbed arm with openings in the chitine; clavus hardly produced, with long hairs; uncus tapered; resica scobinated where it joins the xdœagus at the orifice, with bunches of strong cormuti of various thichmesses. 
Valeria oleagina. From A. Harrison.

Pencils absent.

Harpe rounded, without corona; elasper a straiglıt arm, slightly flattened; clavus produced, spinose; uncus wider in the centre; vesica with five cornuti, and a large and small scobinated process, the latter crested. There is little doubt these two latter species belong to the same genus.

\section{Heliothis marginata; umbra.}

Harpe parallel, rounded at the apex; the cucullus. which is undivided, bends inwards, and is thickly studded with four or five rows of spines; just below the centre of the harpe is a short straight clasper, little more than a papilla; uncus slender; the vesica has a long and a short bulbed cornutus.

Peltigera. From Eustace Bankes. Pencils absent. Harpes widened above, with a long double corona; clasper absent; uncus simple; the vesica has a long hand of ridges, like a spiral wire spring in appearance.

\section{Apmigera.}

Pencils absent.

Harpes wide, parallel, and rounter above, with a double corona, the margin being thickly clothed with beautiful loroad scales: uncus slender; resica with a long band of cornuti gaining in strength towards the tip.

\section{Dipsacea.}

Pencils absent.

Harpe widens above, with domble corona, clasper absent; uncus with scaphinm, very long, slightly broader at the tip which is rounded, and curved outwards terminating in a hook; vesica has a long band of ridges, like a spiral wire spring, similar to peltigera.

The Plusias all bear a strong family likeness. With the exception of moneta, which has none, the remainder of the genus have a pair of long hair pencils arising from the Sth segment. All species without corona.

\section{Plusia chrysitis.}

The harpe narrows to a sharp point, outer edge angulated, each projection terminating with a maroinal spine; clasper 
it short arm flattened below ; clarus a long clubber arm; uncus simple; ædœagus scobinated at the orifice; resica with a mass of very short fine teeth.

\section{Festucæ.}

Harpe not pointed, with marginal spines; clasper a slender arm: clavus very long and clubbed; uncus slender and curved; vesica with a strong cornutus.

\section{Iota.}

Harpe rounded at the anal angle, with marginal spines; clasper a slender arm; clarus a long slender club; uncus simple and curved; vesica with a strong cornutus.

\section{V-aureum; pulchrina.}

Harpe rounded at the anal angle, with marginal spines; clasper a slender arm; clavus a long slender club; uncus simple and curved; vesica with a strong cornutus.

\section{Gamma.}

Harpe wider above, anal angle angulated, with marrinal spines; clasper very slender; clavus a slender club; uncus simple and curved; vesica with one strong cornutus, and a smaller curved one, heavily bulbed.

\section{Interpogationis.}

Harpe narrowed above, with marginal spines; clasper a sharply pointed curved hook; clavus very short, tapered; uncus simple and curved; vesica with curved bulbed cornutus.

Bractea. From J. E. R. Allen. Pencils absent. Harpe not rounded, with marginal spines; clasper very lonir and slender; clavus an exceedingly long clul,; uncus exceedingly long and curved; vesica with a strong cornutus ; the vinculum has two lateral Haps before the tip.

Orichalcea; chryson. From E. R. Banles and J. W. Tutt.

Harpe angulated, with marginal spines; clasper very long and parallel; clavus long and clubbed; uncus simple, slightly larger before the tip; vesica with a short cornutus with a rounded head, and hlunt curved tooth at the orifice of the redongus. 
Moneta. From John E. Rohson.

Harpe short, rounded, with marginal spines; clasper long and slender; clavus a short slender arm; uncus short and curved; vesica with a bulbed cornutus; on the dorsal side below the uncus is a round spined cap.

\section{Amphipyra pyramidea.}

Harpe simple, without armature, the apex thickly clotled with strong hairs; uncus broadens to a pointed bull, at the tip; vesica with a bunch of long teeth or spines.

\section{Tragopogonis.}

Harpe with an undivided eneullus, broader and rounded, thickly clotbed with hair; clasper a short bulbed arm; clavus just raised; uncus broad; vesica with a bunch of long teeth or spines of irregular thickness.

\section{Mania typica. From A. Tippins.}

Harpe narrowed; the sacculus extends to, and joins, the cucullus, forming a hood; the clasper a strong tapered hook; uncus simple and curved; xdoagus scobinated at the orifice.

Maura. From F. Birch.

Harpe squared above; the sacculus extends to the cucullus, forming i hood; the costal tube extends beyond the cucullus in a pointed arm ; the clasper is reduced to a few papilla; uncus simple; vesica with bands of short teeth.

Habrostola urticæ; tripartita. From S. J. Capper.

Harpe peaked, the costal edge being broadly bulged out, without corona; clasper a straight arm; clavus produced and peaked; uncus sickle form; rdoagus with a double toothed process at the orifice; vesica with a mass of slender teeth.

\section{Triplasia. From S. J. Capper.}

Harpe peaked, the costal edge being bulged out, more peaked than the preceding; clasper curled at the tip; clavus peaked; uncus sickle form; redœagus terminating at the orifice with a scobinated process, on one side; and a curved hook, or possibly a bulbed cornutus on the other ; vesica with a mass of large and small spines. 


\section{Gonoptera libatrix.}

This species is a very distinct one, it is usually put in a family by itself, and undoubtedly the genitalia strengthen this arrangement, it is unlike any other pattern of British Nortuide; but the strong scaphium, forming almost a mandibulate uncus, shows that at any rate it is closely connected with some of the enrious little families that are now placed at the end of our Noctuide. These families are no doubt sufficiently divergent, to warrant their being separated, but as the species composing them are largely asymmetrical in the harpes, it is quite a question if they are not more closely allied to one another, than we are generally led to suppose. In the order that they come in the ordinary lists of species, sulphuralis and luctuosa are both asymmetrical. There is no possible similarity between venustula and fuscula, to suggest that they belong to the same genus. $M i$ and glyphicu are obviously far apart, and yet bear some superficial likeness; alchymista is closely connected with the Catocalas, and may be in another genus, but certainly the same family, pastinum and cracece are strongly generic. As the genitalia throw but little light on the groups, I have thought it wise to take them as already placed in the lists.

\section{Gonoptera libatrix.}

Harpe simple, rounded above, without corona; the sacculus extends beyond the cucullus; uneus is flattened at the tip and is hooded; the scaphium is long; ædœagus finely scobinated; juxta double peaked. This is a remarkably small genital appendage compared with the size of the insect.

\section{Anarta melanopa.}

Pencils absent.

Harpe battledore, and turned over as in the Dianthorias; sacculus is peaked alove, and squamous; clavus rounded: uncus broad, with a square tip; vesica has a short bulbed cormutus.

\section{Cordigera.}

Ifarpe incurved along the costa, producing a point where the cucullus brealis away and protrudes outwards; clasper 
appears to join the ampulla, and is a short arm; sacculus extends into a long squamous arm, curled at the lip; uncus short; vesica with a short band of teeth.

\section{Iyptilli.}

Harpe asymmetrical, battledore, similar to melanopa; left clasper a rongh tapered arm; right clasper much larger, produced into a peaked flattened plate; the left sacculus extends to the base of the cueullus, the upper half being squamous, the apex is bifurcate, forming two sharp' prougs; the right sacculus extends just above the centre of the harpe, into a squamous peak; uneus eygnated; vesica with a large bulbed cornutus.

\section{Heliaca arbuti; tenebrata.}

Harpe simple, the armature being only indicated loy a thickening of the skin; uncus sickle form, stouter in the middle ; the vesica thickly elothed with long teeth.

\section{Agrophila sulphuralis; trabealis.}

Harpe almost square above, with colona of fine spines, asymmetrical; the right clasper pointed, broader at the hase than the left; the right ampulla fairly stont, clubbed, and clothed with numerous short spines: that on the left side is slender, not clubbed, and set with two or three short spines; uncus sickle form; vesica with a few short cornuti ; juxta asymmetrical, right side peaked, left side not peaked; there are pencils of hair on the eighth segment.

\section{Acontia luetuosa.}

Harpe roundly peaked, asymmetrical, withont corona ; the light clasper is an ellowed cone, the left side being a round flattened plate with a few spines scattered over it; urcus simple; rockagus is strongly curved; resica has an oval scobinated plate.

\section{Epastria venustula.}

Harpe peaked, spinose; the clasper near the base of the barpe is slender, elbowed above, with a curled sip; ampulla a small papilla at the base of the cucullus; uncus simple vesica witl liage bulbed cornutus. 
Fuscula ; fasciana.

Pencils ahsent.

Jarpe peaked, rounded at the anal angle, below which the edge is emarginate, clasper a fold: sacculus is resterl at the clavus: uncus slender; vesica has a long arm with spatulate head with scobinations upon it.

\section{Bankia argentula.}

Harpe simple, peaked, without corona or armature; mens slender, with a rery small curved hook at the tip.

\section{Hydrelia unca; uncula Without pencils.} Harpe tapered to a point, helow the encullus on the costa is a long peaked arm, armature absent; the mous is slender, terminating in a large club; vesica with a brush of short spines.

Phytometra ænea; viridaria. Pencils absent. Harpe rounded; the cneullus is long, thickly clothed with hair ; at the anal angle is a pollex; clasper very broad at the elbow, the tip open and set with short spines; uncus slender with a scaphiun; vesica without armature; juxta peaked to a point. which is scobinaterl.

\section{Euclidia mi.}

Pencils absent.

Harpe emarginate on the margin, rounder where it meets the costa, peaked on the onter margin, without armature the saceulus extended in a long arm beyond the cucullus; uncus with a claw arising hefore the tip, and overlapping it. vesica "lothed with numerous small teeth; juxta a squamous peak; the similarity of the formation of this species with Ciomonteru libatrix is distmetly noticable.

\section{Glyphica.}

Pencils absent.

Harpe asvmmetrical, almost parallel, slightly broader before the tip, which is rounded and has no corona: the left sacculus branches into two long arms, the outer arm, entirely attacher to the edge of the harpe, is shorter than the other and curved; the inver ar'm, sharply ellowed, extends to a long scolinated club, tipped with a sharp point: the right sacculus, forming a semi-circular plate where it joins the edge of the harpe, clothed with long hairs: uncus elbowed in the middle, with a raised Hap before the pointed lip; xdœagus very long; resica with minute teeth. 


\section{Catephia alchymista.}

Harpe asymmetrical, square above, without corona, the costal margin on the left side extends, leaving the harpe below the cucullus, to a truncated pillar, the upper surface of which is concave; on the right side this is peaked; the clasper on the left side is a plate, broad at the base, emarginate before the tip, forming a sharp curved point; on the right sire it tapers, and extends to a simple arm ; the uncus ends in a long point, and has a strong scaphium; (in this species the uncus is mandibulate); the redcagus is elbowed in the middle like a boomerang, and is without armature; the strong juxta is doubly emarginate produced laterally into two peakes, with a third peak in the centre.

The Catocalas have the largest genitalia, sponsa being the largest of all British species of Noctmidre; they are strongly generic.

Catocala fraxini. From J. E. Robson.

Harpe without corona, the costal edge is a thick chitinous tube, to which is attached a hollow sac of thin membrane: the clasper is a short spatulate arm curled at the tip; the uncus is almost straight terminating in a curved hook; the ædœagus is very long and curiously twisted, the base being almost at right angles, and the upper part bent in the opposite direction, forming a rougl letter $\mathrm{S}$. The juxta is peaked and divided in the centre.

Nupta. From S. J. Capver.

Harpes asymmetrical, the left harpe of thin membrane; the right harpe peaked, the thickened costa extending considerably beyond the harpe, is dentated on the inner edge; the clasper is a curved hook, wider on the right side; the uncus is mandibulate, with scaphium ; the rdœagus is long and slender; the upper and lower parts both being bent in the same direction; juxta not pointed.

\section{Promissa. From S. J. Capper.}

Harpe rounded, with an extended flap on the anal margin ; clasper elbowed, curled at the tip of the arm; uncus mandibulate with scaphium; ædœagus long and slender, upper and lower parts curved in the same direction; juxta roughly peaked. 
Sponsa. From Fred. Birch.

Harpe broad, squared above, the surface being quite plain with the exception of some half dozen spines; the clasper is a curved arm; uncus mandibulate with scaphium; redœagus long and slenier, bent sharply near the base; juxta peaked.

\section{Toxocampa pastinum.}

Harpe narrow, peaked, withont corona; the clasper is just produced, from a long fold which emerges below the cucullus, in a small hook; the ampulla is a little wart with spines; the uncus is curved; the vesica is elothed with minute teeth; the juxta is peaked; the vinculum rounded.

Craccæ. From IV. G. Sheldon and A. Harrison. Harpe peaked; clasper a short arm curled at the tip; the ampulla arises from the surface of the cucullus ; uncus is curved; resica with small scobinated process, and short band of fine teeth; vinculum rounded.

Brephos is undoubtedly a connecting link to the Geometers. The species have notining in common with any group of Noctuide.

\section{Brephos parthenias.}

Harpe simple, without trace of clasper or ampulla; the mons is articulated to the tegumen, and is parallel above. except where it bends, when it is wider ; below the uncus is a plate with a scobinated edge.

Notha. From J. E. Robson.

Pencils alssent.

Harpe broad to the eentre, where it bulges out, above it is peaked, withont armature; the uncus is tongue shaped and articulated to the tegumen; below the uneus is a thin plate with a strong edge, furnished with rows of spines; vesica with small cornutus. 



\section{Mist of Subscribers}

Whose support the Author sratefully acknowededes.

Adkin, Rohert, F.E.S. (2 Copies)

Allen, J. E. R.

Alderson, Miss E. M., F.E.S.

Anning, Villiam, F.E.S. (2 Copies)

Atkinson, Raymond F. M.

Areburg, The Right Hon. Lord,

D.C.I., F.R.S., F.L.S., F.G.S., F.E.S.

Bacot, Arthur $W^{\circ}$., F.E.S. (2 Copies)

Bankes, Eustace R., M.A., F.E.S.

Beare, Professon T. Hudson, B.Sc., M.Inst.C.E., F.E.S.

Bell, William, M.R.C.S., L.S.A., J.P.

Bentall, E. E., F.E.S.

Bethune-Baker, George T., F.L.S., F.Z.S., F.E.S. (2 Copies)

Bignell, George Carter, F.E.S.

Birmingham Library, per C. E. Scarse.

Blair, Kenneth G., F.E.S.

Bowles, E. Augustus, M.A., F.L.S., F.E.S. (2 Copies)

Briggs, Thomas Henry, Mi.A., F.E.S.

Brisht, Percy Ml., F.E.S. (2 Copies)

Buclimaster, The Rev. C. J., M.A.

Burrows, The Rer. C. R. N.

Capper, Henry.

Capper, Samuel James, F.E.S. (4 Copies)

President of the Lancashire and Cheshire Entomolosical Society.

Chapham, Thomas Algernon, M.D., F.Z.S., F.E.S. (4 Copies)

Charnley, James Rowland, F.E.S., F.Z.S.

Clutterbuck, C. Granville, F.E.S.

Connold. Edward T., F.Z.S., F.E.S.

Cotton, John, M.R.C.S.. L.R.C.P., I.S.A., F.E.S.

Cox, G. Lissant.

Crabtree, Benjamin Hill, F.E.S.

Crowfoot, IV. M., M.B.

Deacon, H. Wade, J.P.

Druce, Hamilton H.C.J., F.7.S., F.E.S.

Dutley, A. $\mathrm{H}$.

Dukinfield-Jones, E., F.E.S. 
Edelsten, Hubert M., F.E.S. (2 Copies)

Edwards, James, F.E.S.

Edwards, Percy, M.R.C.S., L.R.C.P., L.S.A.

Edwards, Stanley, F.L.S., F.Z.S., F.E.S.

Fletcher, William Holland B., M.A., F.E.S.

Fountain, J. T.

Freeman, The Rev. R., M.A.

Friedlander, R. und Sohn, Berlin (10 Copies)

Gansthauer, Protessor Ludwig, F.E.S., Vienna.

Gavdner, John, F.E.S.

Gibhons, Iliss Kate M.

Gibbons H. H.

Gibbs, Arthur Ernest, F.L.S.. F.R.H.S., F.E.S.

Godman, Frederick Du Cane,

D.C.L., F.R.S., F.L.S., F.Z.S., F.E.S.

Goodwin, Edward, F.E.S.

Green, Henry.

Hall, A. E., F.E.S.

Hanbury, F. Capel.

Hanbury, Frederick J., F.l..S., F.E.S.

Harrison, Albert, F.L.S., F,C.S., F.R.MI.S., F.E.S. (2 Copies)

Harrison, Oulton (2 Copies)

Hay, John, M.D., M.R.C.P.

Haydon. W. T., F.L.S. (2 Copies)

Heath, G. H.

Horne, Arthur, F.E.S.

Indian Museum, Natural History Dept., Calcutta.

Jackson, Dr. Hatchett.

Jenkinson, W.

Johnson, Alfred.

Johnson, Charles F., F.E.S.

Kaye, William James, F.E.S.

Keynes, John Neville, M.A., D.Sc., F.E.S.

King, James J. F. X., F.E.S.

Larkin, F. Charles, F.R.C.S.

Latter, Oswald H., M.A., F.E.S.

Levett, The Rev. Thomas Princep, F.E.S. (2 Copies)

Lister, A. H.

Liverpool Reference Library, per Peter Cowell, F.E.S.

Longstafi, George Blundell,

M.A., M.D., F.R.C.P., M.R.C.S., F.E.S. (2 Copies)

Lucas, William John, M.A., F.E.S.

Lupton, Henry, F.E.S.

Lyman, Henry H., M.A., F.R.G.S., F.E.S., Montreal.

Longsdon, Alfred A. 
Main, Hugh, B.Sc., F.E.S., F.C.S.

Niacphail, James D.

Mansbridge, William, F.E.S.

Marshall, William, V.M.H., F.R.H.S., F.E.S.

Massey, Herbert, M.B.O.U., F.E.S.

Mathew, Gervase, F., F.L.S., F.E.S,

Veldola, Professor Raphael. F.R.S., F.C.S., F.E.S.

Melvill, James Cosmo, M.A., F.L.S., F.E.S.

Meyrick. Edward, B.A., F.Z.S., F.R.S., F.E.S.

Midgley, Thomas.

Mitchell, Library, Glasgow, per F. T. Barrett.

Ilontciro. Dr. Antonio Augusto de Carvalho, F.E.S., Lisbon

Moore, Mrs. Catharine Maria, F.E.S. (2 Copies)

.Morice, The Rev. F. D., M.A., F.E.S.

Narramore, William, F.I.S.

Nevinson, B. G., M.A., F.\%.S., F.E.S.

Newstead, Rohert, A.L.S., F.E,S., Hon. F.R.H.S.

Nicholson, C.

()@le, Bertram, S., F.E.S.

Pierce, Mliss Elizabeth.

Pierce, Grenville.

Porrit, George T., F.L.S., F.E.S.

Prest, E. E. B., M.A., F.Z.S.

Prout, Louis Beethoven, F.E.S.

Radcliffe, Library, Oxford, per Dr. Hatchett Johnson.

Raren, C. E., B.A.

Raynor, The Rev. Gilbert H., M.A.

Rothschild, The Hon. Nathaniel Charles,

M.A., F.L.S., F.Z.S., F.E.S. (2 Copies)

Routledge, George B., F.E.S. (2 Copies)

Royal Siredish Academy of Science. Sweden.

Robinson, A.

Saunder's, Edward, F.R.S., F.I.S., F.E.S.

Sich, Alfred, F.E.S

Snith, Andrew T.

Smith, WVilliam.

Smith, Professor John B., Philadelphia.

Sopp, Erasmus John Burgess, F.R.Met.S., F.E.S.

South African Museum, Capetown.

South, Richard, F.E.S.

Stott, C. E.

Sweeting, H. R., M.A.

Swinton, A. H., F.E.S.

Tait, R.. Junr.

Tonge, Alfred Ernest, F.E.S.

Trinity, College Library, Dublin, per A. II. Burgh

Turner, Henry J., F.E.S. 
University Museum of Cambridge, per S. F. Harmer.

V'ipan, Capt., J. A. M.

Wallier, Charles Hesketh.

Warrington Municipal Museum, per Charles Madeley.

Watkins and Doncaster (10 Copies)

Waygood, Henry IV. B.

Webster, William, M.R.S.A.1.

Wesley, The Rev. Edmund Alfred, M.A.

Whitley, E.

Whittle, F. G.

Vhittalier, Oscar (2 Copies)

Wigelsworth, Robert $J$.

Wightman, A. J.

Wilding, Richard.

Villiams, C. B.

Williams, J. Michael.

Wood, John H., M.B.

Woodbridge, Francis C., F.E.S.

Wolley-Dod, F. H., F.E.S.

Woods, Joseph A., M.D.S., L.D.S.

A. II. DUNCAN 
Plate1.

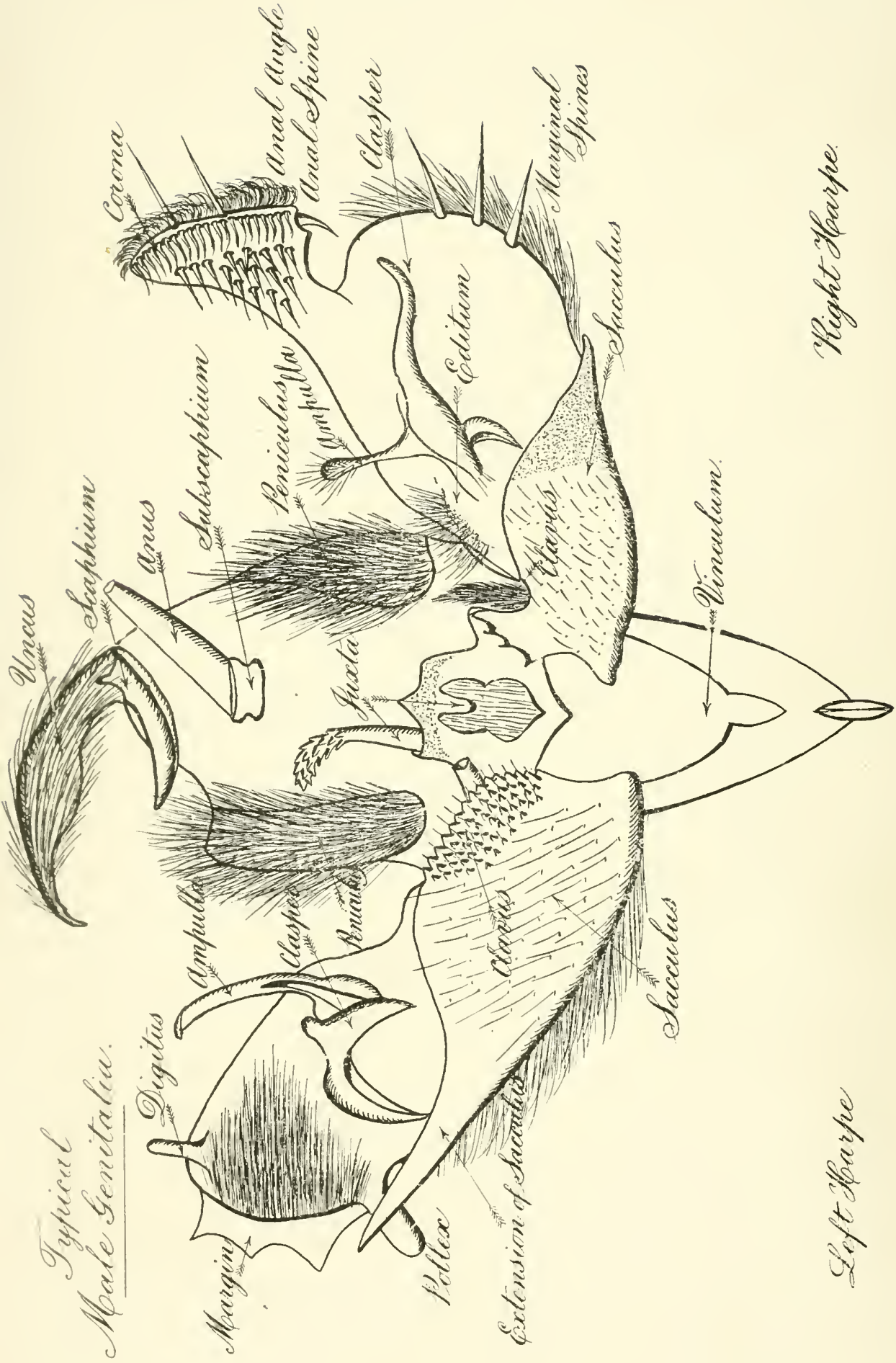










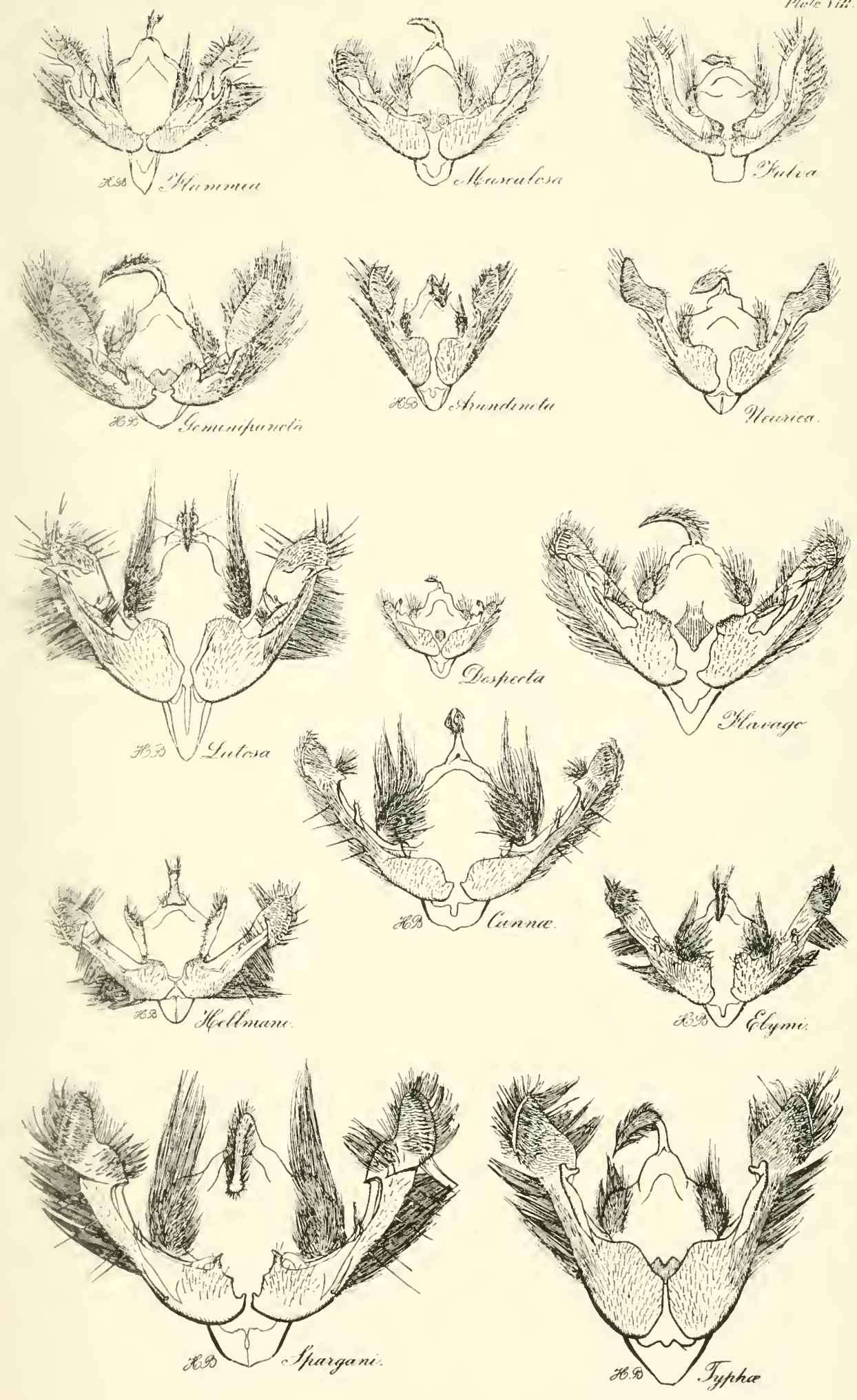



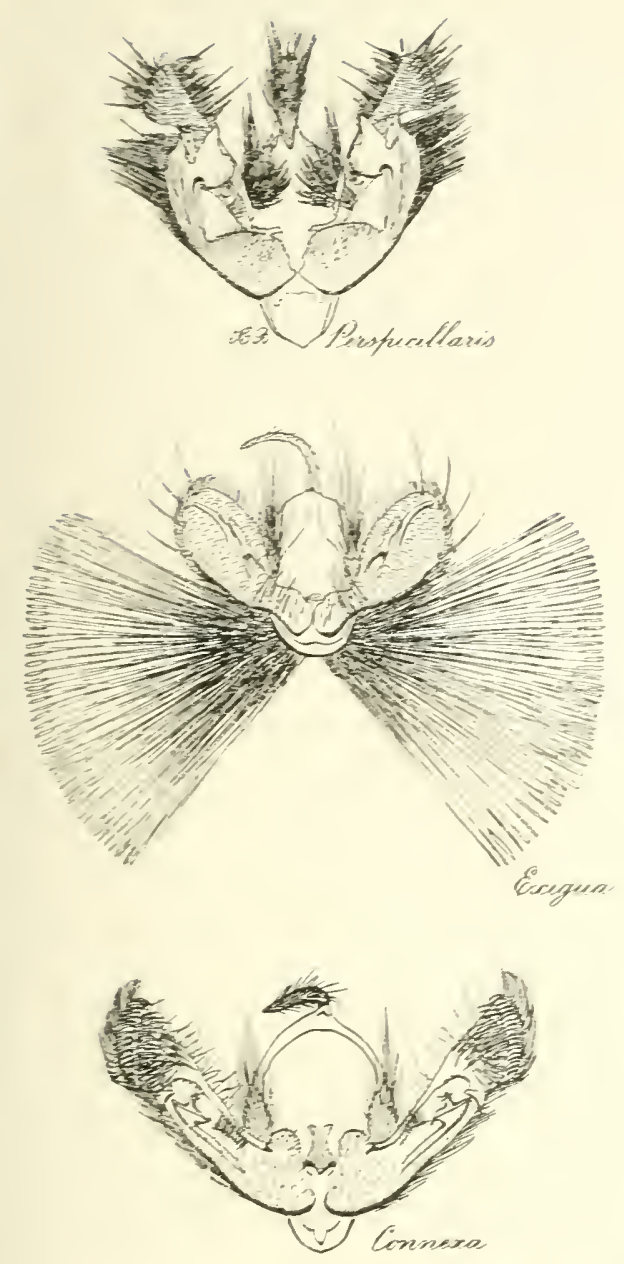
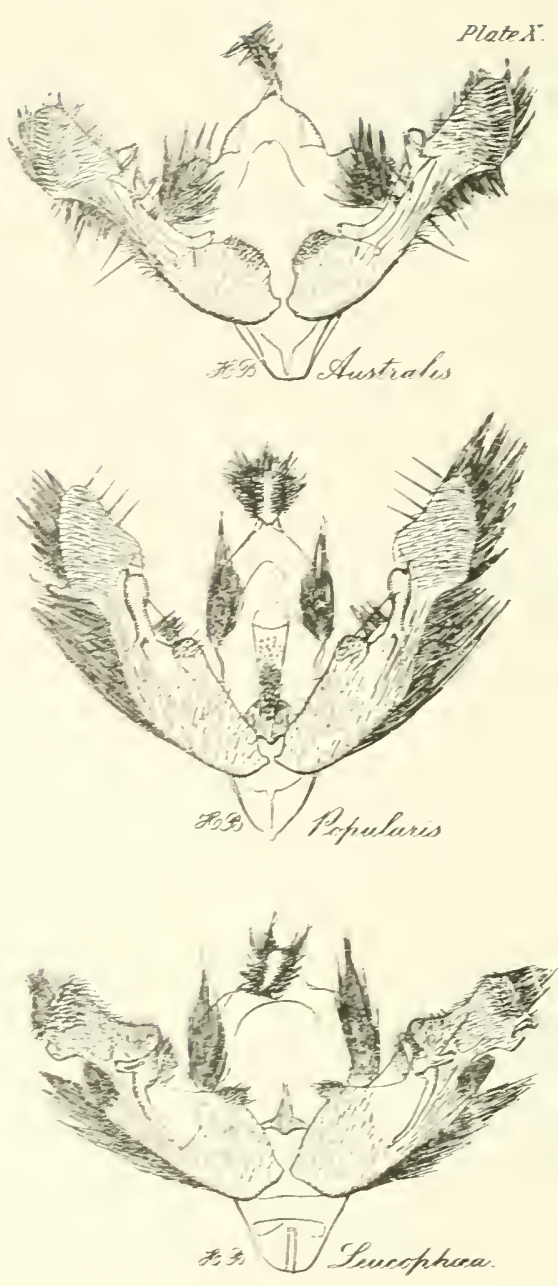
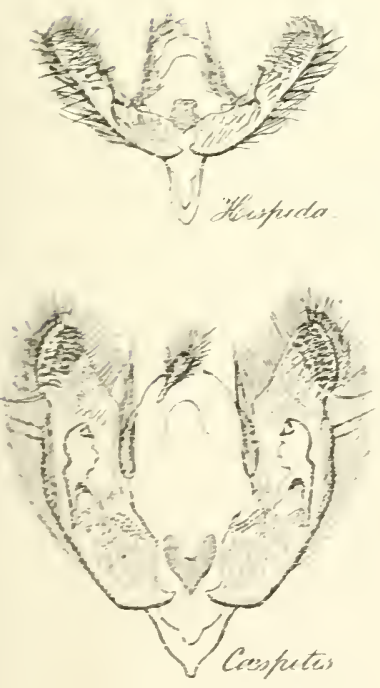
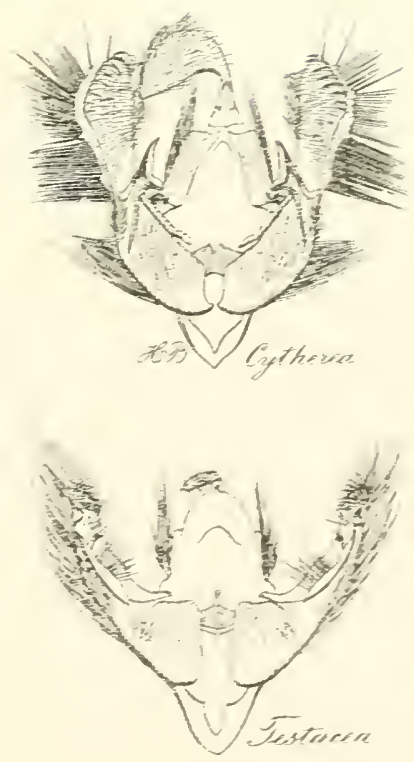
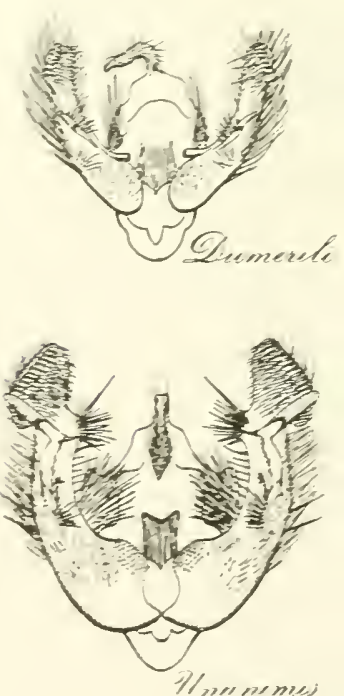


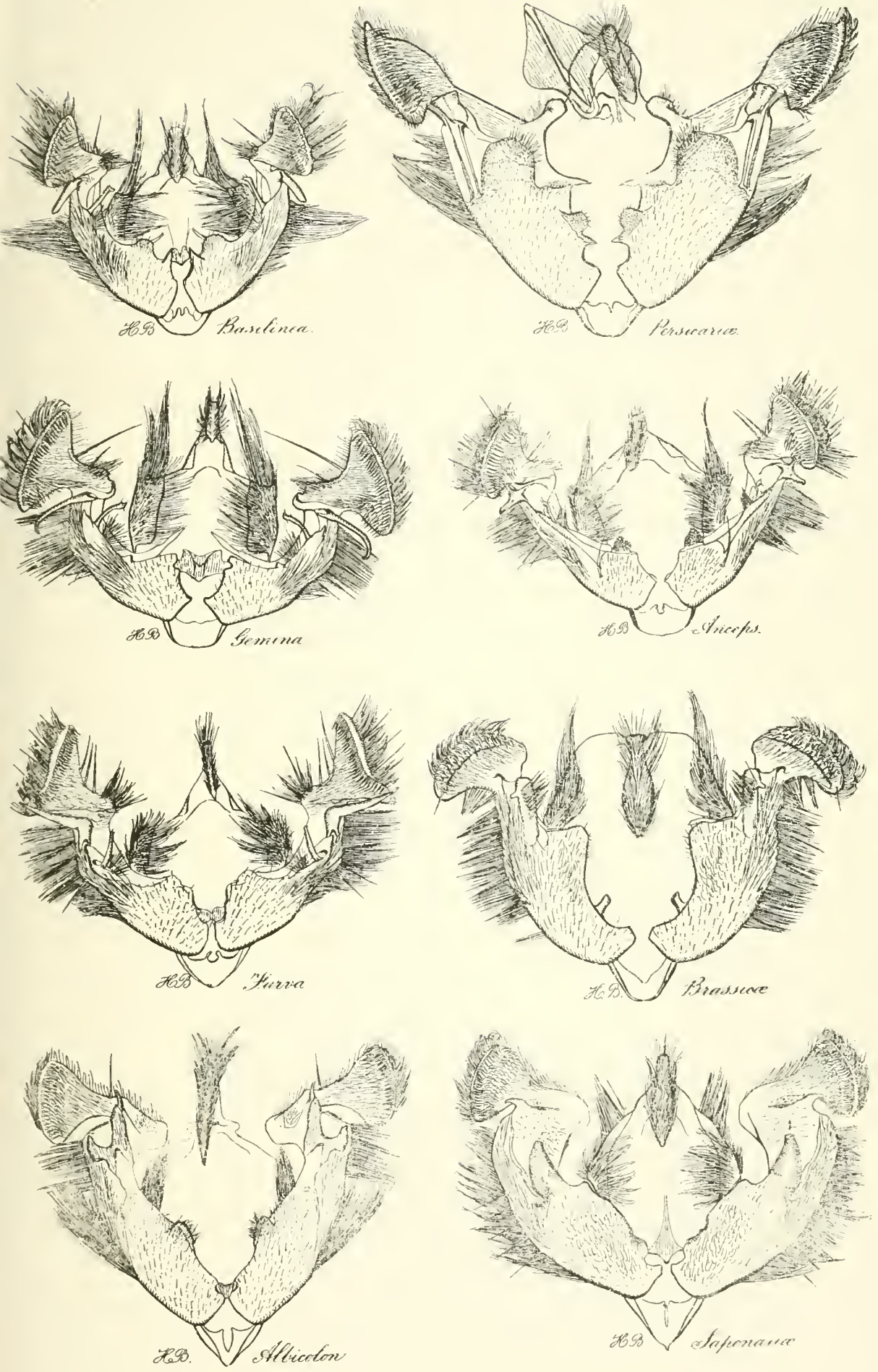



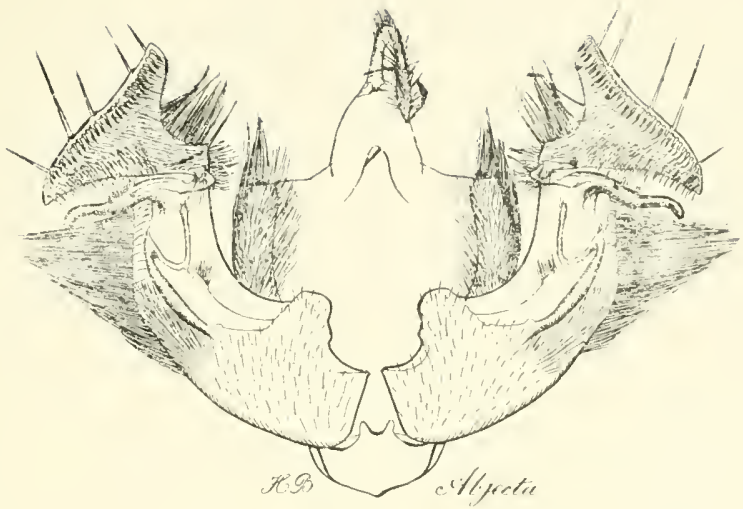

Wis

it we

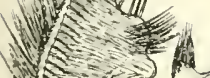

W WV

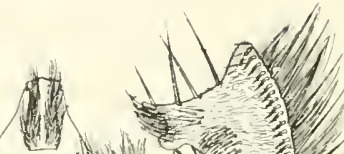

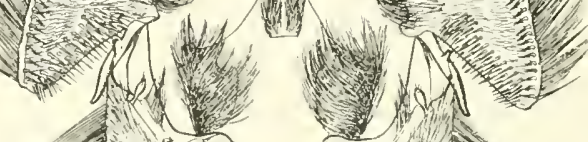

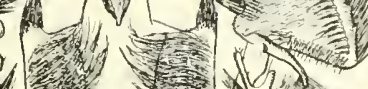
1

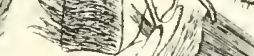

14 .
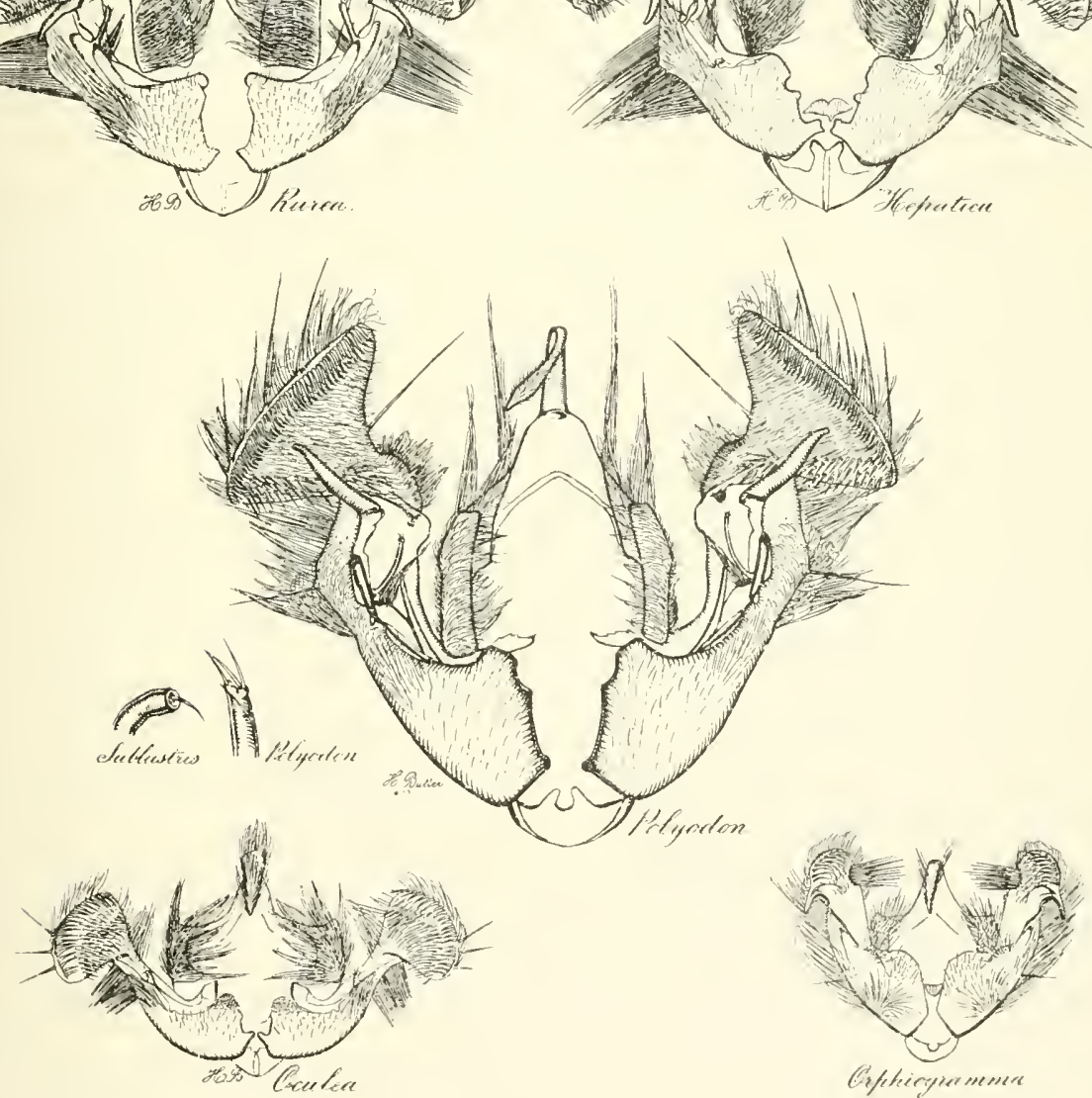





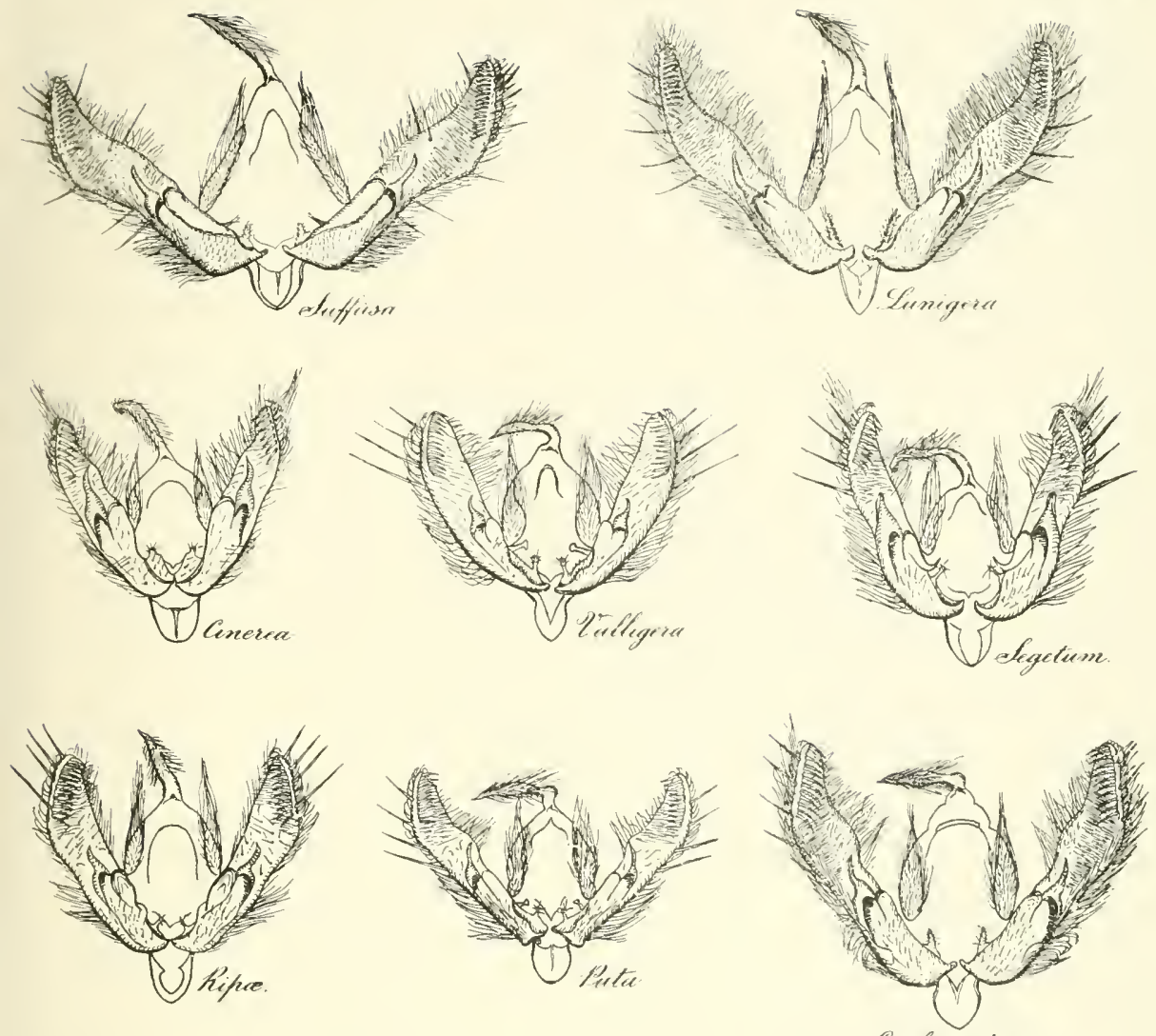

Exchamaternes
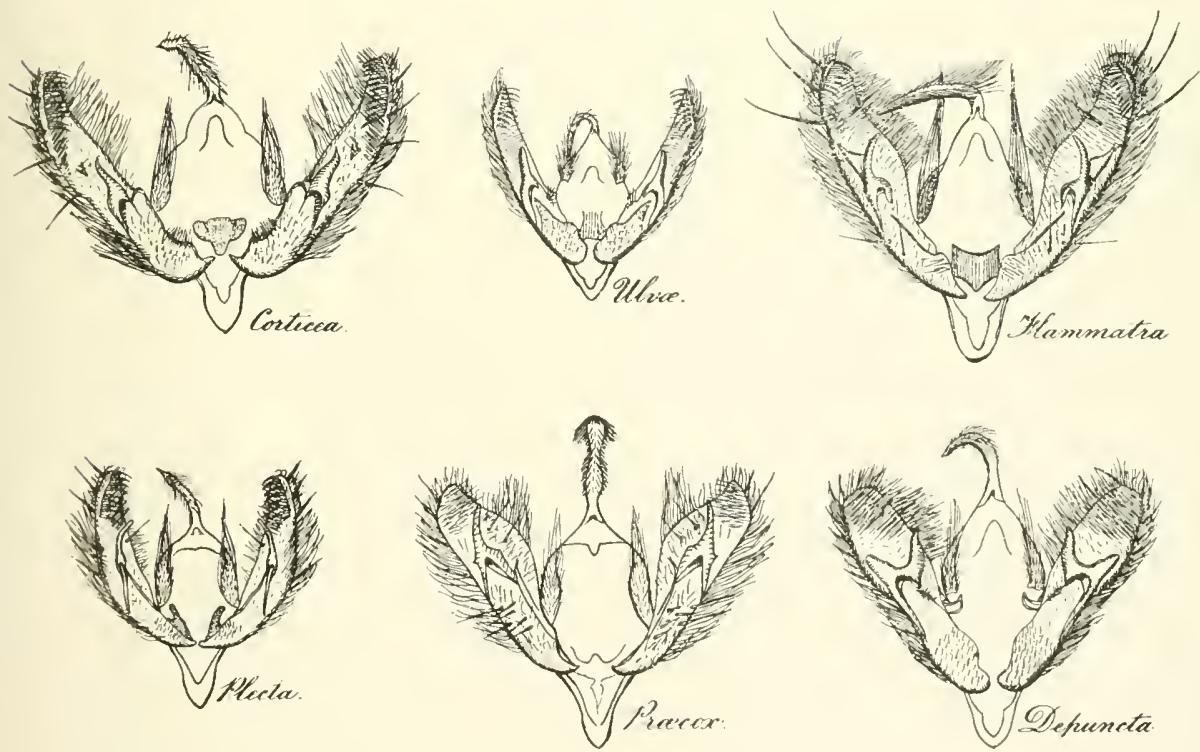


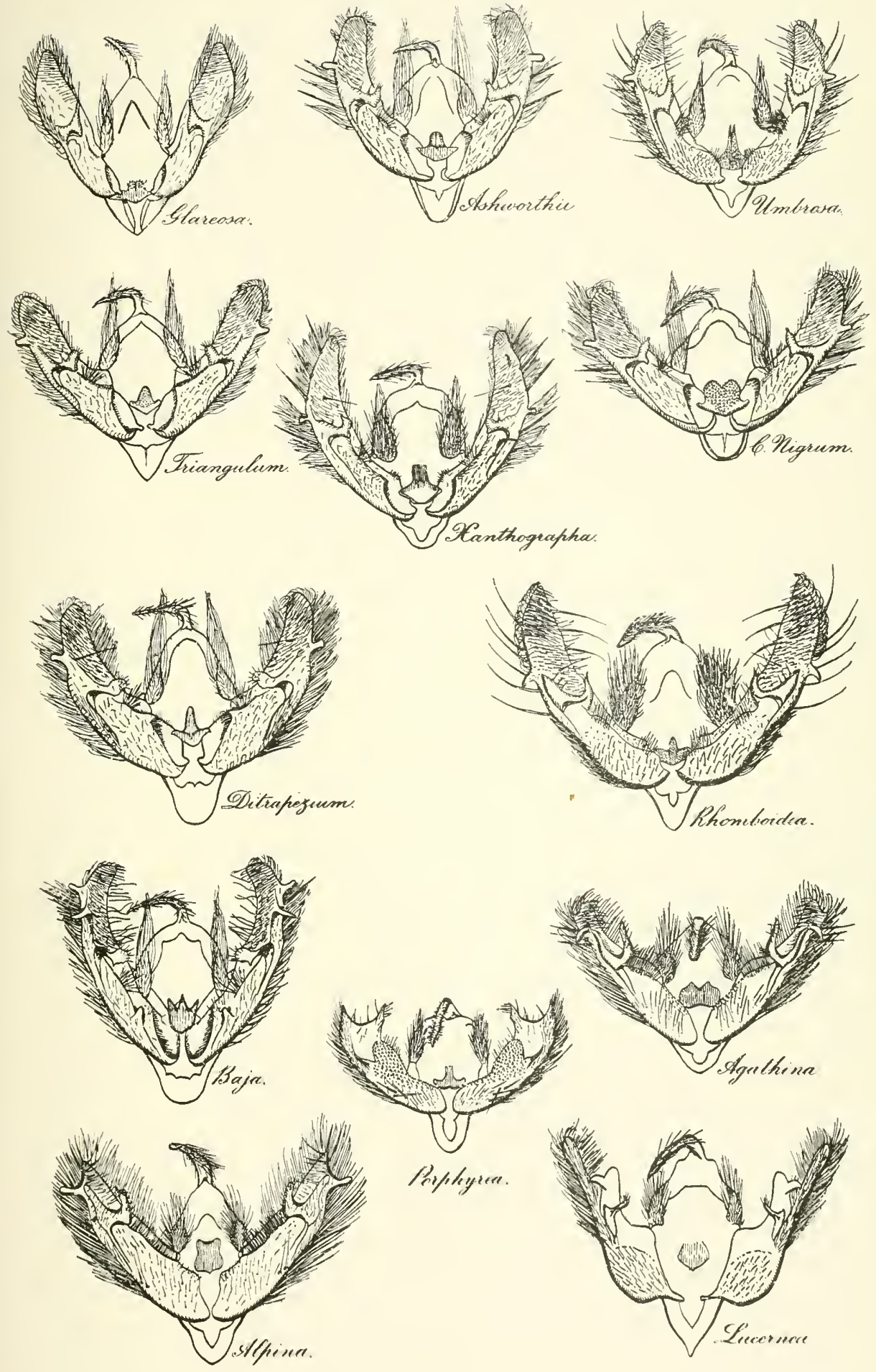


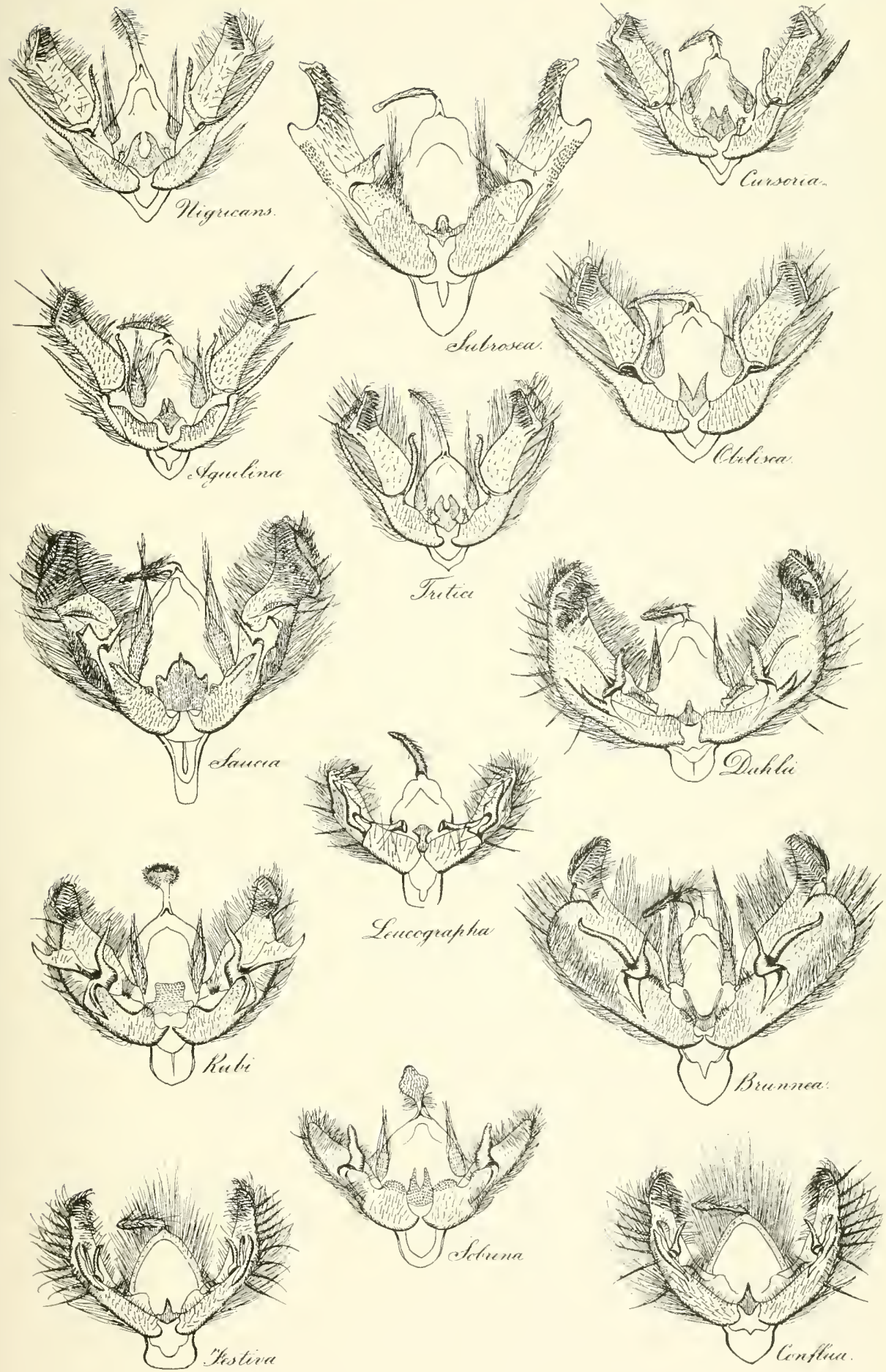

Plate XIX.

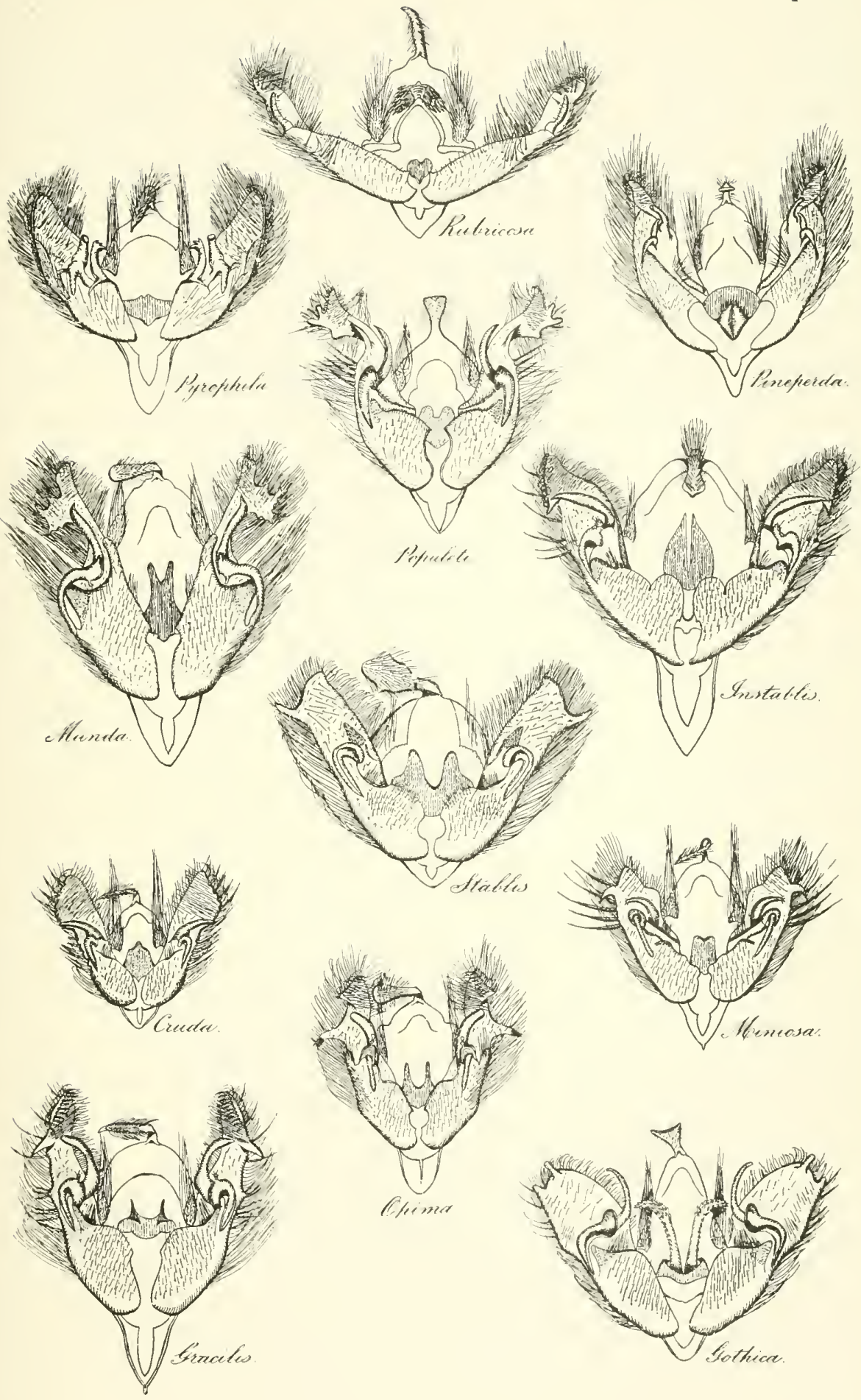




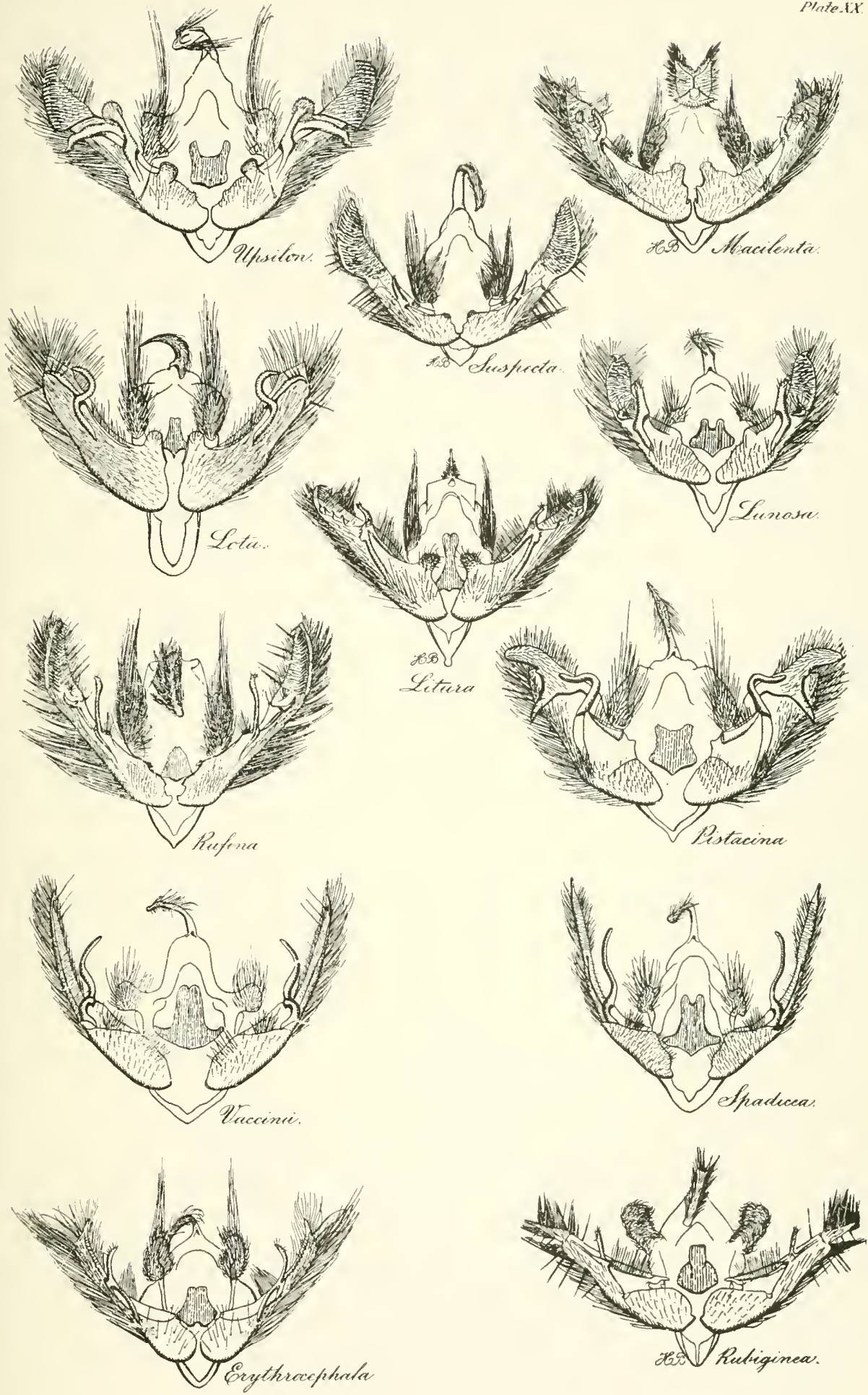


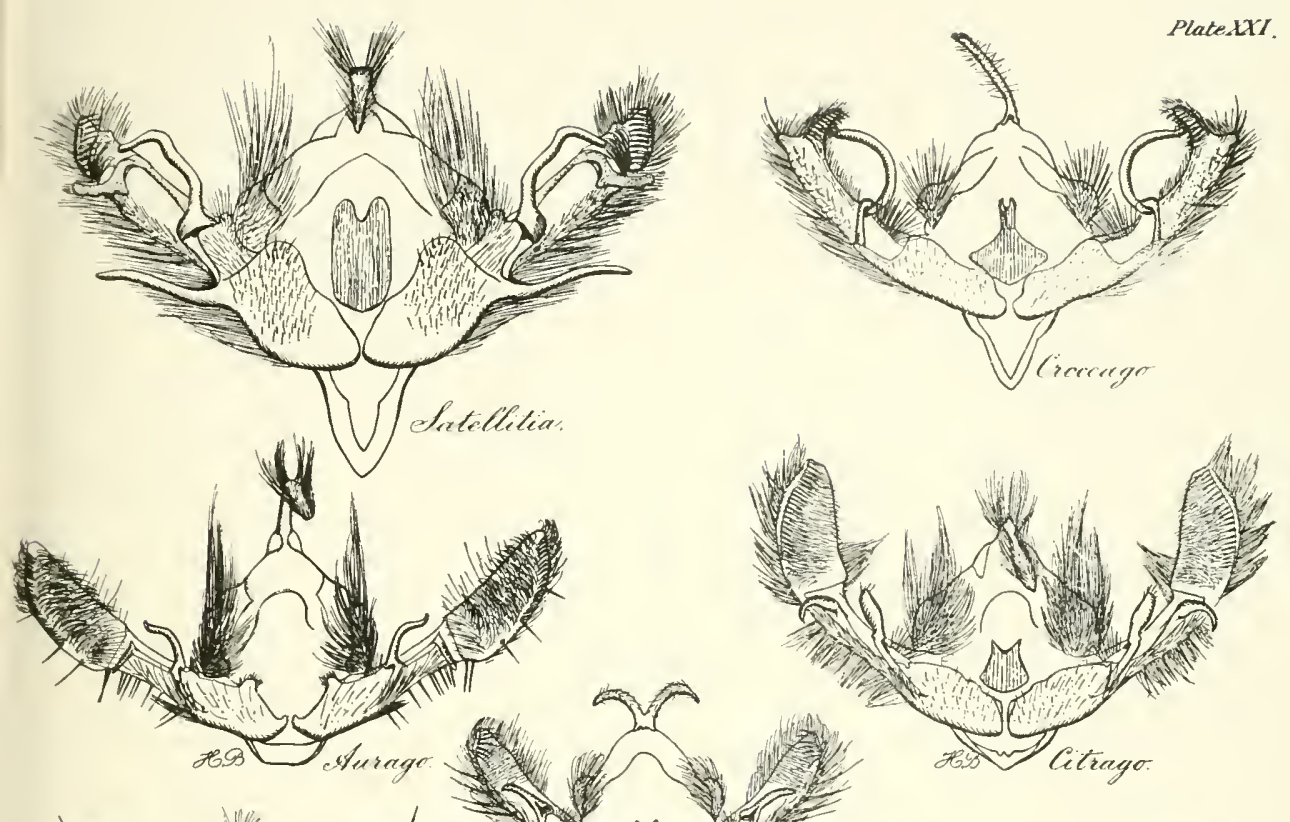

H.

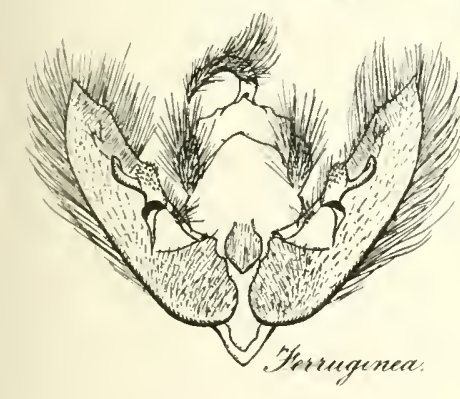

1.vit

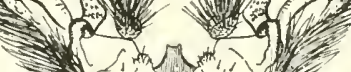
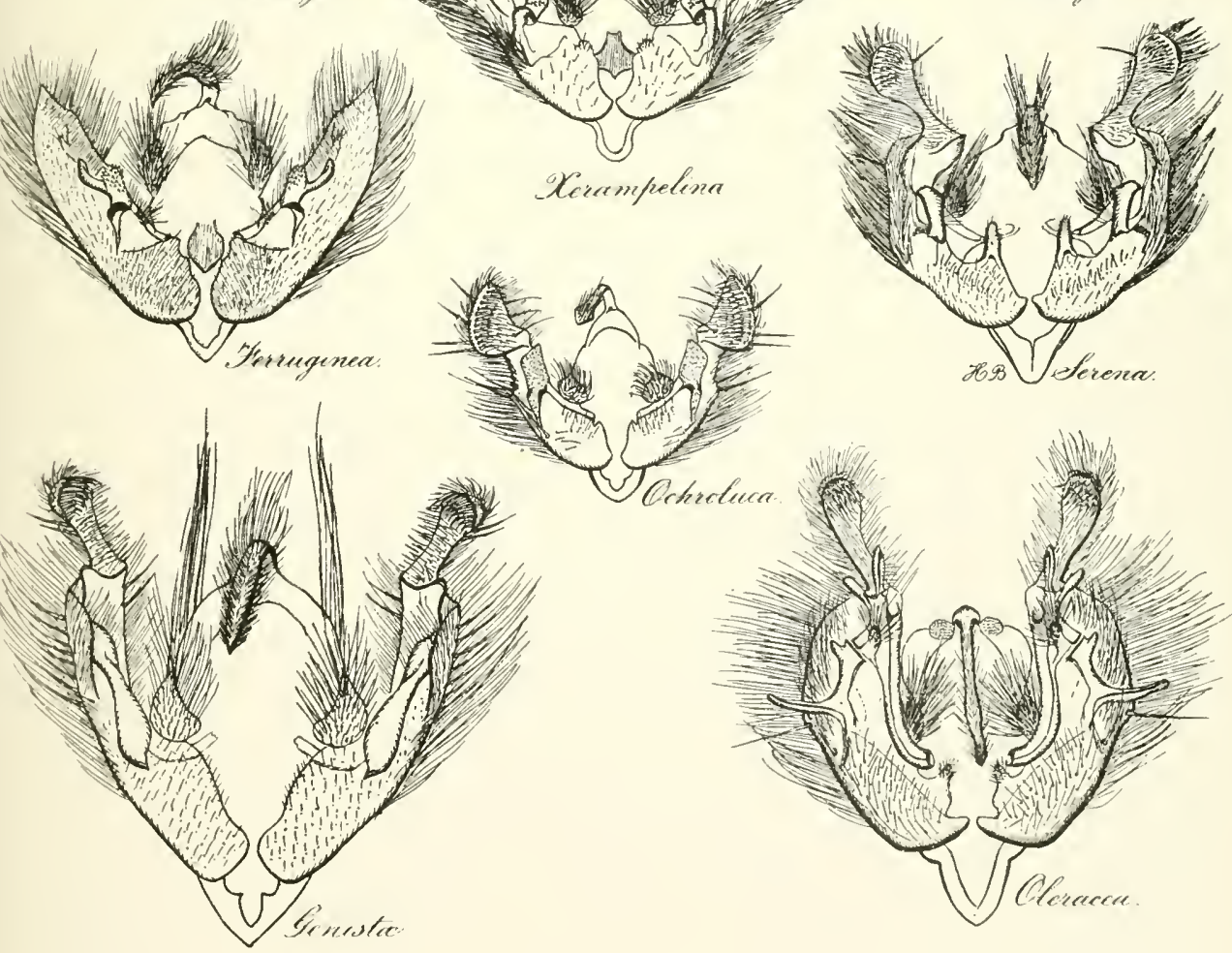

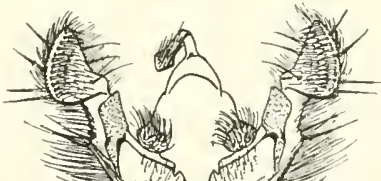

xienmpelina
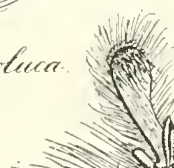

Why

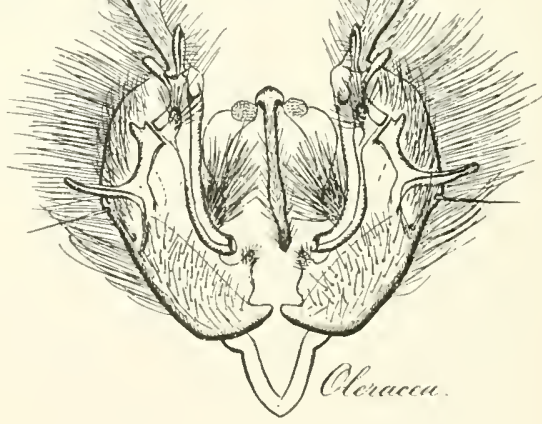





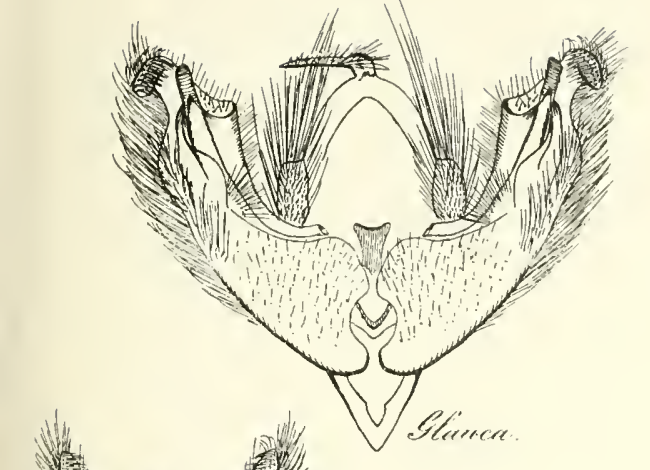

PliteXXII

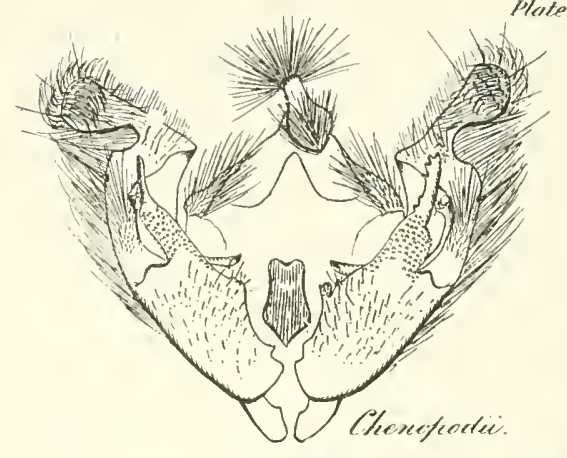

Now

(1) $N$

N(u

M.

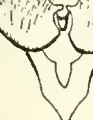

Presferfeleregere.
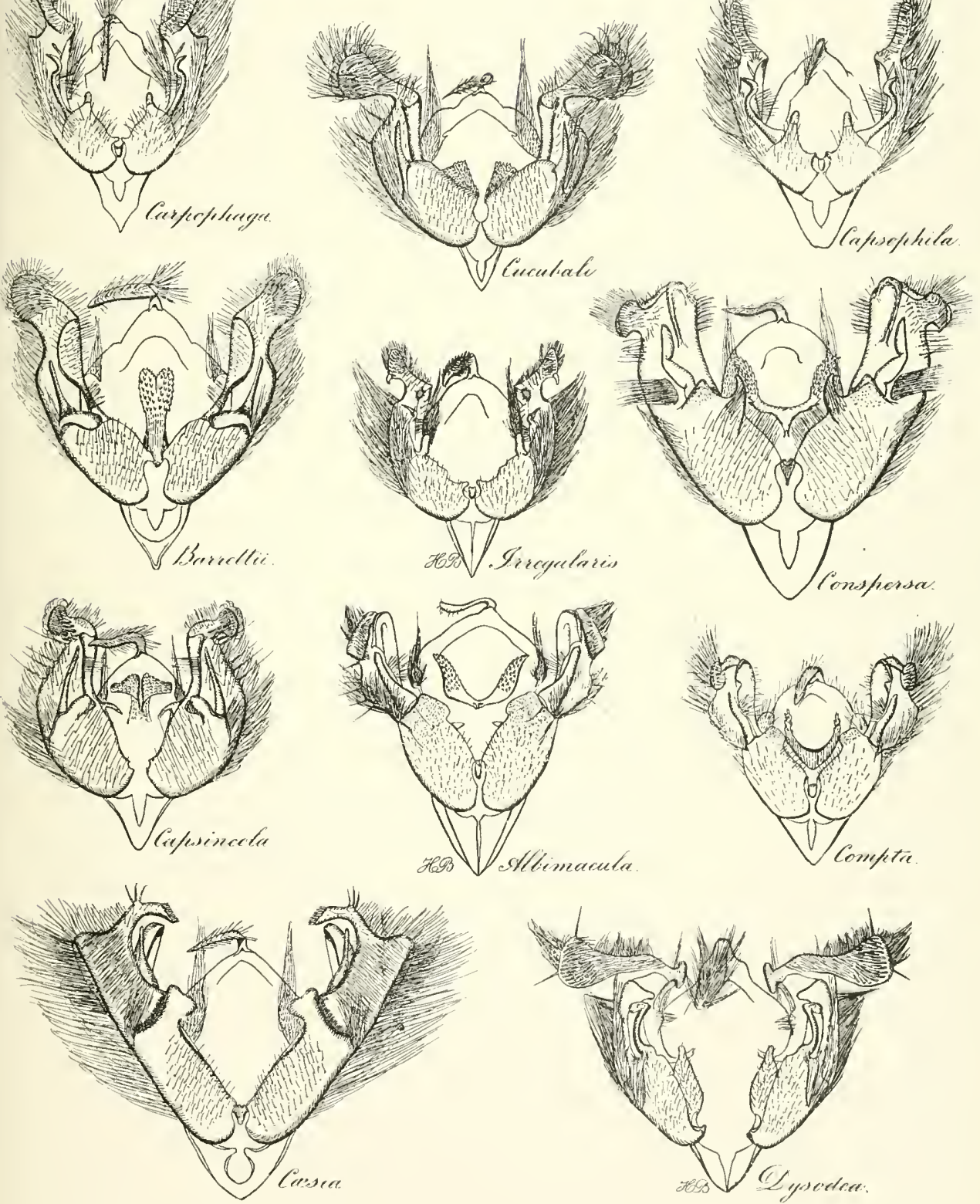



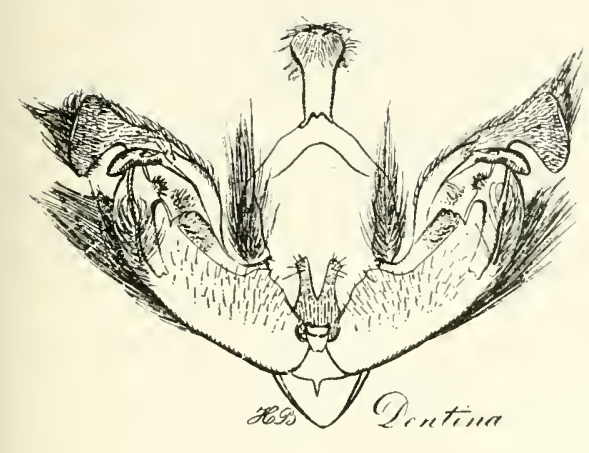

Plate KXII.
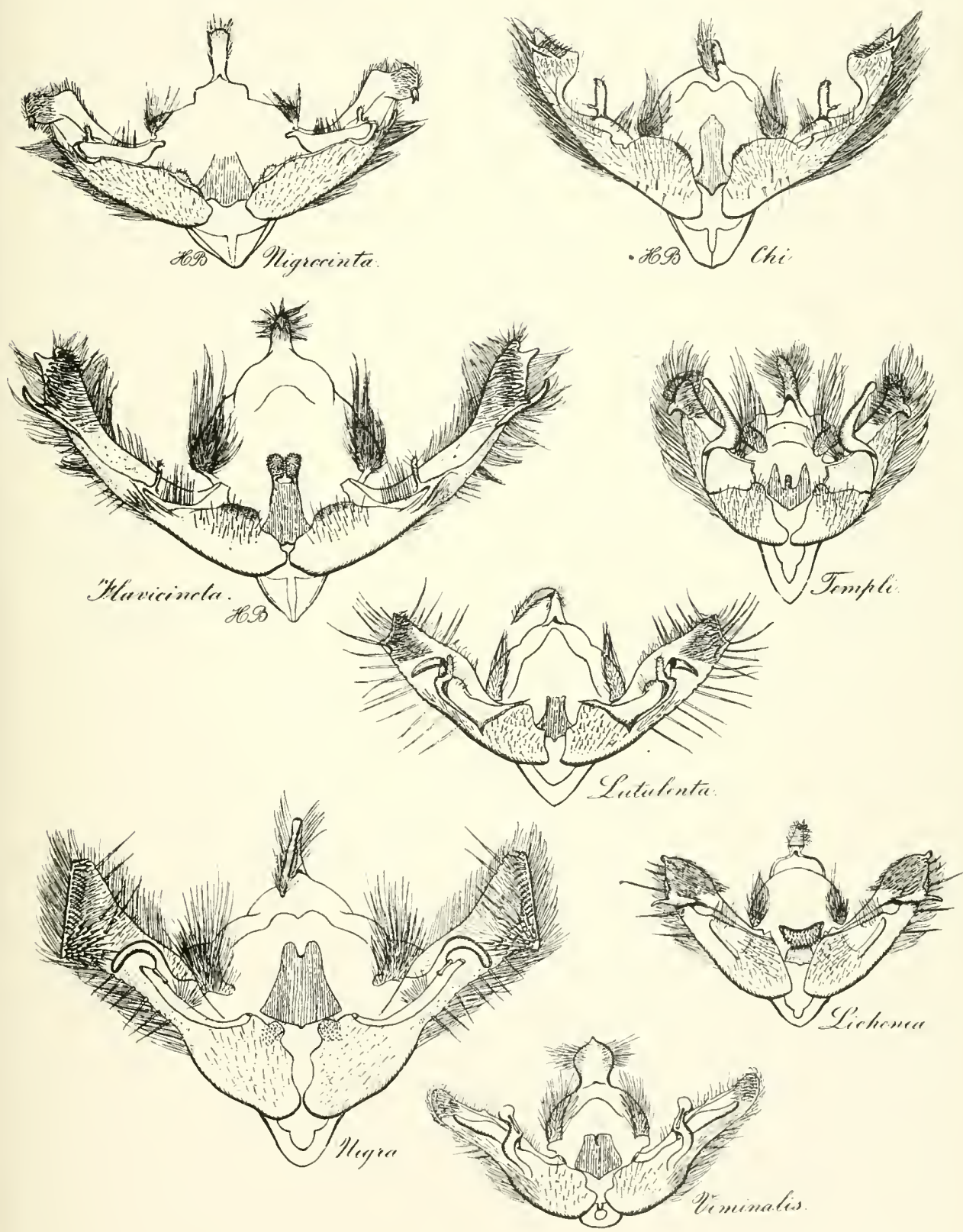


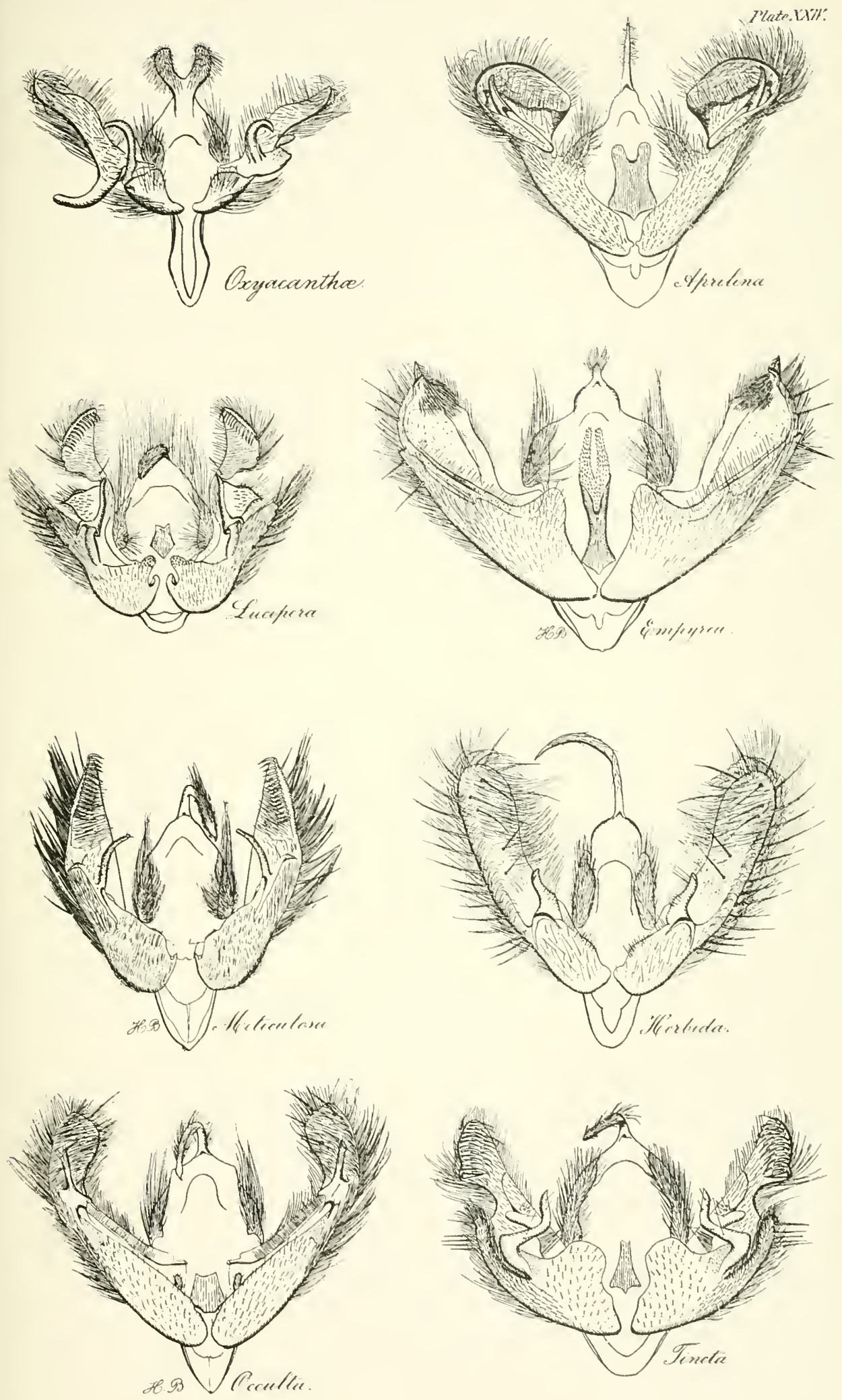


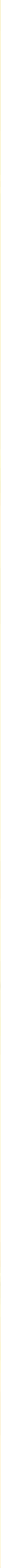




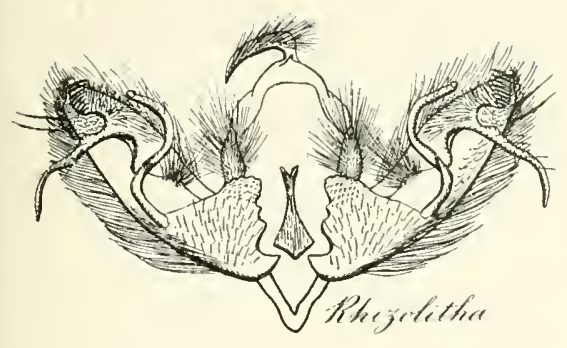

Platedat7/
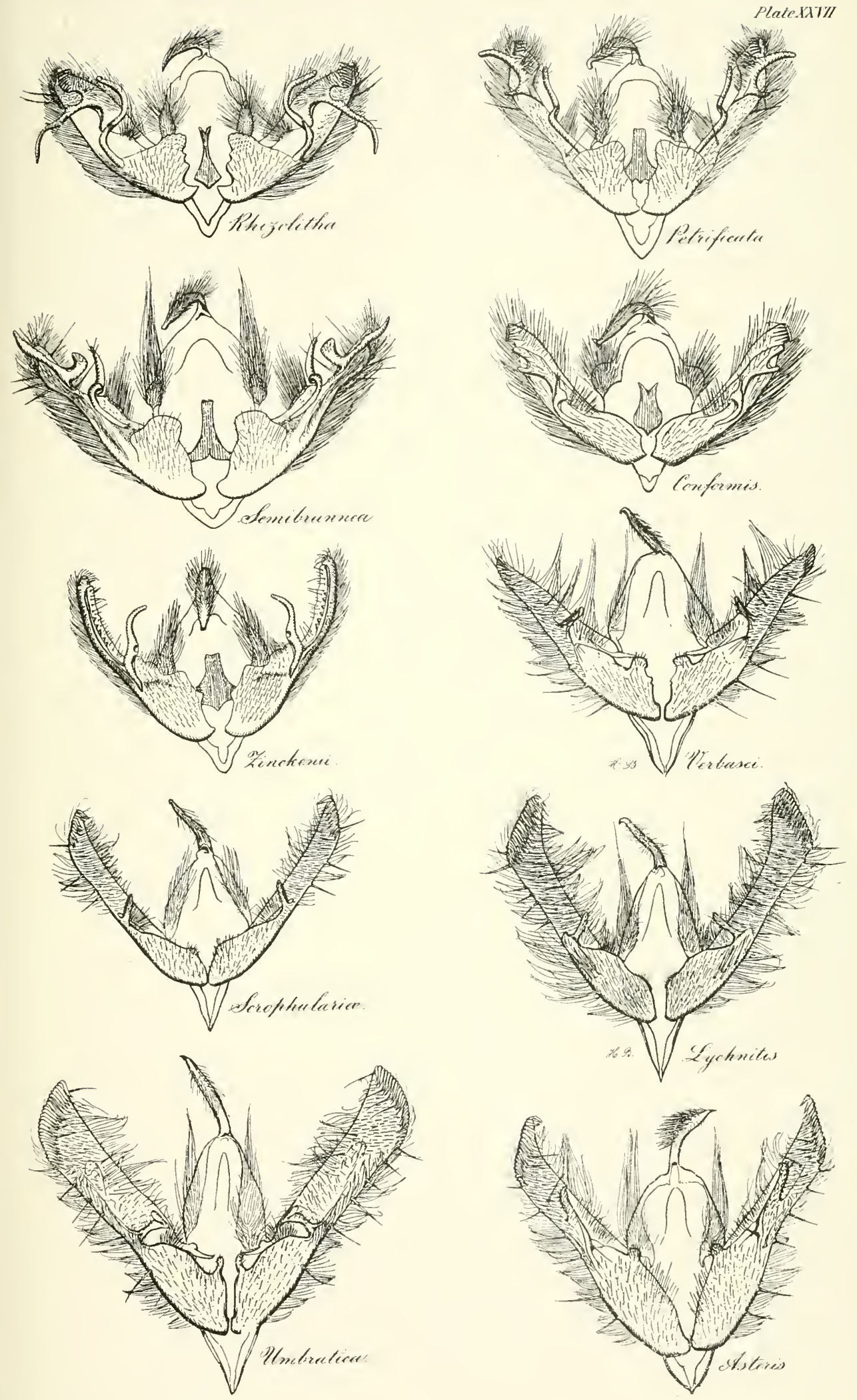


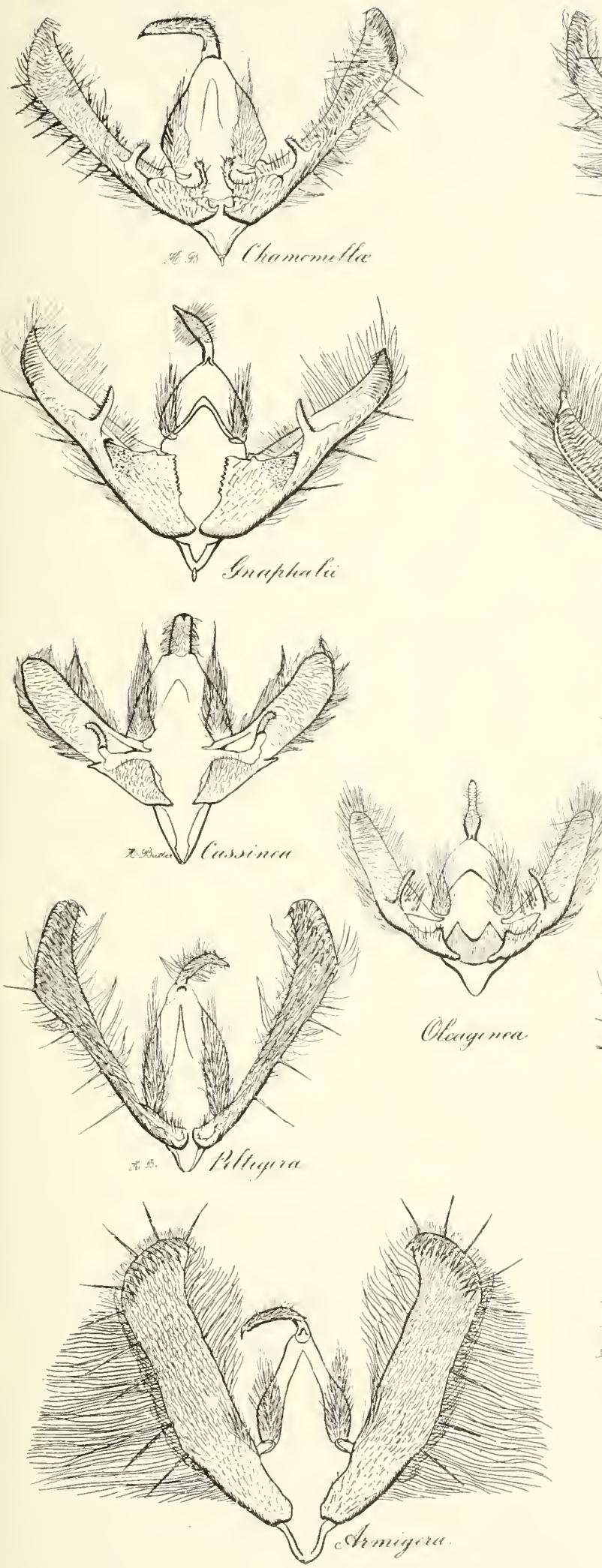


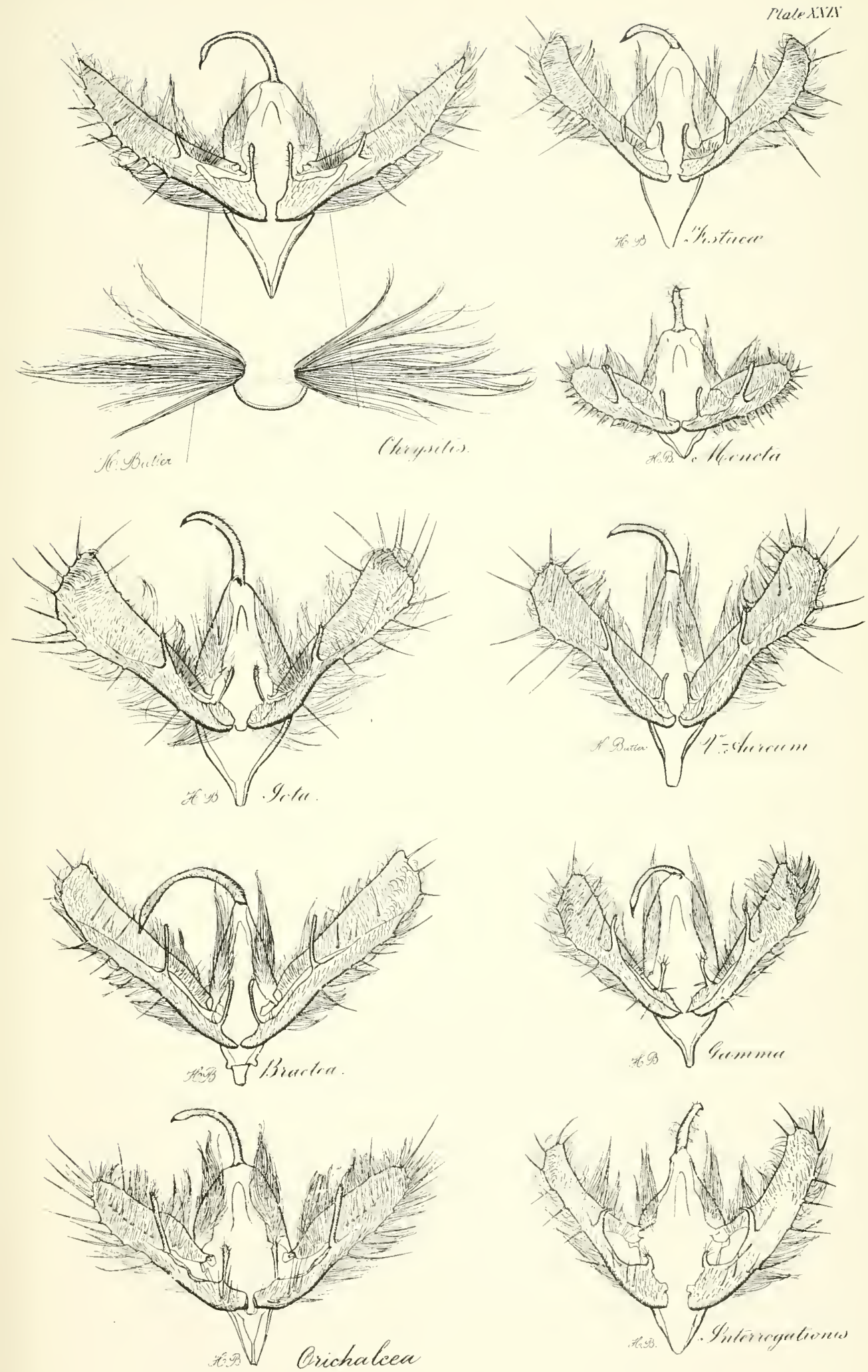



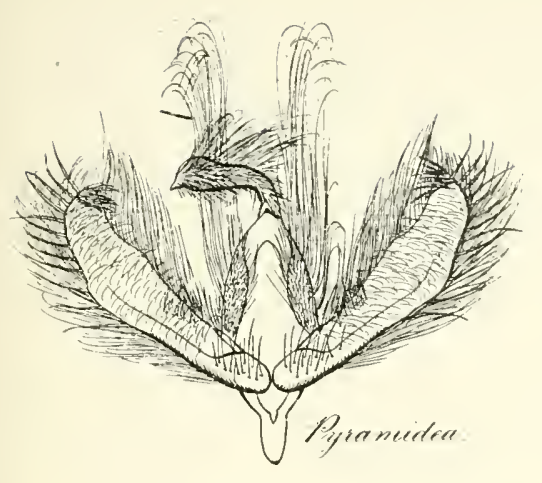

Plelextex
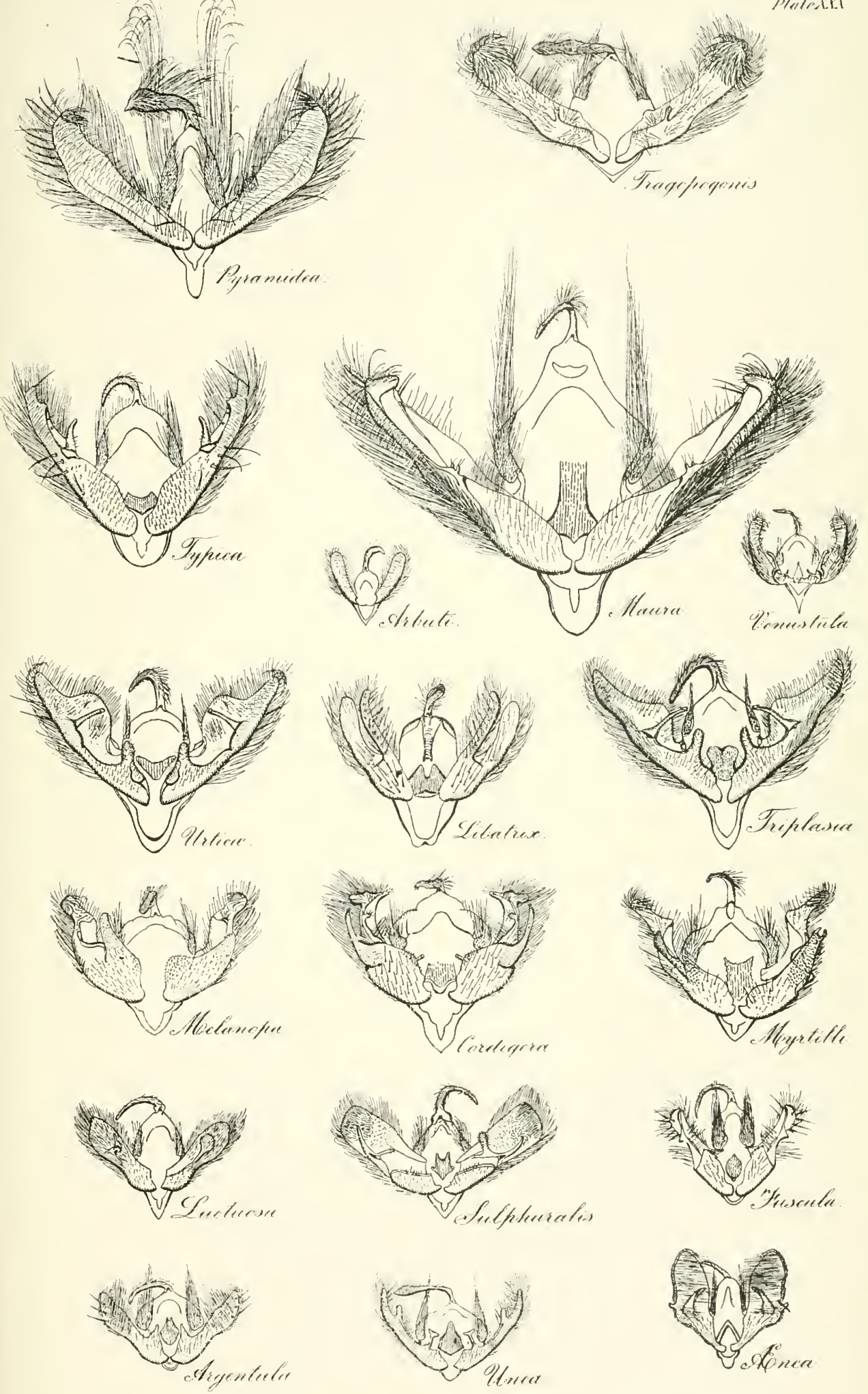



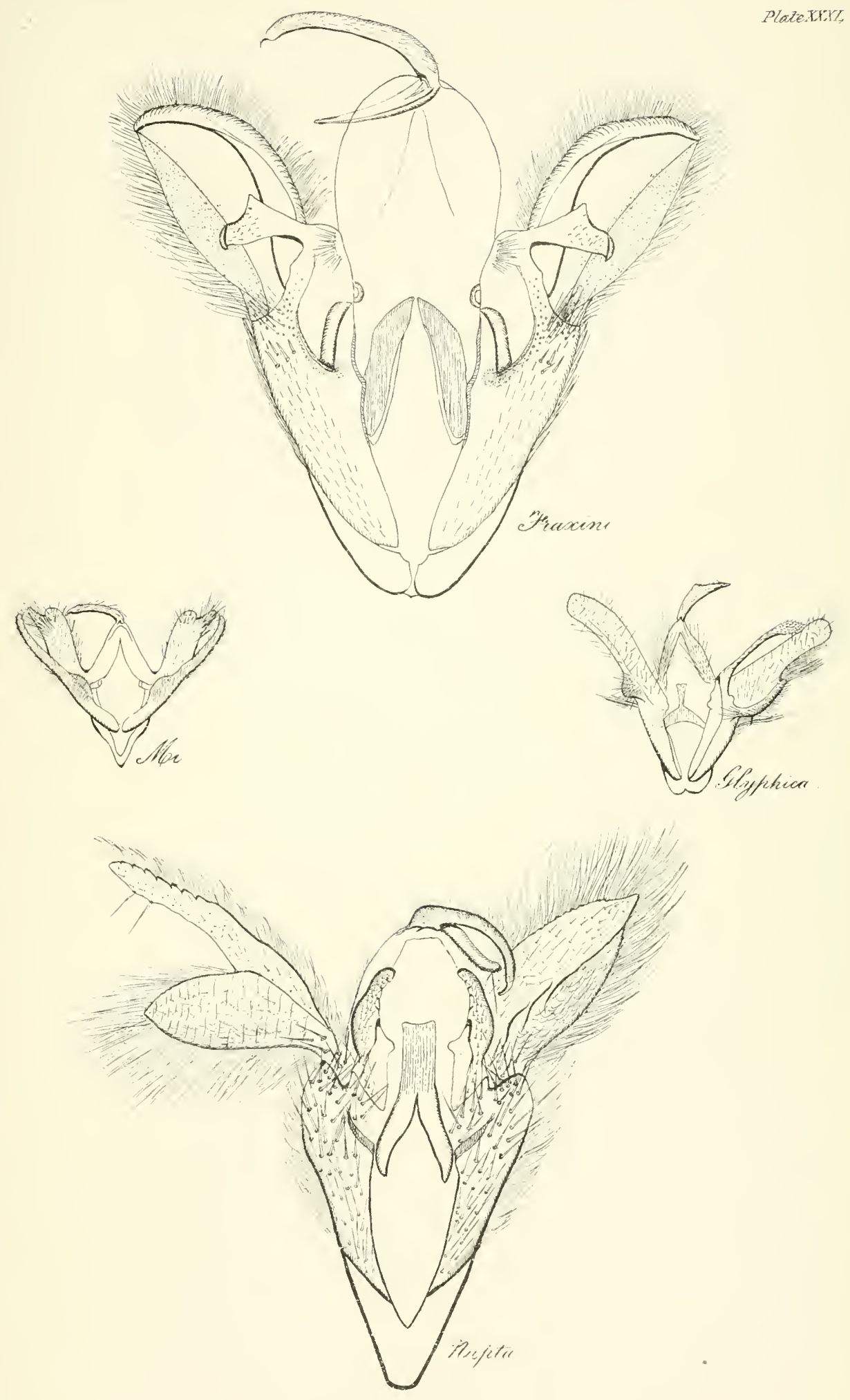





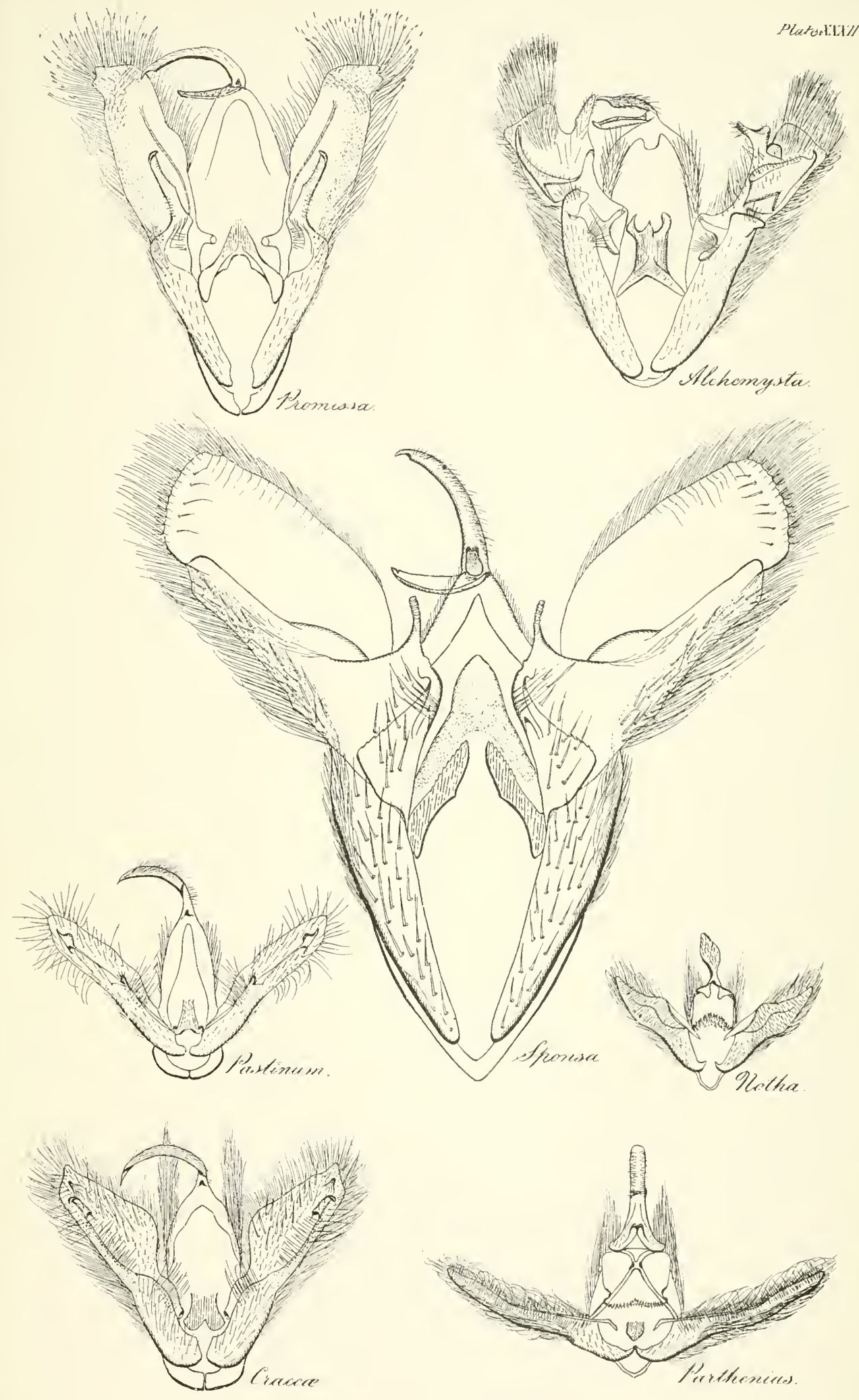






